\title{
Assessment of the Mixing of Polydisperse Solid Particles in the Rotary Drum and Slant Cone Mixers Using Discrete Element Method
}

\author{
by \\ Basel Alchikh-Sulaiman, BEng \\ Chemical Engineering \\ Ryerson University, Toronto, 2011 \\ A Thesis \\ Presented to Ryerson University \\ In Partial Fulfillment of the Requirements for the Degree of \\ Master of Applied Science \\ in the Program of Chemical Engineering
}

Toronto, Ontario, Canada, 2014

Copyright (C) 2014 by Basel Alchikh-Sulaiman 


\section{AUTHOR'S DECLARATION FOR ELECTRONIC SUBMISSION OF A THESIS}

I hereby declare that I am the sole author of this thesis. This is a true copy of the thesis, including any required final revisions, as accepted by my examiners.

I authorize Ryerson University to lend this thesis to other institutions or individuals for the purpose of scholarly research.

I further authorize Ryerson University to reproduce this thesis by photocopying or by other means, in total or in part, at the request of other institutions or individuals for the purpose of scholarly research.

I understand that my thesis may be made electronically available to the public. 


\section{ABSTRACT \\ Basel Alchikh-Sulaiman \\ Assessment of the Mixing of Polydisperse Solid Particles in the Rotary Drum and Slant Cone Mixers Using Discrete Element Method MASc, Chemical Engineering, Ryerson University, Toronto, ON, 2014}

In spite of wide applications of powders in industry, there is a lack of sufficient knowledge regarding the mixing of poly-disperse particles in rotary drum and slant cone mixers. The main objective of this study was to explore the mixing quality of mono-disperse, bi-disperse, tri-disperse, and poly-disperse particles inside rotary drum and slant cone mixers as a function of the drum speed, particle size, agitator speed, and the initial loading method through the discrete element method (DEM). To achieve this objective, experimental work and simulations were carried out. DEM results were validated using experimental data obtained from both sampling and image analysis techniques. DEM simulation results were in good agreement with the experimentally determined data, both qualitatively and quantitatively. Three major loading methods were defined: side-side, top-bottom, and back-front. Also, the mixing metric was utilized to measure the mixing quality. For bi-disperse particles inside the slant cone mixer, the mixing index increased to a maximum and decreased slightly before reaching a plateau at the drum speed of $15 \mathrm{rpm}$ with different loading methods as a direct result of the segregation of particles of different sizes. The same behavior was observed in the rotary drum for bi-disperse, tri-disperse, and poly-disperse particles. The effect of agitator speed on the mixing performance for bi-disperse particles inside the slant cone mixer was also investigated. The addition of the agitator increased the mixing quality and reduced the segregation of particles with different sizes. The best mixing qualities for the tri-disperse and poly-disperse particles inside the rotary drum were recorded for the top-bottom smaller-to-larger loading method. For the slant cone mixer, highest mixing indices for tri-disperse and poly-disperse particles with the top-bottom smaller-to-larger loading method were obtained at drum speeds of 15 and $55 \mathrm{rpm}$, respectively. The impact of segregation for both mixers was reduced by introducing additional intermediate size particles. 


\section{Acknowledgment}

I would first like to express my sincere gratitude and appreciation to my supervisors Dr. Farhad Ein-Mozaffari and Dr. Ali Lohi for their guidance and encouraging enthusiasm throughout this work.

I acknowledge the assistance of all the staff and technologists in the Chemical Engineering Department at Ryerson University. Also, I would like to thank Cosmetica Laboratories Inc. for providing permission to use their slant cone mixer.

I also would like to acknowledge the advice and helpful suggestion of my friends in the Fluid Mixing Technology Laboratory at Ryerson University.

Financial support from the Natural Sciences and Engineering Research Council of Canada (NSERC) is gratefully acknowledged. 
To my mother and brother,

For their Love and Support. 


\section{Table of Contents}

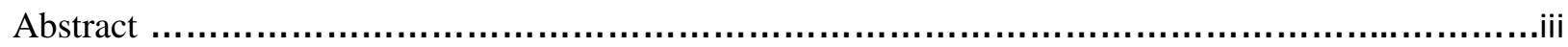

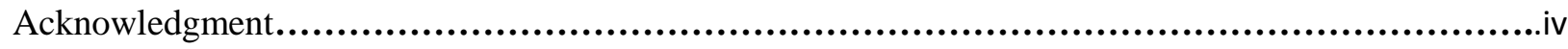

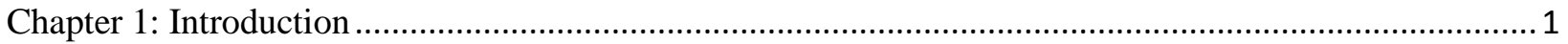

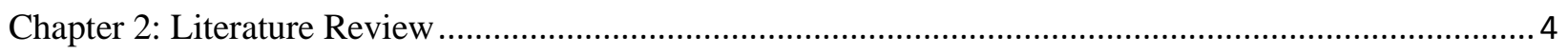

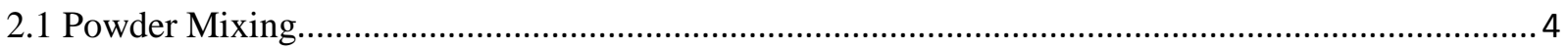

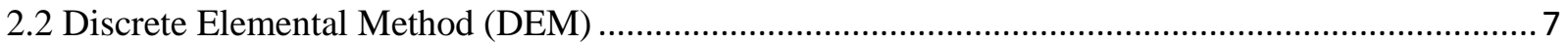

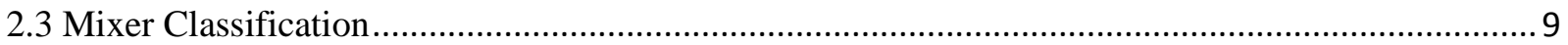

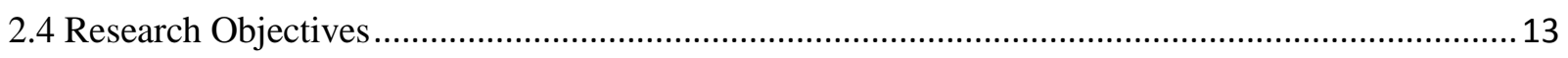

Chapter 3: Specifications of the Mixer and Experimental Methods ..................................................... 14

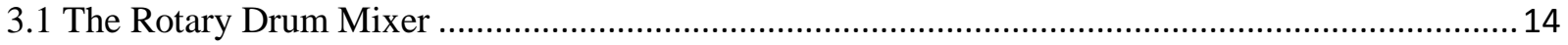

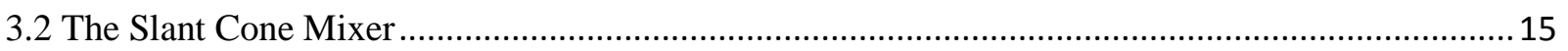

Chapter 4: Discrete Element Method (DEM) …............................................................................ 21

Chapter 5: Using Discrete Element Method to Assess the Mixing of Poly-disperse Solid Particles in a

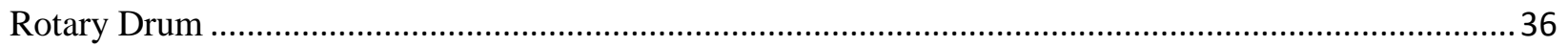

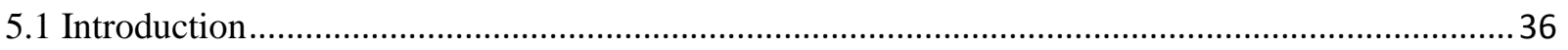

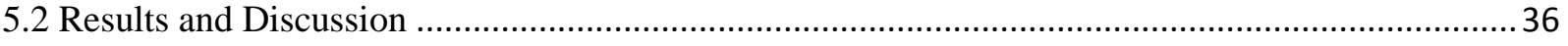

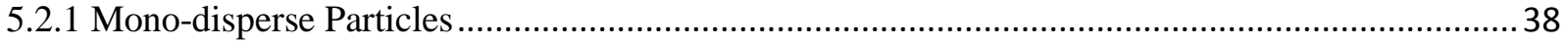

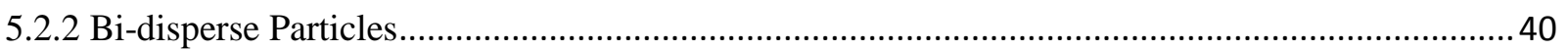

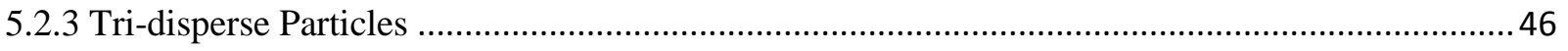

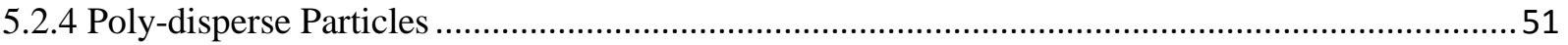

Chapter 6: Evaluation of Polydisperse Solid Particles Mixing in a Slant Cone Mixer Using Discrete

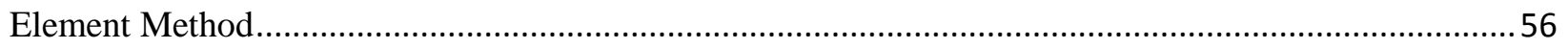

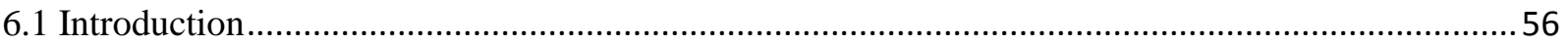

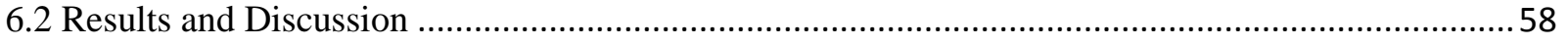

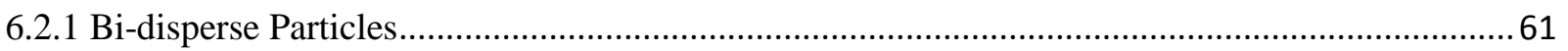

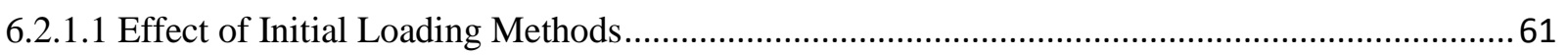

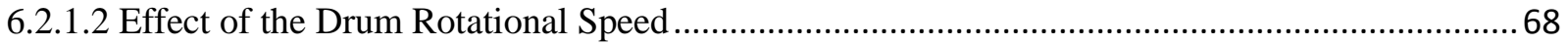

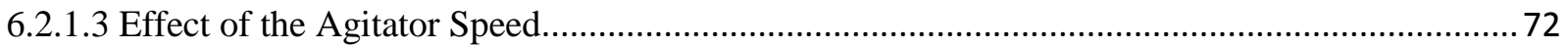

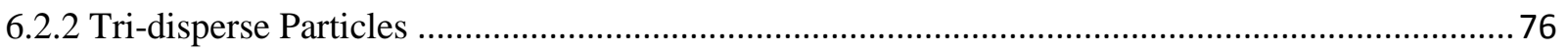




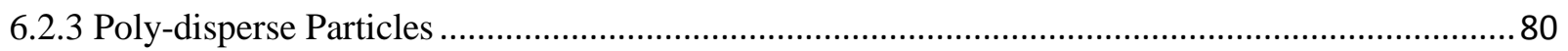

Chapter 7: Conclusions and Recommendations for future work …................................................... 84

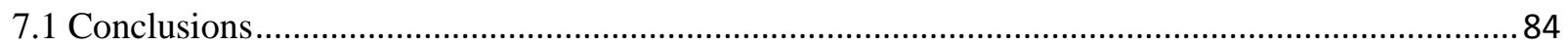

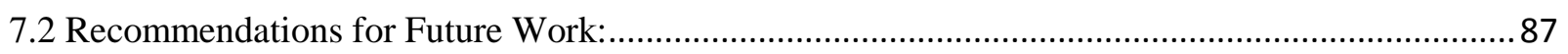

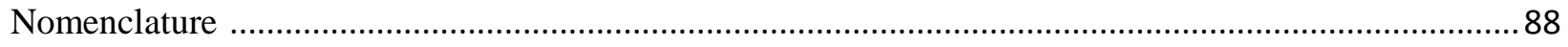

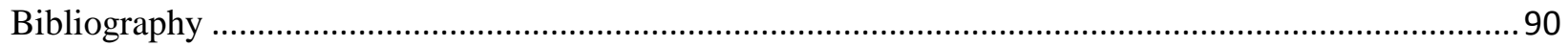




\section{List of Tables}

Table 1: List of paramerets used in DEM simulation (Bertrand et al., 2005; Arntz et al., 2008; Bharadwaj et al., 2010; Alian et al., 2014) .......................................................... 26

Table 2: Simulation parameters and the mass conditions for Mono, Binary, Ternary and Poly disperse systems inside the rotary drum mixer.................................................. 30

Table 3: Simulation parameters and the mass conditions for Mono, Binary, Ternary and Poly disperse systems inside the slant cone mixer .................................................... 33 


\section{List of Figures}

Figure 1: the schematic diagram of the experimental setup utilized in this study. 14

Figure 2: Gemco Slant Cone Mixer used in this study 15

Figure 3: (a) 3D model of the Gemco Slant cone mixer (b) Fill level guideline for the mixer

Figure 4: Intensifier bars of the slant cone mixer with T-shaped blades.............................. 17

Figure 5: (a) Thief sampler and (b) Sampling template .................................................. 20

Figure 6: Comparison between the snapshots of the simulated and real monodisperse solid mixtures at $\mathrm{t}=0,10,20$ second, drum speed of $5.5 \mathrm{rpm}$ and side-side initial loading: (a) experimental results and (b) simulation results.

Figure 7:Mixing index versus time for the mono-disperse particles at the different drum rotational speed and initial loading methods.

Figure 8: Mixing index versus time for the side-side initial loading of the bi-disperse particles at the different drum rotational speeds.

Figure 9 : Snapshots of the mixing of bi-disperse particles for the side-side initial loading at: (a) $5.5 \mathrm{rpm}$, (b) $15 \mathrm{rpm}$, and (c) $30 \mathrm{rpm}$.

Figure 10: Mixing index versus time for the bi-disperse particles at two different drum rotational speeds and two different top-bottom initial loading methods.

Figure 11: Snapshots of the mixing of the bi-disperse particles at: (a) $5.5 \mathrm{rpm}$ for the topbottom larger-to-smaller, (b) $5.5 \mathrm{rpm}$ for the top-bottom smaller-to-larger, (c) $30 \mathrm{rpm}$ for the top-bottom smaller-to-larger, and (d) $30 \mathrm{rpm}$ for the top-bottom larger-to-smaller. 45

Figure 12: Snapshots of the mixing of the tri-disperse particles at $30 \mathrm{rpm}$ for the (a) topbottom larger-to-smaller, (b) top-bottom smaller-to-larger, (c) top-bottom random, (d) sideside initial loading. Black particles with a diameter of $3.0 \mathrm{~mm}$, green particles with a diameter of $4.0 \mathrm{~mm}$, and red particles with a diameter of $5.0 \mathrm{~mm}$.

Figure 13: Mixing index versus time for the different initial loading methods of the tridisperse particles mixed at $30 \mathrm{rpm}$.

Figure 14: Snapshots of the mixing of poly-disperse particles at the drum rotational velocity of 30 rpm for: (a) top-bottom larger-to-smaller, (b) top-bottom smaller-to-larger, (c) topbottom random \#1, (d) top-bottom random \# 2, (e) side-side random, (f) side- side- left-toright larger-to-smaller. Black particles with a diameter of $2.0 \mathrm{~mm}$, white particles with a diameter of $3.0 \mathrm{~mm}$, red particles with a diameter of $5.0 \mathrm{~mm}$, green particles with a diameter of $7.0 \mathrm{~mm}$, and blue particles with a diameter of $10 \mathrm{~mm}$.

Figure 15: Mixing index versus time for the the poly-disperse particles mixed at $30 \mathrm{rpm}$ and different initial loadings 54 
Figure 16: Comparison between the snapshots of the simulated and real solid mixtures at each revolution at the fill level of $70 \%$, drum speed of $15 \mathrm{rpm}$ and up-down initial loading while the agitator was stationary.

Figure 17: Comparison between the mixing index graphs achieved through the experiment and simulation at the fill level of $70 \%$, the drum speed of $15 \mathrm{rpm}$ and the top-bottom initial loading while the agitator was stationary.

Figure 18: Snapshots of the simulated solid mixture for the bi-disperse particles at the fill level of $70 \%$ and the drum speed of $15 \mathrm{rpm}$ while the agitator was stationary (a) side-side initial loading, (b) top-bottom larger-to-smaller, (c) top-bottom smaller-to- larger, (d) smaller back-larger front, and (e) larger back-smaller front. Red particles with a diameter of $6.0 \mathrm{~mm}$, and black particles with a diameter of $4.0 \mathrm{~mm}$.....

Figure 19: Mixing index versus number of revolution for the different initial loading of bidisperse particles at the fill level of $70 \%$ and the drum speed of $15 \mathrm{rpm}$ while the agitator was stationary.

Figure 20: Snapshots of the simulated solid mixture for the bi-disperse particles at the fill level of $70 \%$ and the drum speed of $15 \mathrm{rpm}$ while the agitator was stationary (a) side-side initial loading, (b) top-bottom larger-to-smaller, and (c) top-bottom smaller- to-larger. Red particles with a diameter of $6.0 \mathrm{~mm}$, and black particles with a diameter of $4.0 \mathrm{~mm}$

Figure 21: Mixing index versus number of revolution for the different initial loading of bidisperse particles at the fill level of $70 \%$ and the drum speed of $15 \mathrm{rpm}$ while the agitator was stationary.

Figure 22: Snapshots of the simulated solid mixture at different drum speeds for the bidisperse particles at the fill level of $70 \%$ and the top-bottom smaller-to-larger initial loading method while the agitator was stationary. (a) the drum speed of $7.0 \mathrm{rpm}$, (b) the drum speed of $15 \mathrm{rpm}$, (c) the drum speed of $22.5 \mathrm{rpm}$, (d) the drum speed of $30 \mathrm{rpm}$, (e) the drum speed of $45 \mathrm{rpm}$, and (f) the drum speed of $55 \mathrm{rpm}$. Red particles with a diameter of $6.0 \mathrm{~mm}$, and black particles with a diameter of $4.0 \mathrm{~mm}$.

Figure 23: Mixing index versus number of revolution for the different drum speeds of bidisperse particles at the fill level of $70 \%$ and the top-bottom smaller-to-larger initial loading method while the agitator was stationary.

Figure 24: Snapshots of the simulated solid mixture for the bi-disperse particles at the fill level of $100 \%$ and the drum speed of $15 \mathrm{rpm}$ (a) top-bottom smaller-to-larger with a stationary agitator, (b) top-bottom smaller-to-larger with an agitator speed of $100 \mathrm{rpm}$, (c) top-bottom larger-to-smaller with a stationary agitator, and (d) top-bottom larger-to-smaller with an agitator speed of $100 \mathrm{rpm}$. Red particles with a diameter of $6.0 \mathrm{~mm}$, and black particles with a diameter of $4.0 \mathrm{~mm}$. 
Figure 25: Mixing index versus number of revolution of the bi-disperse particles at the fill level of $100 \%$ and the top-bottom smaller-to-larger and larger-to-smaller loading methods while the agitator was rotating with the speeds of 0 , and $+100 \mathrm{rpm}$. 75

Figure 26: Snapshots of the simulated solid mixture at different drum speeds for the tridisperse particles at the fill level of $70 \%$ and the top-bottom smaller-to-larger initial loading method while the agitator was stationary. (a) the drum speed of $7.0 \mathrm{rpm}$, (b) the drum speed of $15 \mathrm{rpm}$, (c) the drum speed of $22.5 \mathrm{rpm}$, (d) the drum speed of $30 \mathrm{rpm}$, (e) the drum speed of $45 \mathrm{rpm}$, and (f) the drum speed of $55 \mathrm{rpm}$. Gray particles with a diameter of $6.0 \mathrm{~mm}$, red particles with a diameter of $5.0 \mathrm{~mm}$, and black particles with a diameter of $4.0 \mathrm{~mm} . \ldots \ldots . . . .77$

Figure 27: Mixing index versus number of revolution for the different drum speeds of tridisperse particles at the fill level of $70 \%$ and the top-bottom smaller-to-larger initial loading method while the agitator was stationary. 79

Figure 28: Snapshots of the simulated solid mixture at different drum speeds for the polydisperse particles at the fill level of $70 \%$ and the top-bottom smaller-to-larger initial loading method while the agitator was stationary. (a) the drum speed of $7.0 \mathrm{rpm}$, (b) the drum speed of $15 \mathrm{rpm}$, (c) the drum speed of $22.5 \mathrm{rpm}$, (d) the drum speed of $30 \mathrm{rpm}$, (e) the drum speed of $45 \mathrm{rpm}$, and (f) the drum speed of $55 \mathrm{rpm}$. Gray particles with a diameter of $6.0 \mathrm{~mm}$, red particles with a diameter of $5.0 \mathrm{~mm}$, black particles with a diameter of $4.0 \mathrm{~mm}$, and green particles with a diameter of $3.0 \mathrm{~mm}$. 81

Figure 29: Mixing index versus number of revolution for the different drum speeds of polydisperse particles at the fill level of $70 \%$ and the top-bottom smaller-to-larger initial loading method while the agitator was stationary. 83 


\section{Chapter 1: Introduction}

Particle processing is an essential step in a variety of applications spanning the ceramics, polymers, cosmetics, metallurgical, and food industries. The quality of the pharmaceutical tablets and capsules dosage formulations would depend on their mix homogeneity; for that reason, discrepancy in the mixture could be detrimental for the patients.

The tumbling mixer is one of the most common batch industrial mixers, where particles flow by a combination of the drum rotation and gravity. Presently the design of powder mixers is based on trial and error rather than on analytic or quantitative methods. Nonetheless, the quantitative characterizations of mixing performance as a function of basic parameters, such as the filling level, particle size and properties, agitator speed or drum rotational speed, started to appear in the last decades in academic and industrial research papers (Brone et al., 1997; Muzzio et al., 1997; Brone et al., 1998; Brone and Muzzio, 2000; Moakher et al., 2000).

Simulations of powders and granules are based on either continuum or discrete elements models. The discrete element methods (DEM) combine semi-empirical models for the particles' interactions with the equations of motion from Newtonian physics to simulate the explicit trajectories of all solid particles inside the mixer, thus yielding realistic predictions of the mixing behavior.

However, the DEM approach is very demanding computationally, which strongly limits the number of solid particles and the number of revolutions in a simulation (Bertrand et al., 2005). Continuum models do not consider the discrete nature of powders and granules and assume that 
the powder is a continuum that obeys the momentum and mass conservation laws (Arratia et al., 2006). For this reason, continuum models could be scaled up easily (Arntz et al., 2008).

In this study, DEM simulations were done, since in this numerical method the phenomena emerging from the simulations are expected to be the least affected by the details and approximations of the simulation model (Arntz et al., 2008). One advantage of DEM is that once a validated model is obtained, it can provide valuable information that would be not easy to obtain experimentally.

In recent years, the use of particle dynamic simulations was increased rapidly (Walton and Braun, 1986; McNamara and Young, 1992; Walton, 1993; Ristow, 1996; Bizon et al., 1998), and was applied towards solving complex industrial problems (Jenkins and Mancini, 1989; Alexander et al., 2001; Sudah et al., 2005; Arratia et al., 2006; Sahni et al., 2011 ).

The literature review showed that there is a lack of sufficient information about the mixing of the mono, binary, ternary, and poly-disperse particles inside the rotary drum and slant cone mixers. Because of this, the main objective of this study is to investigate the mixing quality of the various particles systems inside the rotary drum and slant cone mixers as a function of the drum speed, particle size, the agitator speed, and the initial loading method through the discrete element method (DEM).

The work in this study is divided into the following chapters:

Chapter two gives a brief review of literature to present the fundamentals of powder mixing, discrete elemental method, and mixer classifications. Also, the research objectives are presented. 
Chapter three is concerned with the design, specification, structure, and operation of the rotary drum and slant cone mixers. Also, this chapter explains the experimental method for both mixers.

Chapter four is organized to review the general information about DEM, such as governing equations, numerical method, and the method of calculating the mixing index for poly-disperse system. Also, this chapter presents the Hertz-Mindlin contact model.

Chapters five and six present the introduction as well as the results and discussion for the rotary drum study and slant cone mixer, respectively. Finally, chapter seven summarizes the overall conclusions of this study and provides the recommendations for future work. 


\section{Chapter 2: Literature Review}

\subsection{Powder Mixing}

Granular materials with different properties are widespread in nature: they can flow like fluid (avalanche, sand flow, and debris flow) under the co-activation of external force and internal stress (Alexander et al., 2001). Despite granules and powders being so prevalent in industries, mixing processes involving granules and powders are poorly understood compared to the fluid mixing counterparts (Meier et al., 2007). One key difference between particles and fluids lies in their mixing properties. While fluids may undergo mixing due to the thermal diffusion, turbulence or chaotic advection, granular materials often have a tendency to segregate and even separate due to differences in particle properties such as the shape, size, and density (Abouzeid and Douglas, 2010).

This fact stems from the reality that scientists and process engineers do not have a set of constitutive equations that are derived from physics in order to explain the flows of powders and granules under defined boundary conditions and a specified initial state (Remy et al., 2009). In other words, the lack of basic understanding of powder mixing leads to broad assumptions during the stage of process design, scale-up, and poor identification of the important process parameters (Geldart, 1990; Masuda et al., 2006; Schulze, 2007).

It has been reported that close to $90 \%$ of granules and powders processing plants experience some kind of major mixing problems during the operation (Wibowo and $\mathrm{Ng}, 2001$ ). Powder and granular mixing operations are frequently encountered in a wide variety of chemical industries. It was estimated that more than $55 \%$ of all products required some sort of particle processing (Bridgwater, 2003). 
In chemical industries, two or more types of solid particles are often required to be mixed to some degree of homogeneity. In the pharmaceutical field, two drug powders or fillers require to be mixed in order to produce composite drugs. Also, two types of monomers or pre-polymers have to mix before polymerization in the plastic injection molding. Examples of chemical operations involving granules and powders include powder mixing and blending for cosmetics industries (Muzzio et al., 2004), the production of concrete for the construction industries (Vidales et al., 2006), the compression of powder drugs into tablets for pharmaceutical applications (Prescott, 2001), and freeze drying for food processing industries (Wang et al., 2006).

Lacey (1954) specified three major mechanisms for mixing that are classified into shear, diffusive, and convective mechanisms. For industrial processes, at least one of these basic mechanisms is responsible for mixing. For the diffusion mechanism, the individual particles during the mixing process would be distributed over a surface developed within the mixture. In the convective mechanism, the particles are mobilized from one location inside the mixer towards another side. On the other hand, the solid particles during the shear mechanism are mixed through the formation of slipping planes which are developed inside the mixture.

If two granules are dissimilar (e.g. in size and/or weight), it is often difficult to mix them homogeneously due to size segregation and/or density segregation (Jiang et al., 2011). Also, serious segregation phenomena can be induced by horizontal and vertical mechanical vibration flow in a cylindrical drum. Segregation is a continued source of setback for industries involving granular materials and could cause dramatic revenue loss (Alexander et al., 2004). 
Particulate de-mixing (segregation) is a phenomenon known to occur in several granular flow processes which does not have a molecular fluid analog (Remy et al., 2009). Under the presence of shear, granules would self-organize into segregated regions where particles with similar size, shape, density or surface characteristics assemble (Porion et al., 2004; Remy et al., 2009).

Depending on the segregation mechanisms, the following segregation patterns have been recognized by the researchers: fluidization, sieving, percolation, trajectory, rolling, displacement, agglomeration, embedding, push-away, concentration-driven displacement, impact-bouncing, angle of repose, and air current (Mosby et al., 1996; McGlinchey, 1998; De Silva et al., 2000). Nonetheless, many of these mechanisms rarely occur in industrial scenarios and many are special cases of other mechanism (Tang and Puri, 2004).

Displacement and percolation segregation are considered a special case of sieving segregation since the commonality of these patterns is that the large particles relatively move up while the small particles move down. Also, these patterns belong to "top-to-bottom segregation" (Tang and Puri, 2004).

The recent studies have shown that the main reason for segregation of the granular materials is the particle size difference (Kudrolli, 2004; Remy et al., 2011). Tang and Puri (2004) suggested a segregation mechanism depending on the role of particle size in the mechanism of segregation. The four proposed primary patterns of segregation were fluidization (fine), agglomeration (cohesive fine), sieving (small particles), and trajectory (large particles).

Trajectory segregation patterns frequently come out in those situations where the large particles are in flight or moving velocity or have relatively high rolling. Trajectory segregation is also 
called the side-to-side segregation since large particles relatively shift in a direction while the small particles shift in the other direction (Tang and Puri, 2004).

\subsection{Discrete Elemental Method (DEM)}

Heuristic rules-of-thumb were used by chemical engineers in order to limit the mixing problems, but these solutions have not consistently prevented complications such as non-uniform flow or segregation from occurring during scale-up. For this reason, a more appropriate approach is required in order to quantitatively predict the particles' mixing behavior from fundamental mechanics principles, powders properties, small-scale laboratory tests, and then to design the process accordingly (Remy et al., 2009).

Experiments to explain solid particles mixtures via continuum-like approaches have had limited success since, unlike the theory of molecular fluids, solid particles mixtures are discrete in nature and have an intense impact at the macroscopic scale in homogeneities at the microscopic level (Goldhirsch, 2003). These characteristics cause the continuum assumption in the classical mechanical model to be questionable for powders and granules systems. Furthermore, the flow of powders and granules exhibit a tremendous range of behavior, ranging from rapid fluid-like scenarios to solid-like quasi-static flow (Campbell, 2006).

The importance of powders and granules, merged with the need for the development of an accurate theoretical structure, has inspired the study of particulate systems by many scientists and process engineers. Following the approach from the early days of fluid flow research, several researchers have worked to understand the behavior of a simple model for a solid particles system that consists of mono-disperse and cohesionless smooth spheres (Savage and Jeffrey, 1981; Lun et al., 1984; Jenkins and Mancini, 1989; Hopkins and Louge, 1991; Savage and Dai, 
1992; Zamankhan et al., 1997; Moakher et al., 2000; Bertrand et al., 2005; Sudah et al.,2005; Bharadwaj et al., 2010; Tahvildarian et al., 2013; Alian et al., 2014) in simple geometries such as shear flows (Campbell, 1982, 2002; Hopkins et al., 1992; Glasser and Goldhirsh 2001), chute flows (Forterre and Pouliquen, 2001, 2002; Conway et al., 2003; LaMarche et al., 2007), rotating drums (Malhotra et al., 1990; Ding et al., 2001; Ottino and Khakhar, 2002; Felix et al., 2007; Arntz et al., 2008; Chand et al., 2012) , and couette cells (Lun, 1996; Tardos et al., 1998; Conway and Glasser, 2004; Liu et al., 2007).

These studies provided rich information on the transient and dynamical behavior of solid particles since these systems contain one or more of the basic elements of industrial flows, such as the gravity or a body force, physical boundaries, and the shear stress.

The technology of computer simulations provides the opportunity of bridging the knowledge gap, as the simulation outputs allow for the analysis of system parameters that are difficult to measure or vary experimentally. In recent decades, the discrete element method (DEM) has been widely used to investigate the flow of solid particles in a variety of systems, ranging from simple shear flows to advance industrial geometries (Remy et al., 2009).

Cundalland and Strack (1979) introduced the discrete element method (DEM), which is a powerful tool to analyze the three-dimensional (3D) flow of particles in powder mixers. It is a mathematical method used to model the movement of particles interacting with other particles and solid surfaces through collisions (Tijskens et al., 2003). In this method, the trajectory of each particle in the system along with particle-particle and particle-boundary interactions is tracked (Bertrand et al., 2005). DEM has been employed to simulate the mixing of solid particles in a variety of mixers. 
Bertrand et al. (2005) discussed with great details the theoretical and practical aspects of this method, and introduced new techniques to handle the simulations of more complex systems. The DEM resembles molecular dynamics approaches since the position of every single particle in a system is obtained by integrating twice with respect to time for Newton's second law of motion. DEM is in fact a time driven soft particle method which lets two particles interpenetrate so as to mimic particle deformation.

Nonetheless, collisions are not instantaneous with DEM and the level of particle interpenetration is connected to the nature of collisions. Thus, DEM is suited for contact dominated flows such as those predominant during the mixing of powders (Bertrand et al., 2005).

\subsection{Mixer Classification}

The industrial powder mixers could be broadly classified into the following categories: agitated mixers, tumbling mixers, pneumatic blenders, gravity silo blenders, high-intensity mixers, and high-intimacy or high-shear mixers. Also, the agitated mixer is divided to the paddle and plough, fluidizing paddle mixers, ribbon blenders, screw mixers, and the sigma-blade and z-blade mixers (Manjunath et al., 2004). The appeal of these mixers comes from their capability to handle a wide variety of particles ranging from free flowing granules to cohesive powders (Muzzio et al., 2004; Faqih et al., 2006; Chandratilleke et al., 2012).

Due to the industrial importance of the tumbling mixers for cosmetics, food and pharmaceutics, this study has focused only on two different types of tumbling mixers: rotary drum and slant cone. Tumbling blenders have many technical advantages that include the moderate mixing intensity, ease of sanitation, simple structure, and the large handling capacity (Jiang et al., 2011). 
The tumbling blender rotates around a horizontal shaft. Inside this blender, the motion of particles is induced by vessel rotation and the force of gravity. Different types of tumbling blenders are: V-and Y-blenders, double cone, bin blenders, rotating drums, and slant cone mixer (Paul et al., 2004). The double cone mixer can also be designed to rotate around two axes, and it is called the biaxial rotary mixer (Cho et al., 2012).

Although the slant cone mixer is defined as a tumbling mixer, this mixer is designed with an internal agitator to enhance the mixing quality (Alian et al., 2014). Even though the design of the rotary drum is simple, it might be introduced with baffles to increase the mixing mechanisms (Jiang et al., 2011).

Tumbling mixers would "tumble the powder mass," where the mixing is achieved predominantly by the random motion when particles roll down a sloping surface. As the entire shell tumbler rests either on its own axis or eccentrically, the ingredients are physically expatriated and mixing takes place in the radial direction (Paul et al., 2004).

Serious segregation phenomena may become visible especially in the mixing of bi-disperse or poly-disperse solid particles with different physical properties inside a tumbler blender. Inside the mixer, segregation generally appears in the free-surface of granular flow, where the lighter or larger particles rise to the top, and the denser or smaller particles sink inside the total mass of particles (Jiang et al., 2011).

Nityanand et al. (1986) studied the mixing inside the rotating drum in both the radial and axial directions. They realized that the mixing in the radial direction was often orders of magnitude faster than the mixing in the axial direction. Moreover, several studies showed that the mixing 
and segregation mechanisms inside the rotary drum took place predominantly at the top most slanted layer of the granular bed (Cho et al., 2012).

Chaudhuri et al. (2006) investigated the mixing of cohesive bi-disperse particles with the sideside loading method. In this study, the same mass condition for each set of particles was introduced in order to settle both sets of particles on the same fill level.

Arntz et al. (2008) investigated the fill level effect on the segregation of the bi-disperse particles, which were initially loaded side by side in a rotary drum. When the particles with different sizes are mixed inside a rotary drum, the smaller particles are relocated inside the occupied mass, and the larger particles are pushed away and relocated at the circumference of the occupied mass. This is called the percolation segregation mechanism (Arntz et al., 2008). According to this mechanism, the larger particles move further away from the small particles where the small particles are surrounded at the center by the larger particles. According to the percolation mechanism, the small particles fall through the voids in the flowing granular bed. It was shown that the most intense segregation occurred at the fill levels $>65 \%$.

Chand et al. (2012) studied the radial segregation for a binary mixture inside a rotary drum. They reported that the radial segregation in the longer drum was higher than that in a shorter drum. Alizadeh et al. (2013) investigated the mixing and segregation of the poly-disperse particles inside a rotary drum through the particle trajectories, which were obtained from the radioactive particle tracking technique. The radial segregation, axial dispersion coefficients, and velocity profiles for mono and poly-disperse systems were studied as a function of the particle size and rotational velocity. Faqih et al. (2006) investigated the flow induced dilation of cohesive granular. The mixing quality inside the rotary blender was a function of the rotational velocity, 
particles sizes, powder composition, flow-induced dilation of cohesive granular powders, and the geometrical parameters of the mixer. Some studies have shown that the mixing quality in the rotary drum blenders can be improved by using internal blades or baffles (Malhotra et al., 1988, 1990; Jiang et al., 2011).

Moakher et al. (2000) studied the double-cone mixer and V-blender. They showed that the topbottom initial loading had a higher mixing efficiency than the back-front loading. Manickam et al. (2010) studied the double cone mixer and concluded that the rotation of the mixer at the higher speeds around the horizontal axis resulted in a better mixing efficiency and lower mixing time. They investigated the effect of fill level on the mixing performance of a double cone mixer, and did not examine any changes in the mixing efficiency when the fill level was changed from $10 \%$ to $40 \%$.

Alexander et al. (2004) investigated the segregation mechanism for the bi-disperse non-cohesive glass beads inside a V-blender. At low rotational velocities, the trajectory segregation mechanism induced by surface flow separated the small and large particles. The large particles accumulated on the convex side, whereas the small particles collected on the concave side of the bend. At high rotational velocities, the large particles moved into the center of each shell, while the small particles accumulated near the center of the V-blender. 


\subsection{Research Objectives}

Our comprehensive literature review revealed that there is a lack of adequate information about the mixing of the mono, binary, ternary, and poly-disperse particles inside the rotary drum and slant cone mixers. Therefore, the main objective of this study is to explore the mixing quality of the mono, binary, ternary and poly-disperse particles inside the rotary drum and slant cone mixers as a function of the rotational speed of the drum, particle size, the agitator speed, and the initial loading method through the discrete element method (DEM). DEM is a reliable simulation method for assessing the particulate behavior systems. To achieve this objective, both experimental work and DEM are utilized. To validate the models developed in this study for the slant cone mixer and the rotary drum, the simulation results are compared to the experimentally measured values. 


\section{Chapter 3: Specifications of the Mixer and Experimental Methods}

\subsection{The Rotary Drum Mixer}

Figure 1 depicts the schematic diagram of the experimental setup utilized in the rotary drum study. The drum was constructed from glass and its length and diameter were $22.90 \mathrm{~cm}$ and $10.40 \mathrm{~cm}$, respectively. The drum was rotated using a roller assembly, which was connected to a motor equipped with a variable frequency drive.

The particle size was measured using a particle size analyzer (Microtrac, Model S3500). The diameter and density of glass beads were $3.0 \pm 0.2 \mathrm{~mm}$ and $2.5 \mathrm{~g} / \mathrm{cm}^{3}$, respectively. To perform the mixing tests, 15,000 red particles and 15,000 black particles were loaded side-by-side into the drum. A custom made separator was fabricated to separate the two sets of particles during the filling to achieve the side-side initial loading method. After loading the cylinder with particles, the physical separator was removed slowly in order to maintain the side-side initial position. The mixer was rotated at the specified rotational speed for a certain time and then stopped for taking photos, which showed the upper and front views of the drum content.

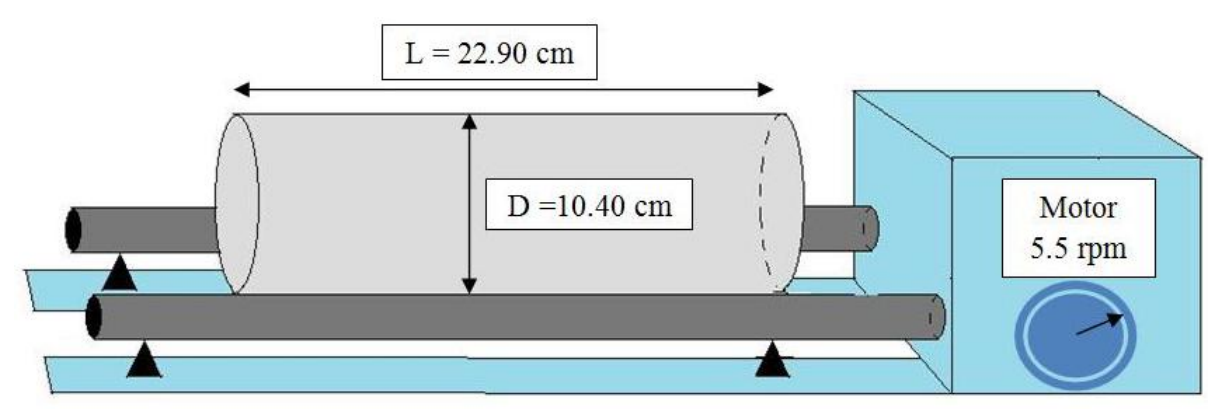

Figure 1: the schematic diagram of the experimental setup utilized in this study. 


\subsection{The Slant Cone Mixer}

In the present study, a 3.7 L slant cone blender fabricated by Gemco (Figure 2) was utilized for the mixing of powders and granules.

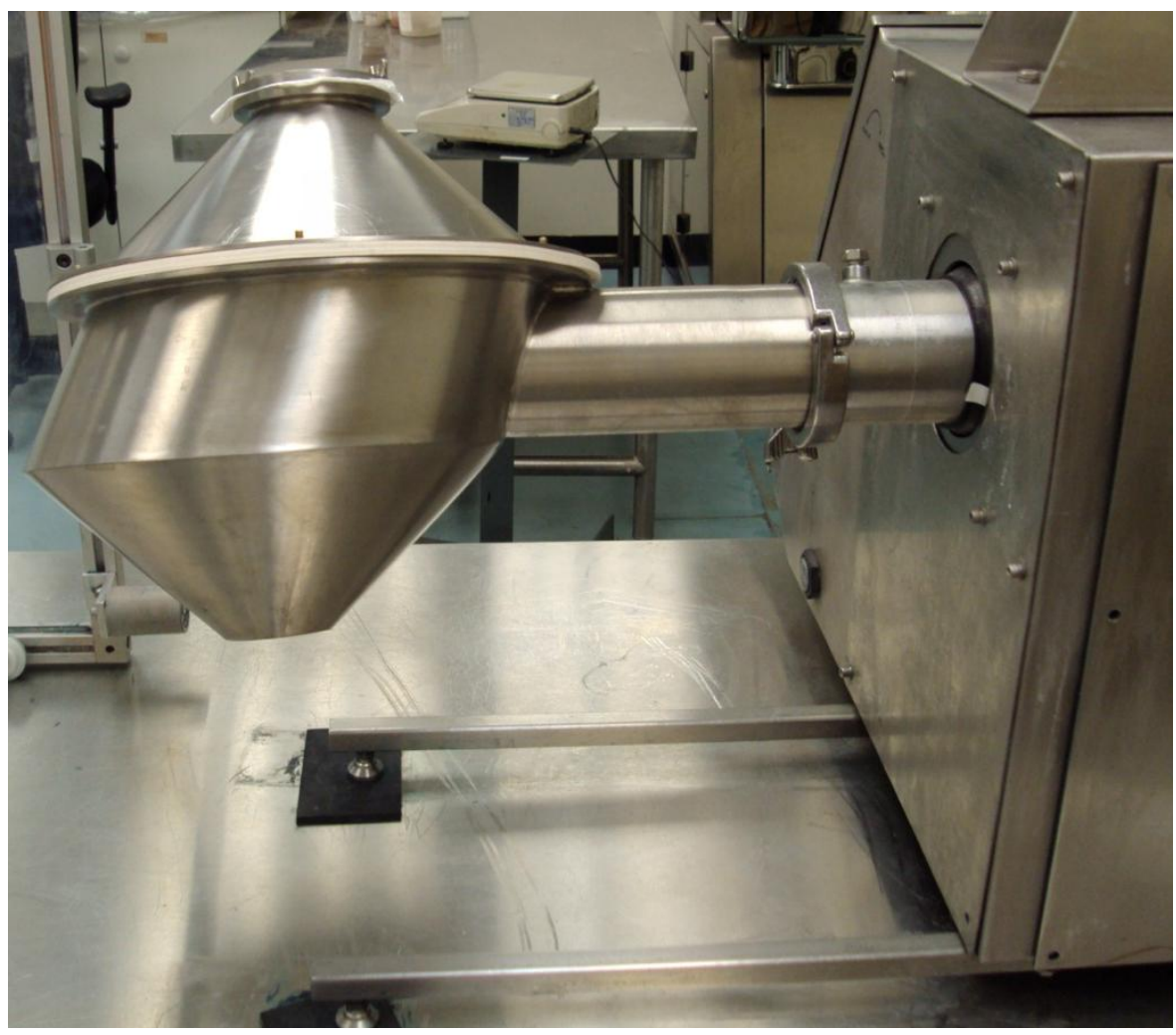

Figure 2: Gemco Slant Cone Mixer used in this study 
Figure 3a depicts the 3D model of the slant cone mixer prepared by SolidWorks ${ }^{\odot}$. Also, Figure $3 \mathrm{~b}$ describes the fill level guideline for the slant cone mixer (Alian et al., 2014). Slant cone blender is classified as a tumbling blender and is asymmetrical in shape.

(a)

(a)

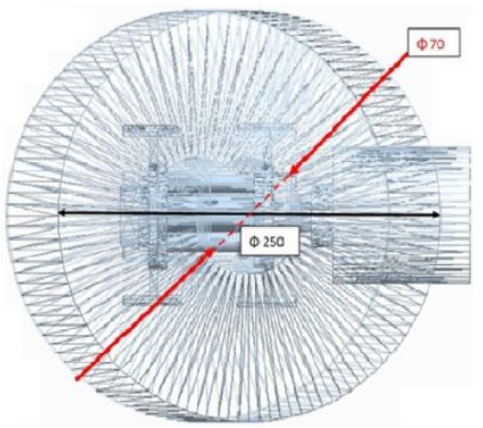

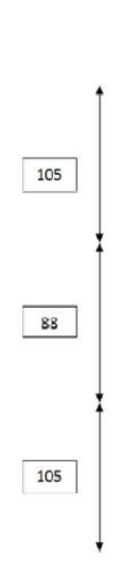
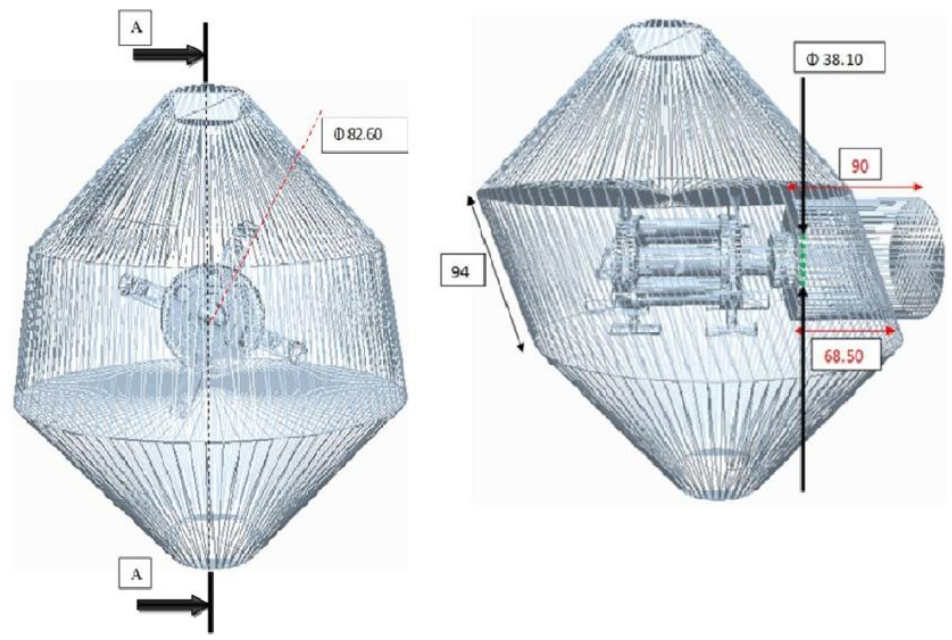

(b)

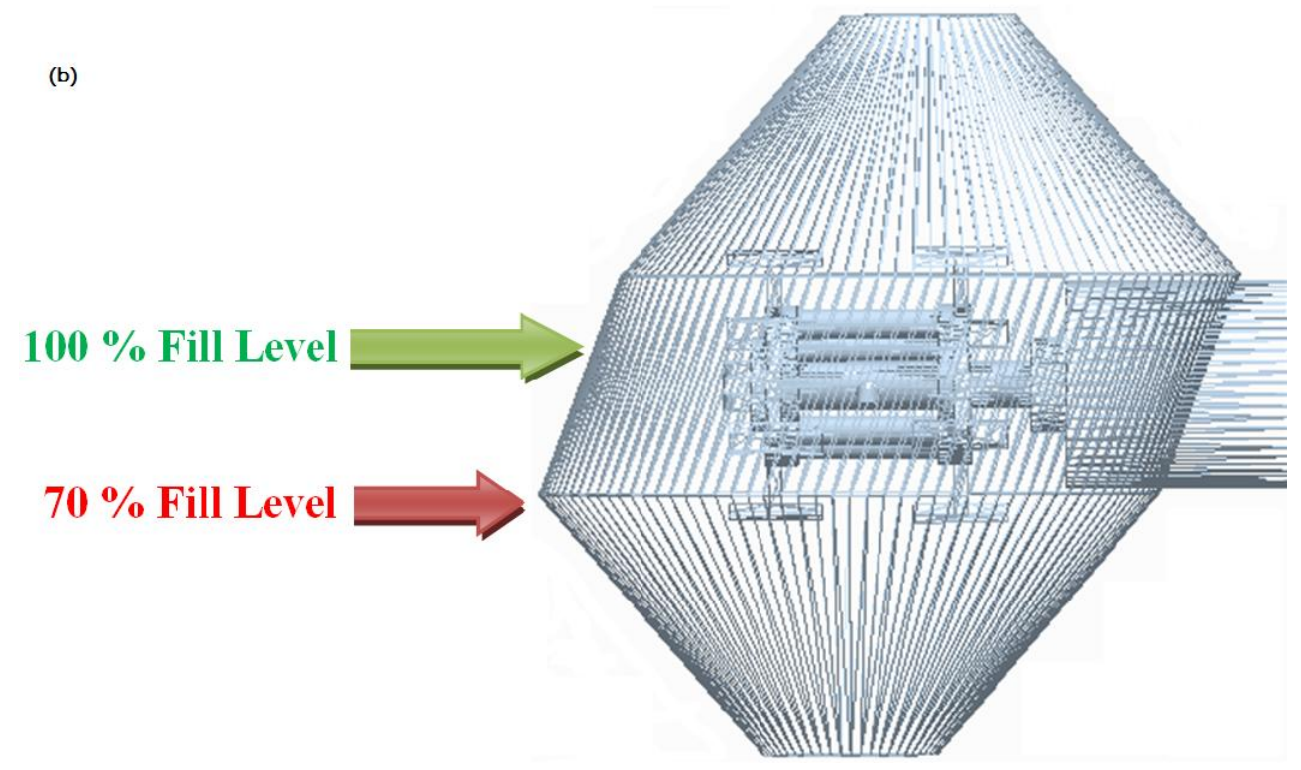

Figure 3: (a) 3D model of the Gemco Slant cone mixer (b) Fill level guideline for the mixer 
This type of blender can be supplied with the intensifier bars with T-shaped blades as shown in Figure 4. These intensifier bars are installed for different applications such as reducing the particle size, mixing liquid such as the binder, dispersing additives like paint, and de-lumping packed material. Moreover, installation of these bars would enhance the mixing efficiency by providing a large amount of kinetic energy to the particles, and generating a more random and intense flow of particles inside the drum.
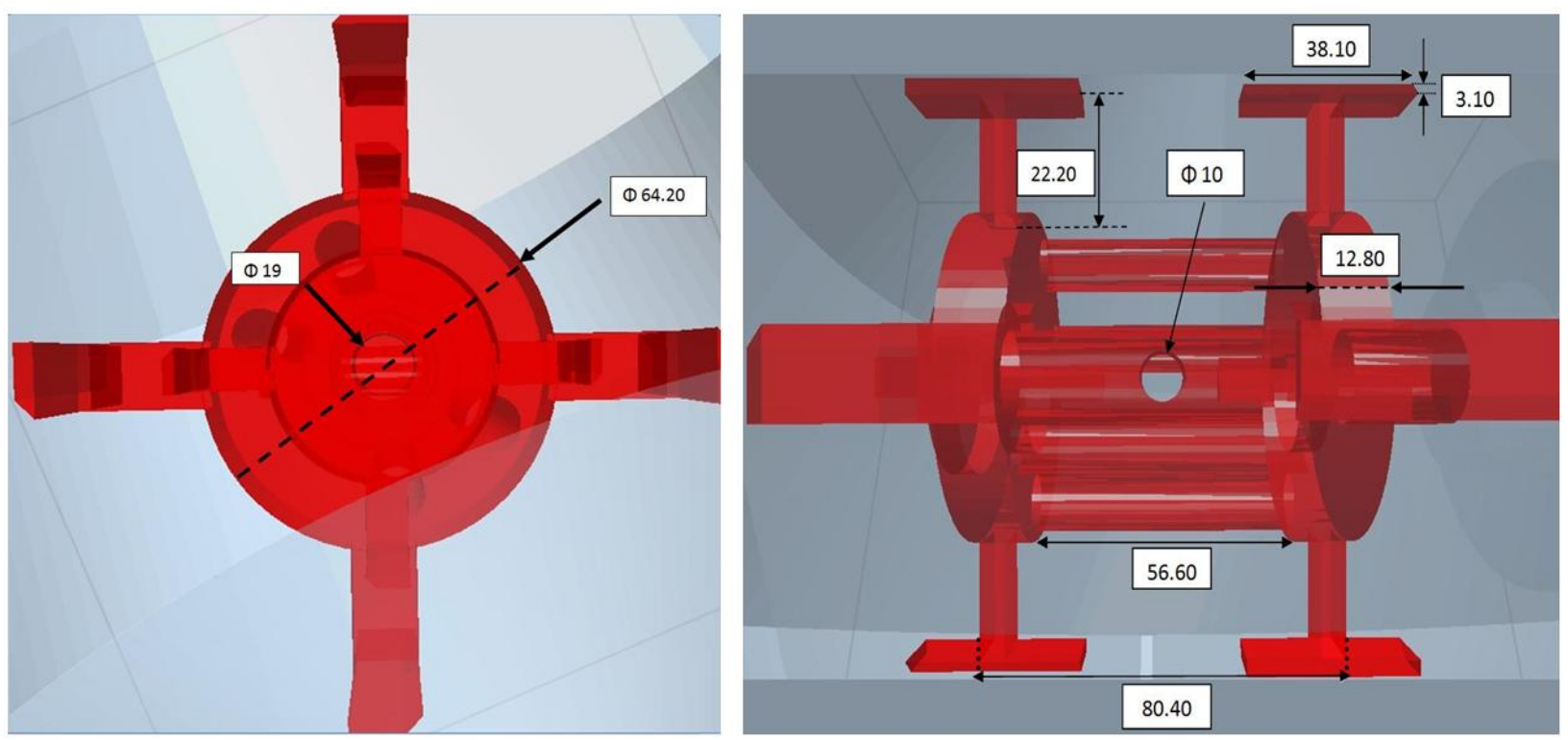

Figure 4: Intensifier bars of the slant cone mixer with T-shaped blades 
As shown in Figure 3a, the blender vessel and the agitator bar stand on the same center of rotation. One of the issues for powder mixing is the quality of the final mixed product. To ensure the homogeneity of the final product, characterization of the mixture plays an important role in the design of the powder blenders. Evaluation of the degree of homogeneity and determination of the mixing time in the mixing volume are based on the statistical and image analyses. In the statistical method, a proper sampling procedure should be applied, and adequate number of samples must be taken. On the other hand, the mixing efficiency in the image analysis method is obtained from digital imaging of the mixture (Daumann and Nirschl, 2008).

Thief is a powder sampling tool which was used as the sampler in this study for the slant cone mixer (Figure 5a). Different regions of the bed should be included in sampling. In order to take a sample from the interior regions, the sampler was inserted into the bed while the mixer was in the static position. If sampling is limited to a few locations, missing the poorly mixed regions would be unavoidable. As a result, false outputs are expected (Muzzio et al., 1997). The results might change due to the disturbance of the mixture caused by the insertion of the sampler (Paul et al., 2004).

Various statistical analyses such as the nearest-neighbors method, mixture variance, relative standard deviation, Lacey index, estimation of intensity of segregation, neighbor-distance method, average-height method, and the mixing metric for poly-disperse mixtures have been developed to assess the quality of solid particles mixing in different industrial processes (Fan et al., 1970; Gotoh et al., 1997; Daumann and Nirschl, 2008; Arntz et al., 2008).

In this study, the mixing metric method was used as a factor to calculate the mixing efficiency, which is described in the next section. 
In order to validate the DEM model developed in this study, spherical non-cohesive "black" and "red" colored glass beads from Metalfini (Metalfini Corporation, Saint-Laurent, QC) were used in our experiments. The diameter of the glass beads was measured using Microtrac S3500 particle size analyzer, and the measured diameter was $3.0 \pm 0.2 \mathrm{~mm}$. A thief sampler (shown in Figure 5a) was employed for sampling the particles.

In order to guarantee that the samples are extracted from the desired positions, a custom-made sampling template with three holes was put on top of the particle bed inside the mixer when the samples were taken. The template is shown in Figure 5b. Each sample had approximately 100200 particles. The percentage of black and red glass beads in each sample was determined manually by counting the particles.

Moreover, a digital camera was employed to capture the mixing of the black and red glass beads. These sampling data and snapshots were compared to the results of the simulations to validate the DEM model developed in this study for the mixing of the solid particles inside the slant cone blender. 
(a)
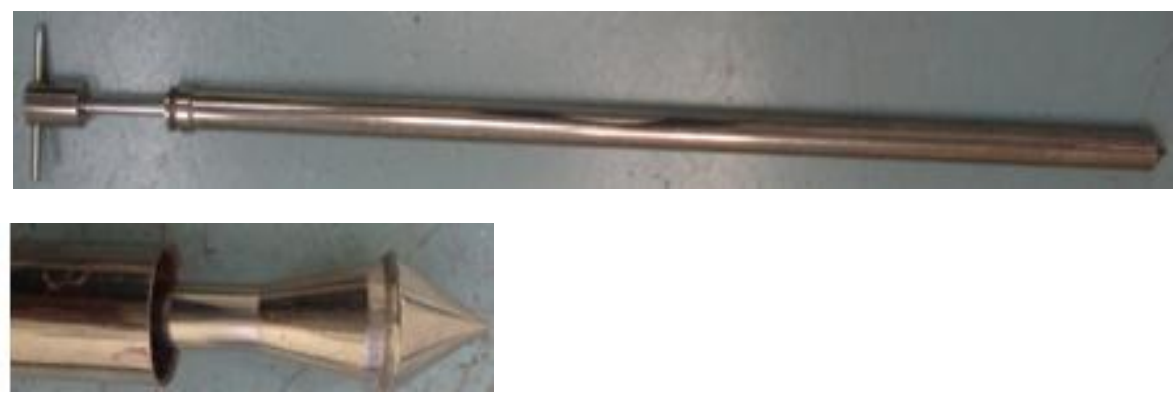

(b)

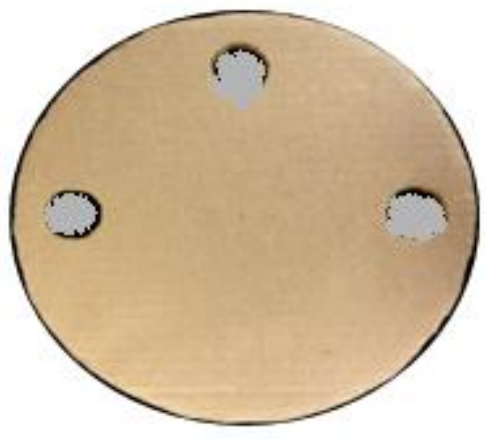

Figure 5: (a) Thief sampler and (b) sampling template 


\section{Chapter 4: Discrete Element Method (DEM)}

In this study, the discrete element method (DEM) was utilized to examine the mixing of glass beads in a slant cone mixer. The theoretical and practical aspects of this routine have been discussed with great details by Bertrand et al. (2005).

DEM is a mathematical algorithm that calculates the position of every particle inside a system by integrating twice with respect to time according to the Newton's second law of motion (Romanski et al., 2011):

$$
\begin{aligned}
& F_{\text {total }, k}=m_{k} a_{k} \\
& a_{k}=\frac{d^{2} L_{k}}{d t^{2}}
\end{aligned}
$$

where $m_{k}$ represents the mass of particle $k, a_{k}$ is the acceleration for the studied particle, and $F_{\text {total,k }}$ is the total force acting on particle $k$.

Newton's second law for rotational motion is defined as (Jiang et al., 2011):

$$
T_{\text {total,k }}=I_{K} \frac{d \omega}{d t}
$$

where $I_{K}$ represents the moment of inertia of particle $k, L_{k}=\left(X_{k}, Y_{k}, Z_{k}\right)$ is the Cartesian

coordinates of its center of gravity, $\frac{d \omega}{d t}$ is the angular acceleration for the studied particle, and $T_{\text {total,k }}$ is the total torque acting on this particle.

The mathematical concept for the discrete element method (DEM) is simple and powerful: the particle's trajectory inside a mixer is calculated, considering all the forces applying on the particle and integrating Newton's second law of motion and the related kinematic equations for 
the space position and velocity. Typical forces considered for a mixing system are the cohesive forces, solid-solid interactions for example the electrostatic, gravitation, Van der Waals, contact forces due to collisions, and bridging due to humidity and fluid-solid interactions in multiphase flows (Di Renzo and Di Maio, 2004). Also, the rotation of each particle would be calculated in a similar method through an angular momentum balance.

In the context of mixing, the total force acting on a particle $k$ would be defined as (Bertrand et al., 2005):

$$
F_{\text {total }, k}=\sum_{k \neq m} F_{\text {contact }, k m}+F_{\text {Hydrodynamic }, k}+F_{\text {non-Hydrodynamic }, k}
$$

where $F_{\text {non-Hydrodynamic, } k}$ would be affected in cohesive systems and would represent for any colloidal or capillary forces. The term $F_{H y d r o d y n a m i c, k}$ represents the gravitational force, the drag force and any buoyant force might be exerted by the fluid phase. A model is required to evaluate the total contact force term $F_{\text {contact }, \mathrm{km}}$.

EDEM software provides several models to evaluate the contact force. However, Bharadwaj et al. (2010) suggested applying the Hertz-Mindlin models because it offers an accurate representation of the physical situation inside the mixer. The Hertz-Mindlin contact model is a variant of the non-linear spring-dashpot contact model based on the Hertz-Mindlin contact theory (Johnson, 1987). This model was used in both studies, where a great correspondence and an accurate representation between simulation and experimental pictures for the rotary drum mixer were found as shown in Figure 6 on page 37. Also, a good agreement for the slant cone study was observed between the simulation and experimental results, as shown in Figures 16 and 17 on 
pages 59 and 60, respectively. The forces between two spheres, A and B, are described by the following equation (Jiang et al., 2011):

$$
\sum_{k \neq m} F_{\text {contact }, k m}=F_{n}+F_{t}
$$

where $F_{n}$ is the normal force and $F_{t}$ is the tangential force component.

The total torque $T_{\text {total,k }}$ is consisted of $T_{r}$ and $T_{t}$, where the torque $T_{r}$ is due to the rolling friction and the torque $T_{t}$ is generated by the tangential contact force (Jiang et al., 2011) :

$$
T_{\text {total }, k}=T_{r}+T_{t}
$$

The normal force vector is defined as (Di Renzo and Di Maio, 2004):

$$
F_{n}=-k_{n} \delta_{n}^{3 / 2}
$$

where $k_{n}$ and $\delta_{\mathrm{n}}$ define the normal spring stiffness, and normal overlap, respectively. The normal spring stiffness is calculated as follows (Chand et al., 2012):

$$
k_{n}=\frac{4}{3} E_{e f}\left(R_{e f}^{*}\right)^{1 / 2}
$$

where $E_{e f}$ and $R_{e f}{ }^{*}$ define the equivalent Young's modulus and effective radius of the colliding particles, respectively.

The tangential contact force is calculated using the following equation (Di Renzo and Di Maio, 2004):

$$
F_{t}=-S_{t} \delta_{t}
$$


where $S_{t}$ and $\delta_{t}$ define the tangential spring stiffness and tangential displacement, respectively.

The tangential damping force is calculated using the following equation (Kruggel-Emden et al., 2008):

$$
F_{t D}=\sqrt{\frac{10}{3}} \dot{\delta}_{t} \beta\left(\frac{S_{t}}{M_{e f}}\right)^{0.5}
$$

where $\dot{\delta}_{t}$ and $M_{e f}$ define the relative tangential velocity and the effective particle mass, respectively.

The tangential spring stiffness is expressed by (Romanski et al., 2011):

$$
S_{t}=8 G_{e q} R_{e f}{ }^{* 1 / 2} \delta_{n}{ }^{1 / 2}
$$

where $G_{e q}$ is defined as the equivalent shear modulus.

$\beta$ in Equation (10) is defined by the following equation (Bharadwaj et al., 2010):

$$
\beta=\frac{-\ln \left(C_{n \text { rest }}\right)}{\sqrt{\ln \left(C_{n \text { rest }}\right)^{2}+\pi^{2}}}
$$

where $C_{n \text { rest }}$ is defined as the coefficient of restitution.

The effective radius is defined according to the following equation (Remy et al., 2011):

$$
R_{e f}^{*}=\frac{R_{A} R_{B}}{R_{A}+R_{B}}
$$

where $R_{A}$ and $R_{B}$ are the radius of particle $\mathrm{A}$ and particle $\mathrm{B}$, respectively. 
The effective Young's modulus of two colliding individuals (particle- wall or particle- particle) is defined by (Romanski et al., 2011):

$$
E_{e f}=\frac{E_{A} E_{B}}{\left(1-v_{A}^{2}\right) E_{B}+\left(1-v_{B}^{2}\right) E_{A}}
$$

Also, the effective particle mass is expressed by (Chand et al., 2012):

$$
M_{e f}=\frac{M_{A} M_{B}}{M_{A}+M_{B}}
$$

Moreover, the equivalent shear modulus is calculated using the following equation (Romanski et al., 2011):

$$
G_{e q}=\frac{G_{A} G_{B}}{\left(2-v_{A}\right) G_{B}+\left(2-v_{B}\right) G_{A}}
$$

where $M_{A}$ and $M_{B}$ are the masses of sphere $\mathrm{A}$ and sphere $\mathrm{B}$, and $R_{A}$ and $R_{B}$ are the radii of the spheres. $E_{A}$ and $E_{B}$ are Young's modulus of the two spheres, and $v_{A}$ and $v_{B}$ are the Poisson coefficients.

The rolling resistance torque is expressed by (Bharadwaj et al., 2010):

$$
T_{r}=\mu_{R} F_{n} L \omega
$$

where $\mu_{R}, L$, and $\omega$ are defined as the rolling friction coefficient, the distance of the contact point from the center of mass, and the relative angular velocity of particles, respectively.

The torque generated by the tangential force is defined by the following vector product equation (Jiang et al., 2011):

$$
T_{t}=L N \times F_{t}
$$


where $L, N$, and $F_{t}$ define the distance from the center of one particle to the contact plane with the other particle, the normal unit vector, and the vector of tangential contact force, respectively. The physical and mechanical properties of the glass beads and the drum wall, which were used in the DEM simulations, were extracted from the literature, and have been listed in Table 1.

Table 1: List of paramerets used in DEM simulation (Bertrand et al., 2005; Arntz et al., 2008; Bharadwaj et al., 2010; Alian et al., 2014)

\begin{tabular}{|l|c|}
\hline \multicolumn{1}{|c|}{ Parameter } & Value \\
\hline & \\
Particle Density $\left(\mathrm{Kg} / \mathrm{m}^{3}\right)$ & 2,500 \\
\hline Particle Poisson's Ratio & 0.3 \\
\hline Rotary Drum Wall Density $\left(\mathrm{Kg} / \mathrm{m}^{3}\right)$ & 2,500 \\
\hline Slant Cone Wall Density (Kg/m $\left.{ }^{3}\right)$ & 7,850 \\
\hline Young's modulus for the particle (Pa) & $2.16 \times 10^{6}$ \\
\hline Wall Poisson's Ratio (Rotary Mixer, and Slant Cone) & 0.3 \\
\hline Particle Shear modulus (Pa) & $2.4 \times 10^{10}$ \\
\hline Rotary Drum Glass Shear modulus (Pa) & $2.4 \times 10^{10}$ \\
\hline Slant Cone Stainless Steel Shear modulus (Pa) & $7.3 \times 10^{10}$ \\
\hline Particle/ Particle Static Friction Coefficient & 0.5 \\
\hline Particle/ Particle Dynamic Friction Coefficient & 0.05 \\
\hline Particle/ Wall (Rotary Drum) & 0.5 \\
Static Friction Coefficient & \\
\hline Particle/ Wall (Slant Cone) & 0.4 \\
Static Friction Coefficient & $2.0 \times 10^{-6}$ \\
\hline Particle/ Wall Dynamic Friction Coefficient & \\
\hline Fixed Time Step (Sec) & \\
\hline
\end{tabular}


To assess the mixing quality in these studies, the mixing index $\psi_{\text {was employed (Remy et al., }}$ 2011):

$$
\psi=\frac{\pi}{\pi_{m i x}}
$$

where $\pi$ represents the degree of mixing for a system of defined number of particles at a specific time step and $\pi_{m i x}$ defines the degree of mixing for the same defined number of particles in a well-mixed system. According to this mixing index, the values of the mixing index for a perfectly mixed system and for a fully segregated system are $\psi=1$ and $\psi=0$, respectively. In order to calculate the mixing index, the computational domain is divided into $M$ cells and the value of $\pi$ is calculated using the following equation:

$$
\pi=\sum_{M}\left(n_{M} \sum_{j} x_{j}^{M} \ln x_{j}^{M}\right)
$$

where $n_{M}$ is the total particle number fraction in cell $M$ and $x_{j}^{M}$ is the number fraction of species $j$ in cell $M$ (Remy et al., 2011).

Alian et al. (2014) defined the optimum number of grids as the minimum number of calculations, the smallest number of cells available, and sufficient number of particles in each cell while the mixing index was approximately constant with the change in the number of cells.

Arntz et al. (2008) worked intensively over the influence of the number of grid cells on the mixing index value in the steady state for the rotary drum mixer. They showed that dividing the entire volume of the rotary mixer for $12 \times 12 \times 1$ provided the most accurate value for the mixing index. 
According to table 2 for the rotary drum mixer, the mixing index for simulation- 1 was evaluated at two different mesh sizes. When, the mesh size was increased from $(6 \times 6 \times 1)$ to $(12 \times 12 \times 1)$ the number of calculations increased and the average number of particles in each cell decreased, however the mixing index was slightly affected. To calculate the mixing index $\psi$ in the rotary drum study, the simulation domain was divided into 144 cells and each cell was considered as a sample for mixing calculations.

On the other hand, the simulation domain for the slant cone mixer was divided into 3,375 cells, and each cell was considered as a sample for mixing calculations, whereas Alian et al. (2014) had done a sensitivity analysis regarding the number of cells for the slant cone mixer and showed that the optimized number of grids were $(15 \times 15 \times 15)$ cells.

By definition, $\pi_{m i x}$ was calculated where the number concentration of each species in each cell was exactly equal to the system number concentration for that species under the well-mixed condition (Arntz et al., 2008).

In these studies, the flow of the particles inside the rotary drum and slant cone mixers were simulated using a commercial DEM package called EDEM (DEM Solutions Ltd; United Kingdom; Version: 2.5). Four processors were utilized for all the simulations according to the availability of EDEM computational license. CPU times for simulations of the rotary drum mixer were between 24 hours to 48 hours for 20 seconds of the real time. Moreover, CPU times for simulations were between 48 hours to 96 hours for the time required for the slant cone mixer to complete 6 revolutions in real time. 
In the rotary drum study, DEM was employed to explore the effects of the initial loading method (side-side and top-bottom) and the drum rotational speed $(5.5 \mathrm{rpm}, 15 \mathrm{rpm}$, and $30 \mathrm{rpm}$ ) on the mixing quality for mono, binary, ternary, and poly-disperse particles.

Table 2 shows the parameters used in all simulations for mono, binary, ternary and poly-disperse systems inside the rotary drum. It must be mentioned that all simulations for binary, ternary and poly-disperse systems were performed under the condition of the equal mass for each set of particles, without considering the effect of the filling level. 
Table 2: Simulation parameters and the mass conditions for Mono, Binary, Ternary and Poly disperse systems inside the rotary drum mixer.

\begin{tabular}{|c|c|c|c|c|c|}
\hline $\begin{array}{l}\text { Simulation } \\
\text { number }\end{array}$ & $\begin{array}{l}\text { Diameter of } \\
\text { the particles } \\
(\mathbf{m m})\end{array}$ & $\begin{array}{l}\text { Initial } \\
\text { Loading } \\
\text { Method }\end{array}$ & $\begin{array}{c}\text { Rotational } \\
\text { Velocity } \\
\text { (RPM) }\end{array}$ & $\begin{array}{l}\text { Number of Particles } \\
\text { used in Simulation } \\
\text { (On order with } \\
\text { respect to the size of } \\
\text { particles) }\end{array}$ & $\begin{array}{c}\text { Mass } \\
\text { Condition } \\
\text { (gram) }\end{array}$ \\
\hline 1-Mono & 3.0 and 3.0 & Side-Side & 5.5 & $15000+15000$ & $530+530$ \\
\hline 2-Mono & 3.0 and 3.0 & Side-Side & 15 & $15000+15000$ & $530+530$ \\
\hline 3-Mono & 3.0 and 3.0 & Side-Side & 30 & $15000+15000$ & $530+530$ \\
\hline 4-Mono & 3.0 and 3.0 & Top-Bottom & 5.5 & $15000+15000$ & $530+530$ \\
\hline 5-Mono & 3.0 and 3.0 & Top-Bottom & 15 & $15000+15000$ & $530+530$ \\
\hline 6-Mono & 3.0 and 3.0 & Top-Bottom & 30 & $15000+15000$ & $530+530$ \\
\hline 7-Binary & 3.0 and 5.0 & Side-Side & 5.5 & $14141+3054$ & $500+500$ \\
\hline 8-Binary & 3.0 and 5.0 & Side-Side & 15 & $14141+3054$ & $500+500$ \\
\hline 9-Binary & 3.0 and 5.0 & Side-Side & 30 & $14141+3054$ & $500+500$ \\
\hline 10-Binary & 3.0 and 5.0 & $\begin{array}{l}\text { Top-Bottom } \\
\text { (Larger-to- } \\
\text { smaller) }\end{array}$ & 5.5 & $14141+3054$ & $500+500$ \\
\hline 11-Binary & 3.0 and 5.0 & $\begin{array}{c}\text { Top-Bottom } \\
\text { (Smaller-to- } \\
\text { Larger) }\end{array}$ & 5.5 & $14141+3054$ & $500+500$ \\
\hline 12-Binary & 3.0 and 5.0 & $\begin{array}{c}\text { Top-Bottom } \\
\text { (Smaller-to- } \\
\text { Larger) }\end{array}$ & 30 & $14141+3054$ & $500+500$ \\
\hline 13-Binary & 3.0 and 5.0 & $\begin{array}{c}\text { Top-Bottom } \\
\text { (Larger-to- } \\
\text { smaller) }\end{array}$ & 30 & $14141+3054$ & $500+500$ \\
\hline 14-Ternary & $\begin{array}{c}3.0,4.0 \text { and } \\
5.0\end{array}$ & $\begin{array}{c}\text { Top-Bottom } \\
\text { (Larger-to- } \\
\text { smaller) } \\
\end{array}$ & 30 & $14141+5965+3054$ & $\begin{array}{c}500+500+ \\
500\end{array}$ \\
\hline 15-Ternary & $\begin{array}{c}3.0,4.0 \text { and } \\
5.0\end{array}$ & $\begin{array}{c}\text { Top-Bottom } \\
\text { (Smaller-to- } \\
\text { Larger) }\end{array}$ & 30 & $14141+5965+3054$ & $\begin{array}{c}500+500+ \\
500\end{array}$ \\
\hline 16-Ternary & $\begin{array}{c}3.0,4.0 \text { and } \\
5.0\end{array}$ & $\begin{array}{c}\text { Top-Bottom } \\
\text { (Random) }\end{array}$ & 30 & $14141+5965+3054$ & $\begin{array}{c}500+500+ \\
500\end{array}$ \\
\hline 17-Ternary & $\begin{array}{c}3.0,4.0 \text { and } \\
5.0\end{array}$ & Side-Side & 30 & $14141+5965+3054$ & $\begin{array}{c}500+500+ \\
500 \\
\end{array}$ \\
\hline
\end{tabular}




\begin{tabular}{|c|c|c|c|c|c|}
\hline 18-Poly & $\begin{array}{l}2.0,3.0,5.0, \\
7.0 \text { and } 10\end{array}$ & $\begin{array}{l}\text { Top-Bottom } \\
\text { (Larger-to- } \\
\text { smaller) }\end{array}$ & 30 & $\begin{array}{c}31830+9432+2038 \\
+742+254\end{array}$ & $\begin{array}{c}333+333+ \\
333+333+ \\
333\end{array}$ \\
\hline 19-Poly & $\begin{array}{c}2.0,3.0,5.0, \\
7.0 \text { and } 10\end{array}$ & $\begin{array}{c}\text { Top-Bottom } \\
\text { (Smaller-to- } \\
\text { Larger) }\end{array}$ & 30 & $\begin{array}{c}31830+9432+2038 \\
+742+254\end{array}$ & $\begin{array}{c}333+333+ \\
333+333+ \\
333 \\
\end{array}$ \\
\hline 20-Poly & $\begin{array}{c}2.0,3.0,5.0, \\
7.0 \text { and } 10\end{array}$ & $\begin{array}{l}\text { Top-Bottom } \\
\text { (Random\#1) }\end{array}$ & 30 & $\begin{array}{c}31830+9432+2038 \\
+742+254\end{array}$ & $\begin{array}{c}333+333+ \\
333+333+ \\
333\end{array}$ \\
\hline 21-Poly & $\begin{array}{c}2.0,3.0,5.0, \\
7.0 \text { and } 10\end{array}$ & $\begin{array}{l}\text { Top-Bottom } \\
\text { (Random\#2) }\end{array}$ & 30 & $\begin{array}{c}31830+9432+2038 \\
+742+254\end{array}$ & $\begin{array}{c}333+333+ \\
333+333+ \\
333\end{array}$ \\
\hline 22-Poly & $\begin{array}{l}2.0,3.0,5.0, \\
7.0 \text { and } 10\end{array}$ & $\begin{array}{l}\text { Side-Side } \\
\text { left-to-right } \\
\text { Larger-to - } \\
\text { smaller }\end{array}$ & 30 & $\begin{array}{c}31830+9432+2038 \\
+742+254\end{array}$ & $\begin{array}{c}333+333+ \\
333+333+ \\
333\end{array}$ \\
\hline 23-Poly & $\begin{array}{c}2.0,3.0,5.0 \\
7.0 \text { and } 10\end{array}$ & $\begin{array}{l}\text { Side-Side } \\
\text { (Random) }\end{array}$ & 30 & $\begin{array}{c}31830+9432+2038 \\
+742+254\end{array}$ & $\begin{array}{c}333+333+ \\
333+333+ \\
333\end{array}$ \\
\hline
\end{tabular}


For the slant cone study, DEM was employed to explore the effects of the initial loading method (side-side, top-bottom, and back-front) and the vessel rotational speed (7.0 rpm, $15 \mathrm{rpm}, 22.5$ rpm, $30 \mathrm{rpm}, 45 \mathrm{rpm}$, and $55 \mathrm{rpm}$ ) on the mixing quality for bi-disperse, tri-disperse, and polydisperse particles.

Table 3 shows the parameters used in all simulations for mono-disperse, bi-disperse, tri-disperse, and poly-disperse systems inside the slant cone mixer. It must be mentioned that all simulations for binary, ternary and poly-disperse systems were performed under the condition of the equal mass for each set of particles under a constant $70 \%$ fill level condition.

Alian et al. (2014) investigated the optimum fill level for the mixing of the mono-disperse particles inside the slant cone mixer in cases where the agitator was stationary. They reported that the optimum fill level was $70 \%$. Also, it must be mentioned that the fill level is based on the volume occupied by the solid particles, not the mass of the bulk. 
Table 3: Simulation parameters and the mass conditions for Mono, Binary, Ternary and Poly disperse systems inside the slant cone mixer.

\begin{tabular}{|c|c|c|c|c|c|c|}
\hline $\begin{array}{l}\text { Simulation } \\
\text { number }\end{array}$ & $\begin{array}{l}\text { Diameter } \\
\text { of the } \\
\text { particles } \\
(\mathbf{m m})\end{array}$ & $\begin{array}{l}\text { Initial } \\
\text { Loading } \\
\text { Method }\end{array}$ & $\begin{array}{c}\text { Vessel } \\
\text { Rotational } \\
\text { Velocity } \\
\text { (RPM) }\end{array}$ & $\begin{array}{l}\text { Agitator } \\
\text { Rotational } \\
\text { Velocity } \\
\text { (RPM) }\end{array}$ & $\begin{array}{l}\text { Number of Particles used } \\
\text { in Simulation } \\
\text { (On order with respect to } \\
\text { the size of particles) }\end{array}$ & $\begin{array}{c}\text { Mass Condition } \\
\text { (gram) }\end{array}$ \\
\hline 1-Mono & 3.0 and 3.0 & $\begin{array}{c}\text { Top- } \\
\text { Bottom }\end{array}$ & 15 & 0 & $47534+47534$ & $1675+1675$ \\
\hline 2-Binary & 4.0 and 6.0 & Side-Side & 15 & 0 & $20000+5926$ & $1675+1675$ \\
\hline 3-Binary & 4.0 and 6.0 & $\begin{array}{l}\text { Top- } \\
\text { Bottom } \\
\text { (larger-to- } \\
\text { smaller) }\end{array}$ & 15 & 0 & $20000+5926$ & $1675+1675$ \\
\hline 4-Binary & 4.0 and 6.0 & $\begin{array}{l}\text { Top- } \\
\text { Bottom } \\
\text { (smaller- } \\
\text { to-larger) }\end{array}$ & 15 & 0 & $20000+5926$ & $1675+1675$ \\
\hline 5-Binary & 4.0 and 6.0 & $\begin{array}{l}\text { smaller } \\
\text { back- } \\
\text { larger } \\
\text { front }\end{array}$ & 15 & 0 & $20000+5926$ & $1675+1675$ \\
\hline 6-Binary & 4.0 and 6.0 & $\begin{array}{l}\text { larger } \\
\text { back- } \\
\text { smaller } \\
\text { front }\end{array}$ & 15 & 0 & $20000+5926$ & $1675+1675$ \\
\hline 7-Binary ${ }^{1}$ & 4.0 and 6.0 & Side-Side & 15 & 0 & $20000+5926$ & $1675+1675$ \\
\hline 8-Binary ${ }^{2}$ & 4.0 and 6.0 & $\begin{array}{c}\text { Top- } \\
\text { Bottom } \\
\text { (Larger- } \\
\text { to- } \\
\text { smaller) }\end{array}$ & 15 & 0 & $20000+5926$ & $1675+1675$ \\
\hline 9-Binary ${ }^{3}$ & 4.0 and 6.0 & $\begin{array}{c}\text { Top- } \\
\text { bottom } \\
\text { (Smaller- } \\
\text { to-larger) }\end{array}$ & 15 & 0 & $20000+5926$ & $1675+1675$ \\
\hline 10-Binary & 4.0 and 6.0 & $\begin{array}{l}\text { Top- } \\
\text { Bottom } \\
\text { (Smaller- } \\
\text { to-larger) }\end{array}$ & 7.0 & 0 & $20000+5926$ & $1675+1675$ \\
\hline
\end{tabular}

\footnotetext{
${ }^{1}$ This simulation was done for 10 revolutions

${ }^{2}$ This simulation was done for 10 revolutions

${ }^{3}$ This simulation was done for 10 revolutions
} 


\begin{tabular}{|c|c|c|c|c|c|c|}
\hline 11-Binary & 4.0 and 6.0 & $\begin{array}{c}\text { Top- } \\
\text { Bottom } \\
\text { (Smaller- } \\
\text { to-larger) }\end{array}$ & 15 & 0 & $20000+5926$ & $1675+1675$ \\
\hline 12-Binary & 4.0 and 6.0 & $\begin{array}{l}\text { Top- } \\
\text { Bottom } \\
\text { (Smaller- } \\
\text { to-larger) }\end{array}$ & 22.5 & 0 & $20000+5926$ & $1675+1675$ \\
\hline 13-Binary & 4.0 and 6.0 & $\begin{array}{c}\text { Top- } \\
\text { Bottom } \\
\text { (Smaller- } \\
\text { to-larger) } \\
\end{array}$ & 30 & 0 & $20000+5926$ & $1675+1675$ \\
\hline 14-Binary & 4.0 and 6.0 & $\begin{array}{l}\text { Top- } \\
\text { Bottom } \\
\text { (Smaller- } \\
\text { to-larger) }\end{array}$ & 45 & 0 & $20000+5926$ & $1675+1675$ \\
\hline 15-Binary & 4.0 and 6.0 & $\begin{array}{l}\text { Top- } \\
\text { Bottom } \\
\text { (Smaller- } \\
\text { to-larger) }\end{array}$ & 55 & 0 & $20000+5926$ & $1675+1675$ \\
\hline 16-Binary ${ }^{4}$ & 4.0 and 6.0 & $\begin{array}{l}\text { Top- } \\
\text { Bottom } \\
\text { (Smaller- } \\
\text { to-larger) }\end{array}$ & 15 & 0 & $50000+14815$ & $4190.5+4190.5$ \\
\hline $17-$ Binary $^{5}$ & 4.0 and 6.0 & $\begin{array}{c}\text { Top- } \\
\text { Bottom } \\
\text { (Smaller- } \\
\text { to-larger) }\end{array}$ & 15 & 100 & $50000+14815$ & $4190.5+4190.5$ \\
\hline 18-Binary ${ }^{6}$ & 4.0 and 6.0 & $\begin{array}{c}\text { Top- } \\
\text { Bottom } \\
\text { (Larger- } \\
\text { to- } \\
\text { smaller) }\end{array}$ & 15 & 0 & $50000+14815$ & $4190.5+4190.5$ \\
\hline 19-Binary ${ }^{7}$ & 4.0 and 6.0 & $\begin{array}{c}\text { Top- } \\
\text { Bottom } \\
\text { (Larger- } \\
\text { to- } \\
\text { smaller) }\end{array}$ & 15 & 100 & $50000+14815$ & $4190.5+4190.5$ \\
\hline 20-Ternary & $\begin{array}{l}4.0,5.0 \\
\text { and } 6.0\end{array}$ & $\begin{array}{c}\text { Top- } \\
\text { Bottom } \\
\text { (Smaller- } \\
\text { to-Larger) }\end{array}$ & 7.0 & 0 & $13328+6824+3949$ & $\begin{array}{c}1116.6+1116.6+ \\
1116.6\end{array}$ \\
\hline
\end{tabular}

\footnotetext{
${ }^{4}$ This simulation was done at $100 \%$ fill level.

${ }^{5}$ This simulation was done at $100 \%$ fill level.

${ }^{6}$ This simulation was done at $100 \%$ fill level.

${ }^{7}$ This simulation was done at $100 \%$ fill level.
} 


\begin{tabular}{|c|c|c|c|c|c|c|}
\hline 21-Ternary & $\begin{array}{l}4.0,5.0 \\
\text { and } 6.0\end{array}$ & $\begin{array}{c}\text { Top- } \\
\text { Bottom } \\
\text { (Smaller- } \\
\text { to-Larger) }\end{array}$ & 15 & 0 & $13328+6824+3949$ & $\begin{array}{c}1116.6+1116.6+ \\
1116.6\end{array}$ \\
\hline 22-Ternary & $\begin{array}{l}4.0,5.0 \\
\text { and } 6.0\end{array}$ & $\begin{array}{c}\text { Top- } \\
\text { Bottom } \\
\text { (Smaller- } \\
\text { to-Larger) }\end{array}$ & 22.5 & 0 & $13328+6824+3949$ & $\begin{array}{c}1116.6+1116.6+ \\
1116.6\end{array}$ \\
\hline 23-Ternary & $\begin{array}{l}4.0,5.0 \\
\text { and } 6.0\end{array}$ & $\begin{array}{c}\text { Top- } \\
\text { Bottom } \\
\text { (Smaller- } \\
\text { to-Larger) }\end{array}$ & 30 & 0 & $13328+6824+3949$ & $\begin{array}{c}1116.6+1116.6+ \\
1116.6\end{array}$ \\
\hline 24-Ternary & $\begin{array}{l}4.0,5.0 \\
\text { and } 6.0\end{array}$ & $\begin{array}{c}\text { Top- } \\
\text { Bottom } \\
\text { (Smaller- } \\
\text { to-Larger) }\end{array}$ & 45 & 0 & $13328+6824+3949$ & $\begin{array}{c}1116.6+1116.6+ \\
1116.6\end{array}$ \\
\hline 25-Ternary & $\begin{array}{l}4.0,5.0 \\
\text { and } 6.0\end{array}$ & $\begin{array}{c}\text { Top- } \\
\text { Bottom } \\
\text { (Smaller- } \\
\text { to-Larger) }\end{array}$ & 55 & 0 & $13328+6824+3949$ & $\begin{array}{c}1116.6+1116.6+ \\
1116.6\end{array}$ \\
\hline 26-Poly & $\begin{array}{c}3.0,4.0, \\
5.0 \text { and } 6.0\end{array}$ & $\begin{array}{c}\text { Top- } \\
\text { Bottom } \\
\text { (Smaller- } \\
\text { to-Larger) }\end{array}$ & 7.0 & 0 & $\begin{array}{c}23696+9997+5118 \\
+2962\end{array}$ & $\begin{array}{c}837.5+837.5+ \\
837.5+837.5\end{array}$ \\
\hline 27-Poly & $\begin{array}{c}3.0,4.0 \\
5.0 \text { and } 6.0\end{array}$ & $\begin{array}{c}\text { Top- } \\
\text { Bottom } \\
\text { (Smaller- } \\
\text { to-Larger) }\end{array}$ & 15 & 0 & $\begin{array}{c}23696+9997+5118 \\
+2962\end{array}$ & $\begin{array}{c}837.5+837.5+ \\
837.5+837.5\end{array}$ \\
\hline 28-Poly & $\begin{array}{c}3.0,4.0, \\
5.0 \text { and } 6.0\end{array}$ & $\begin{array}{c}\text { Top- } \\
\text { Bottom } \\
\text { (Smaller- } \\
\text { to-Larger) }\end{array}$ & 22.5 & 0 & $\begin{array}{c}23696+9997+5118 \\
+2962\end{array}$ & $\begin{array}{c}837.5+837.5+ \\
837.5+837.5\end{array}$ \\
\hline 29-Poly & $\begin{array}{c}3.0,4.0, \\
5.0 \text { and } 6.0\end{array}$ & $\begin{array}{c}\text { Top- } \\
\text { Bottom } \\
\text { (Smaller- } \\
\text { to-Larger) }\end{array}$ & 30 & 0 & $\begin{array}{c}23696+9997+5118 \\
+2962\end{array}$ & $\begin{array}{c}837.5+837.5+ \\
837.5+837.5\end{array}$ \\
\hline 30-Poly & $\begin{array}{c}3.0,4.0, \\
5.0 \text { and } 6.0\end{array}$ & $\begin{array}{c}\text { Top- } \\
\text { Bottom } \\
\text { (Smaller- } \\
\text { to-Larger) }\end{array}$ & 45 & 0 & $\begin{array}{c}23696+9997+5118 \\
+2962\end{array}$ & $\begin{array}{c}837.5+837.5+ \\
837.5+837.5\end{array}$ \\
\hline 31-Poly & $\begin{array}{c}3.0,4.0, \\
5.0 \text { and } 6.0\end{array}$ & $\begin{array}{c}\text { Top- } \\
\text { Bottom } \\
\text { (Smaller- } \\
\text { to-Larger) }\end{array}$ & 55 & 0 & $\begin{array}{c}23696+9997+5118 \\
+2962\end{array}$ & $\begin{array}{c}837.5+837.5+ \\
837.5+837.5\end{array}$ \\
\hline
\end{tabular}




\section{Chapter 5: Using Discrete Element Method to Assess the Mixing of Poly- disperse Solid Particles in a Rotary Drum}

\subsection{Introduction}

Different types of tumbling mixers such as the double cone, $\mathrm{V}, \mathrm{Y}$, and rotary drum blenders have been used in industry (Paul et al., 2004). The rotary drum blenders, which can be utilized in both batch and continuous processes, are widely used for the mixing of powders in the food industry (Onwulata, 2005), bioremediation of contaminated soil for environmental applications (Gray et al., 1994; Woo and Park, 1999), mixing of slurries such as the hot water extraction of bitumen from the Athabasca tar sands (Carrigy, 1963), and drying processes in the mineral industry (Renaud et al., 2000; Ahmadian et al., 2011).

Our comprehensive literature review revealed that there is a lack of sufficient information about the mixing of the binary, ternary, and poly-disperse particles inside rotary drum mixers. Therefore, the main objective of this study is to explore the mixing quality of the mono, binary, ternary and poly-disperse particles in a rotary drum mixer as a function of the rotational speed of the drum and the initial loading method.

\subsection{Results and Discussion}

To validate the discrete element model developed in this study, the experimental results were compared to the simulation outputs. Figure 6 shows the experimental and simulation results recorded for the mixing of 15,000 red and 15,000 black particles of $3.0 \mathrm{~mm}$ diameter, loaded initially side by side in the drum rotated at $5.5 \mathrm{rpm}$. The snapshots of the upper and front views of the rotary drum were captured at time $t=0,10$ and 20 seconds. Reasonable agreement was 
observed between the experimental and simulation results for the mixing of the red and black particles inside the rotary drum mixer.

(a)
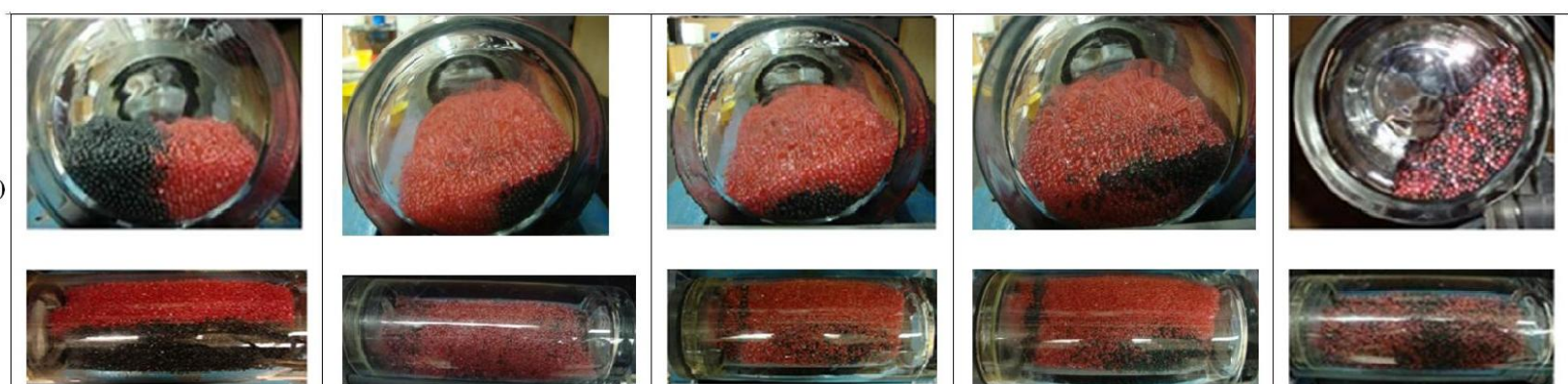

(b)

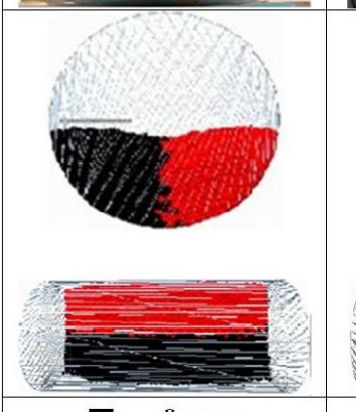

$\mathbf{T}=\mathbf{0} \sec$

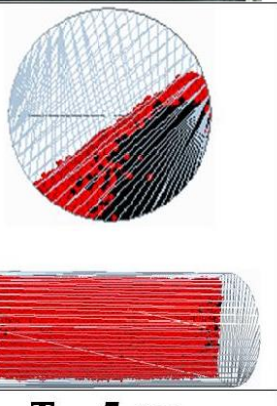

$\mathbf{T}=\mathbf{5} \mathrm{sec}$
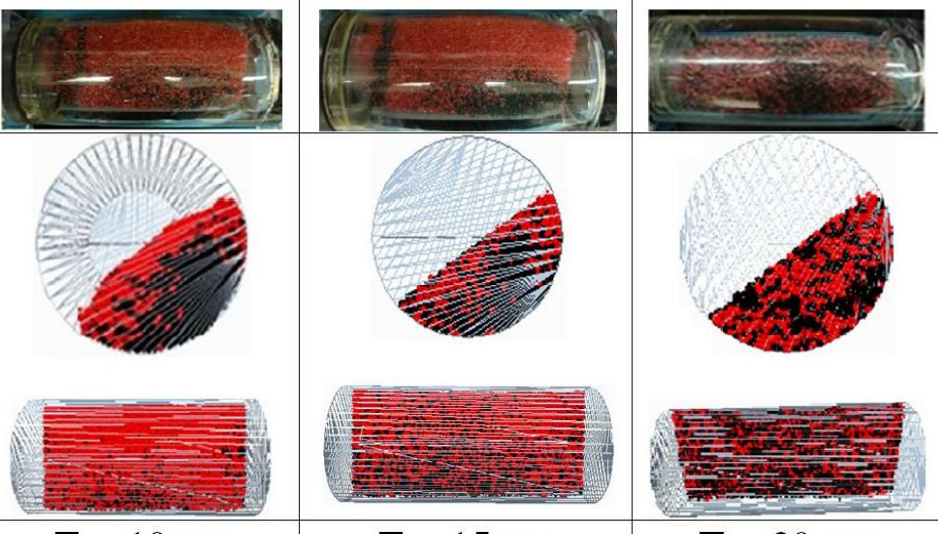

$\mathrm{T}=\mathbf{1 0} \mathrm{sec}$

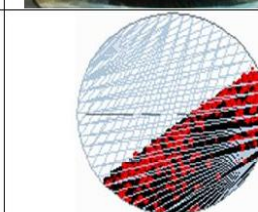

Figure 6: Comparison between the snapshots of the simulated and real monodisperse solid mixtures at $\mathrm{t}=0,10,20$ second, drum speed of $5.5 \mathrm{rpm}$ and side-side initial loading: (a) experimental results and (b) simulation results. 


\subsubsection{Mono-disperse Particles}

In this part of the study, the mixing of monodisperse particles of $3.0 \mathrm{~mm}$ diameter in the rotary drum mixer was evaluated using the validated model as a function of the initial loading method and the drum rotational speed. The drum was rotated for 20 seconds in all simulations. Figure 7 depicts the mixing index versus time as a function of the rotational speed of the drum for sideside and top-bottom initial loading, respectively. These results show that the mixing quality was enhanced with an increase in rotational speed and reached its highest value at $30 \mathrm{rpm}$ for both forms of initial loading. The data presented in Figure 7 show that the mixing qualities achieved for both top-bottom and side-side initial loading of the monodisperse particles were almost the same at $30 \mathrm{rpm}$. However, the mixing indices obtained for the top-bottom initial loading at the lower rotational speeds (e.g. 5.5 and $15 \mathrm{rpm}$ ) were higher than those achieved for the side-side initial loading. It must be mentioned that the mixing indices at $t=0$ s were $\psi=0.290$ and $\psi=$ 0.074 for the top-bottom and side-side initial loading methods, respectively. It is postulated that the higher initial mixing index for the top-bottom loading method was due to the higher initial contact surface between the red and black particles for this loading pattern compared to that for the side-side loading method. 


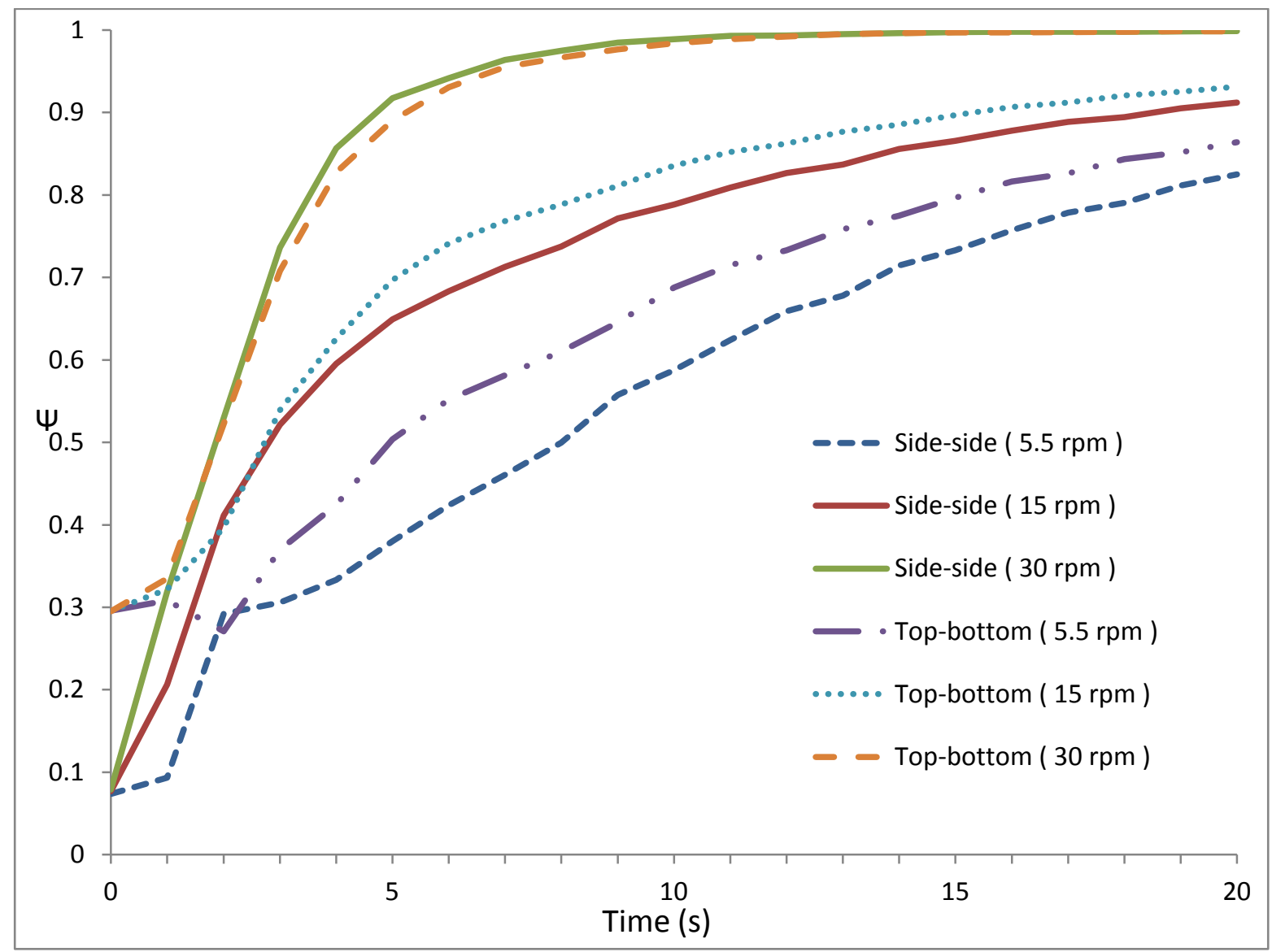

Figure 7:Mixing index versus time for the mono-disperse particles at the different drum rotational speed and initial loading methods. 


\subsubsection{Bi-disperse Particles}

To investigate the mixing of bi-disperse particles, 14,141 glass beads with a diameter of $3.0 \mathrm{~mm}$ and 3,054 glass beads with a diameter of $5.0 \mathrm{~mm}$ were loaded into the rotary drum mixer. As mentioned in Table 2, the total mass of each set of particles was the same (500 g). Figure 8 depicts the mixing index versus time as a function of the drum rotational speed for the side by side initial loading method. It can be seen that the mixing quality achieved at $30 \mathrm{rpm}$ was higher than those at the lower rotational speed (i.e. 5.5 and $15 \mathrm{rpm}$ ). The mixing index at $t=0 \mathrm{~s}$ was $\psi=0.20$, which was due to the contact surface area between two sets of the particles in the sideside initial loading. These data show that the degree of mixing at $30 \mathrm{rpm}$ reached a maximum $(\Psi=0.862)$ at $t=4.7 \mathrm{~s}$ and then decreased with time till it reached a plateau $(\psi=0.755)$. It can be seen that the degree of mixing for the bi-disperse particles was smaller than that for the monodisperse particles. Arntz et al. (2008) reported the segregation of the bi-disperse particles in a rotary drum blender. When the particles with different sizes are mixed inside a rotary drum, the smaller particles are relocated inside the occupied mass, and the larger particles are pushed away and relocated at the circumference of the occupied mass. This is called percolation segregation mechanism (Arntz et al., 2008). According to this mechanism, the larger particles move further away from small particles where the smaller particles are surrounded at the center by the larger particles. Figure 9 shows the simulated snapshots of the mixing of bi-disperse particles inside the rotary drum mixer for the side-side initial loading at different rotational velocities. These results show the accumulation of the smaller particles (black particles) at the centre and the larger particles (red particles) at the boundary of the loaded mass inside the drum. This confirms the segregation phenomenon in the mixing of bi-disperse particles. 


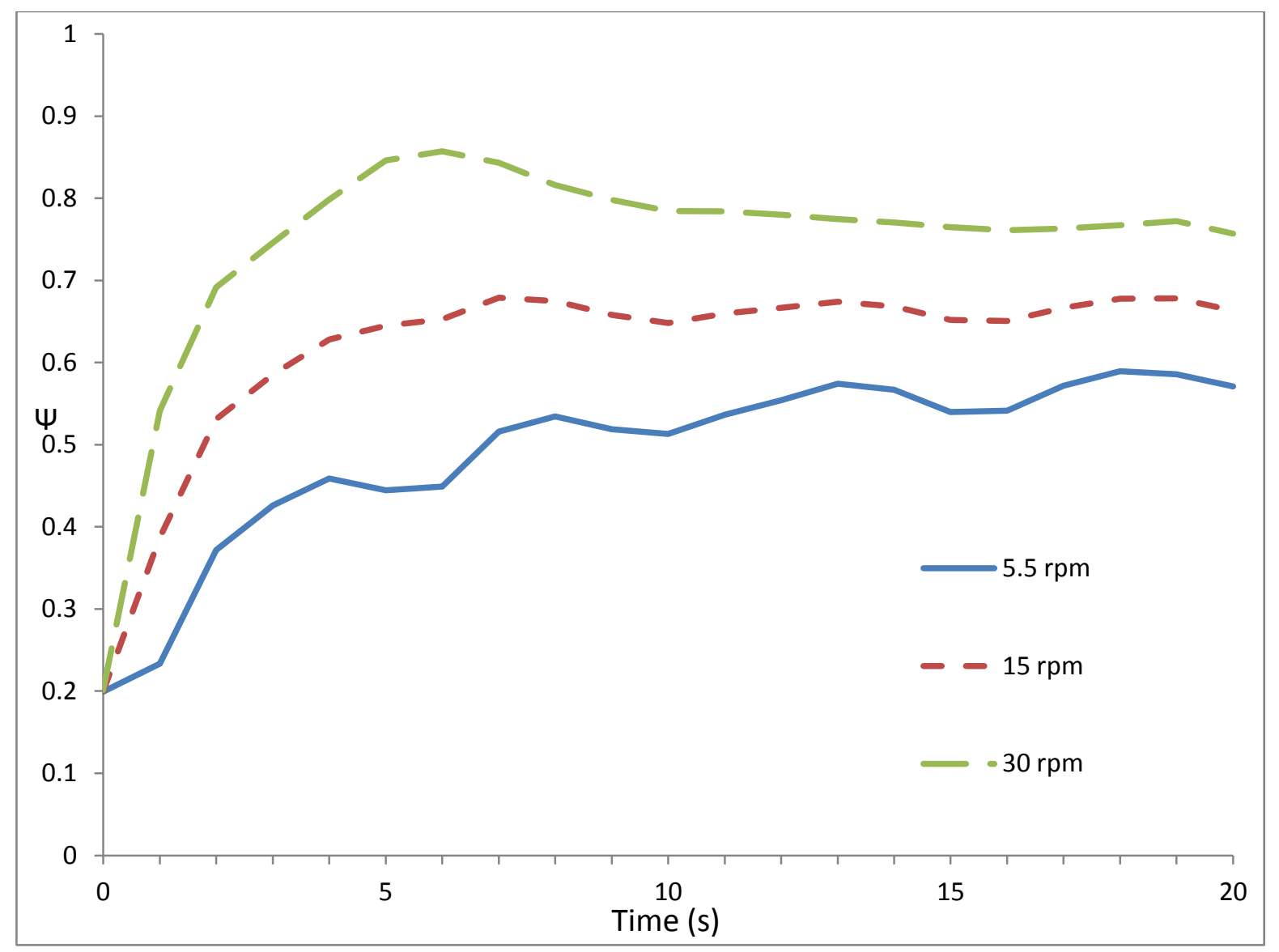

Figure 8: Mixing index versus time for the side-side initial loading of the bi-disperse particles at the different drum rotational speeds. 


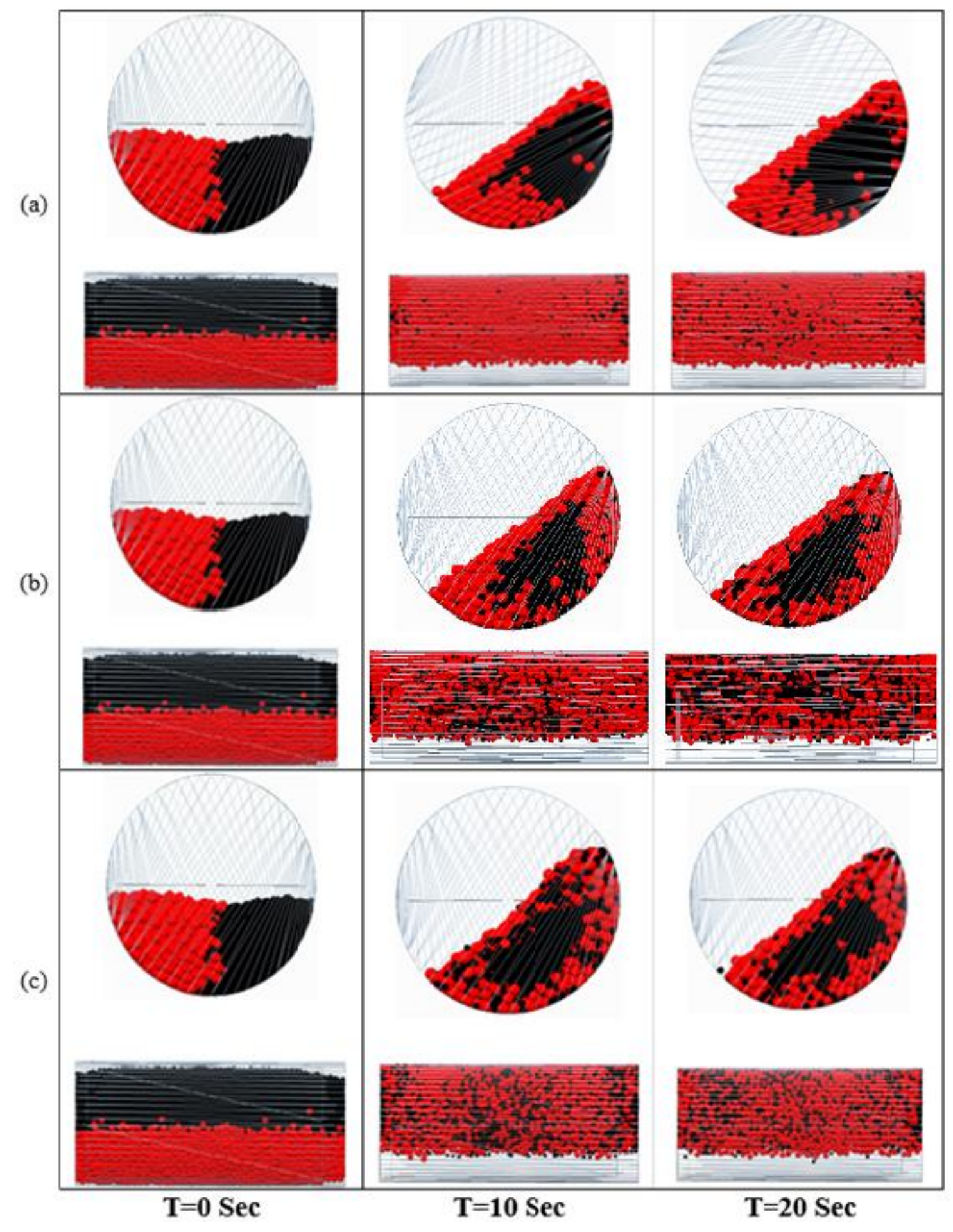

Figure 9 : Snapshots of the mixing of bi-disperse particles for the side-side initial loading at: (a) $5.5 \mathrm{rpm}$, (b) $15 \mathrm{rpm}$, and (c) $30 \mathrm{rpm}$. 
Figure 10 shows the mixing index versus time for different top-bottom initial loading patterns at 5.5 and $30 \mathrm{rpm}$. It must be mentioned that we employed two methods for the top-bottom initial loading of bi-disperse particles in this study as illustrated in Figure 11. In the first method, the bottom of the drum was filled with the larger size particles $(5.0 \mathrm{~mm}$ diameter) and then the smaller size particles (3.0 mm diameter) were loaded on top of the larger particles. This filling method was called: top-bottom larger-to-smaller initial loading. In the second method, the bottom of the drum was filled with the smaller sized particles (3.0 $\mathrm{mm}$ diameter) and then the larger sized particles (5.0 mm diameter) were loaded on top of the smaller particles. This filling method was called: top-bottom smaller-to-larger initial loading.

The data presented in Figure 10 show that the initial mixing index at $t=0 \mathrm{~s}$ for the larger-tosmaller loading method $(\psi=0.334)$ was higher than that for the smaller-to-larger pattern $(\psi=$ 0.264). This was due to the fact that the small particles, when loaded on the top of the large particles, moved down through the void spaces among the large particles. This resulted in a higher initial contact surface between the small and large particles for this initial loading method.

The simulation results for the bi-disperse particles (Figure 10) demonstrate that the mixing indices achieved at $30 \mathrm{rpm}$ were significantly higher than those at $5.5 \mathrm{rpm}$ for both methods of the top-bottom initial loading. In fact, higher rotational speed is required to mobilize the bidisperse particles in the radial direction, which improves the quality of mixing. The mixing index at $30 \mathrm{rpm}$ reached a maximum and then decreased slightly to a plateau. This was due to the segregation according to the percolation mechanism.

Figure 11 illustrates the snapshots of the mixing of the bi-disperse particles in the rotary drum for two methods of the top-bottom initial loading at 5.5 and $30 \mathrm{rpm}$. 


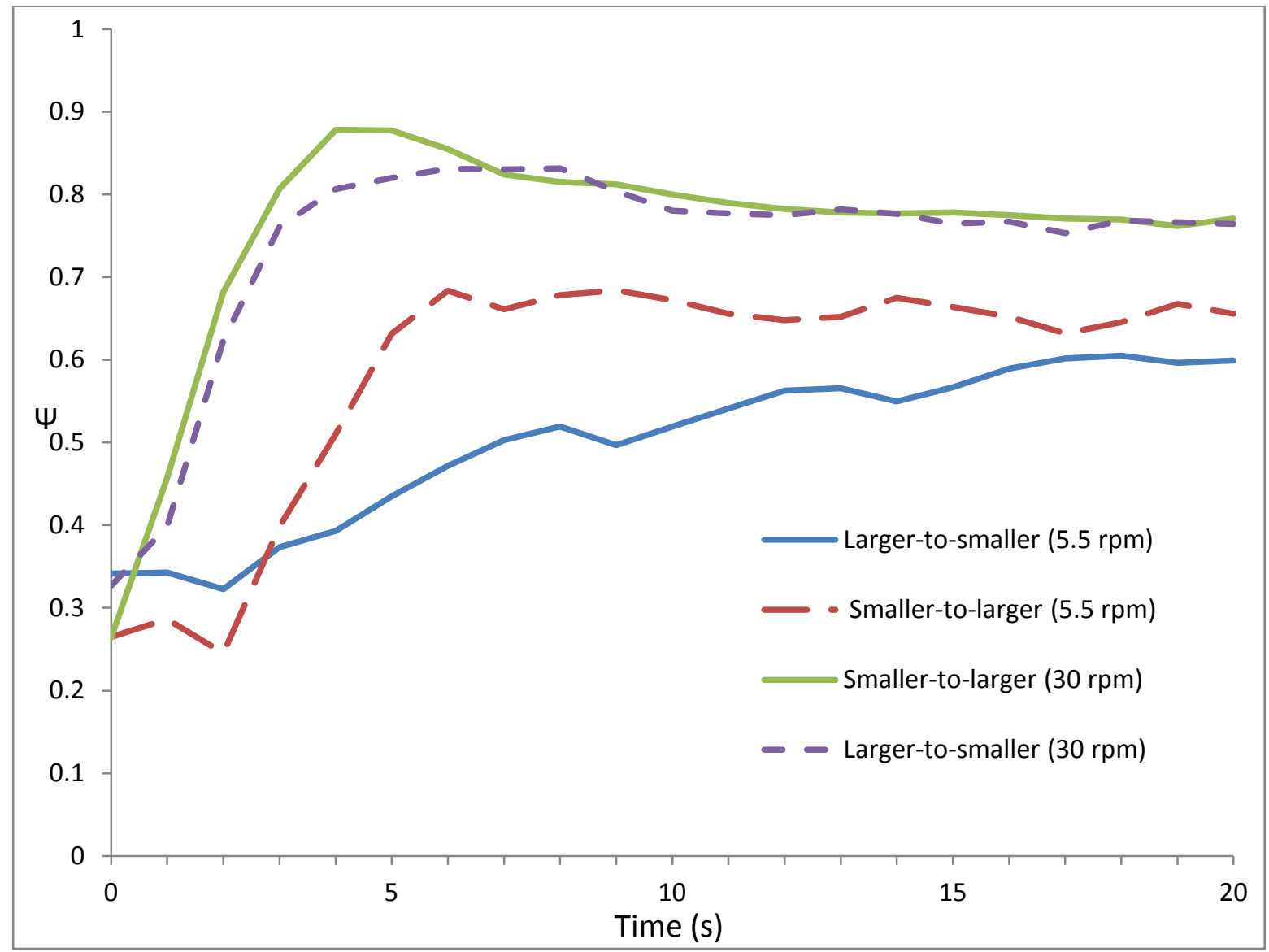

Figure 10: Mixing index versus time for the bi-disperse particles at two different drum rotational speeds and two different top-bottom initial loading methods. 


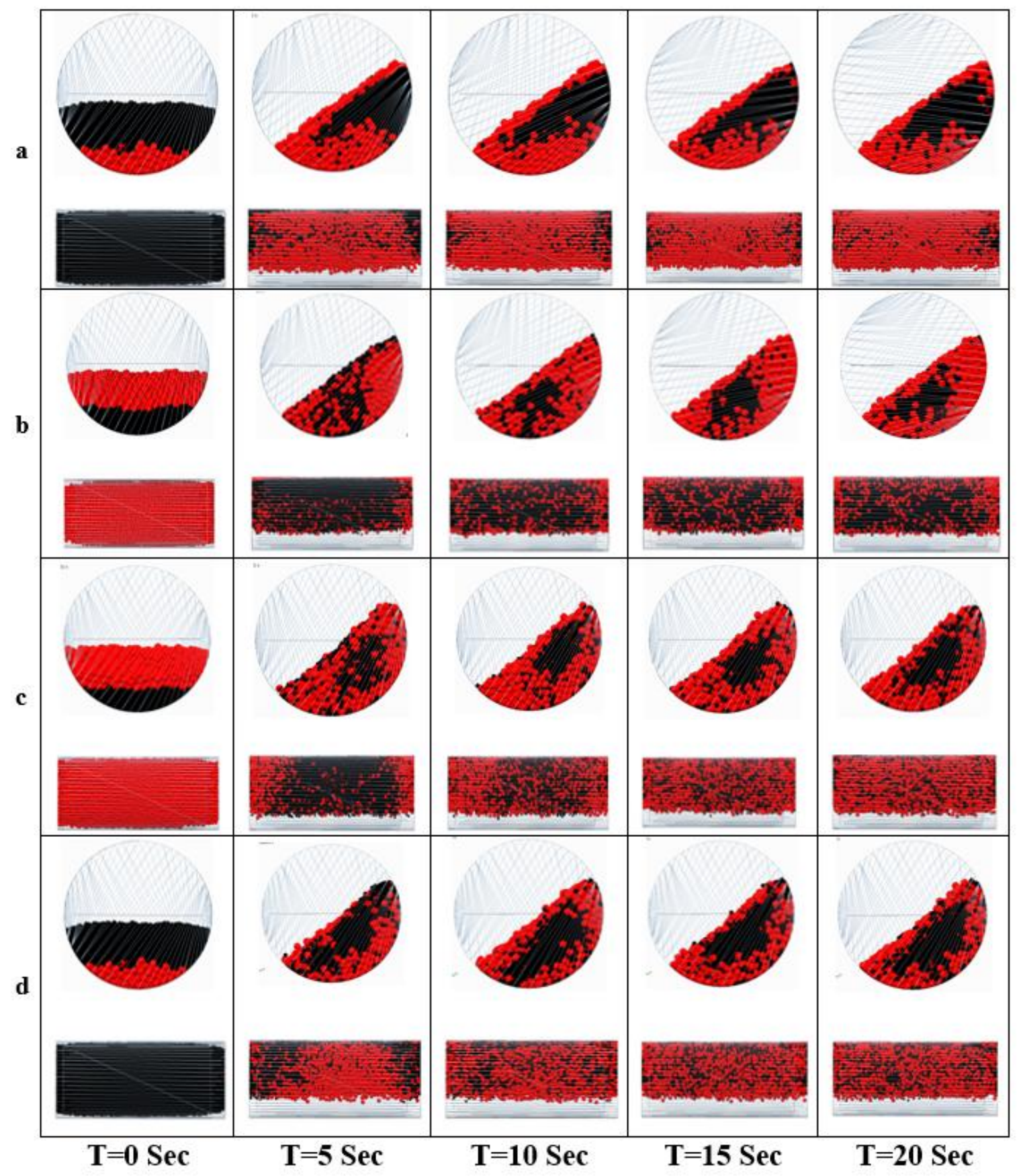

Figure 11: Snapshots of the mixing of the bi-disperse particles at: (a) $5.5 \mathrm{rpm}$ for the top-bottom larger-to-smaller, (b) $5.5 \mathrm{rpm}$ for the top-bottom smaller-to-larger, (c) $30 \mathrm{rpm}$ for the top-bottom smaller-to-larger, and (d) $30 \mathrm{rpm}$ for the top-bottom larger-to-smaller. 
These snapshots show that the smaller particles accumulated at the centre and the larger particles moved to the boundary of the loaded mass.

Moreover, it can be seen from Figure 10 that the degree of mixing achieved for the smaller-tolarger initial loading was higher compared to that for the larger-to-smaller loading especially at the lower rotational speed. Figure 10 demonstrates that the segregation taken place due to the percolation mechanism was more pronounced for the top-bottom larger-to-smaller loading.

\subsubsection{Tri-disperse Particles}

To investigate the mixing of tri-disperse particles, 14,141 glass beads with a diameter of $3.0 \mathrm{~mm}$, 5,965 glass beads with a diameter of $4.0 \mathrm{~mm}$, and 3,054 glass beads with a diameter of $5.0 \mathrm{~mm}$ were loaded into the rotary drum mixer. As mentioned in Table 2, the total mass of each set of particles was the same $(500 \mathrm{~g})$ and the angular velocity of the drum was fixed at $30 \mathrm{rpm}$.

Figure 12 depicts the snapshots of the tri-disperse particles for the side-side and different topbottom loading methods. It must be mentioned that we employed three methods for the topbottom initial loading of tri-disperse particles in this study. In the first method, the bottom of the drum was filled with the larger size particles $(5.0 \mathrm{~mm}$ diameter), and the medium size particles ( $4.0 \mathrm{~mm}$ diameter) were loaded on top of the larger particles. The smaller size particles $(3.0 \mathrm{~mm}$ diameter) were then loaded on top of the medium particles. This filling method was called: topbottom larger-to-smaller initial loading. In the second method, the bottom of the drum was filled with the smaller size particles $(3.0 \mathrm{~mm}$ diameter $)$ and the medium size particles $(4.0 \mathrm{~mm}$ diameter) were loaded on top of the smaller particles. The larger particles $(5.0 \mathrm{~mm}$ diameter $)$ were then loaded on top of the medium particles. This filling method was called: top-bottom smaller-to-larger initial loading. In the third method, the bottom of the drum was filled with the 
medium size particles $(4.0 \mathrm{~mm}$ diameter $)$ and the smaller size particles $(3.0 \mathrm{~mm}$ diameter $)$ were loaded on top of the medium size particles. The larger particles $(5.0 \mathrm{~mm}$ diameter) were loaded on top of the smaller particles. This filling method was called: top-bottom random initial loading. Figure 12 shows that the smaller particles accumulated at the centre and the larger particles moved to the boundary of the loaded mass, whereas the medium particles surrounded from the outer surfaces the smaller particles. Figure $12 \mathrm{c}$ had the smallest number of $3.0 \mathrm{~mm}$ black particles in the center of the mixture after 5 seconds from the rotation. 
(a)

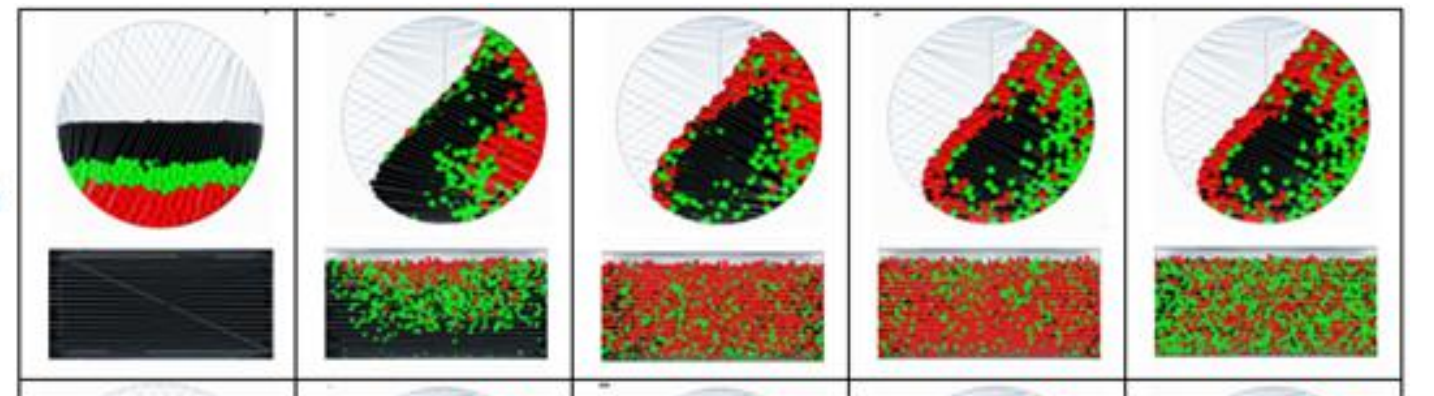

(b)

(c)

(d)

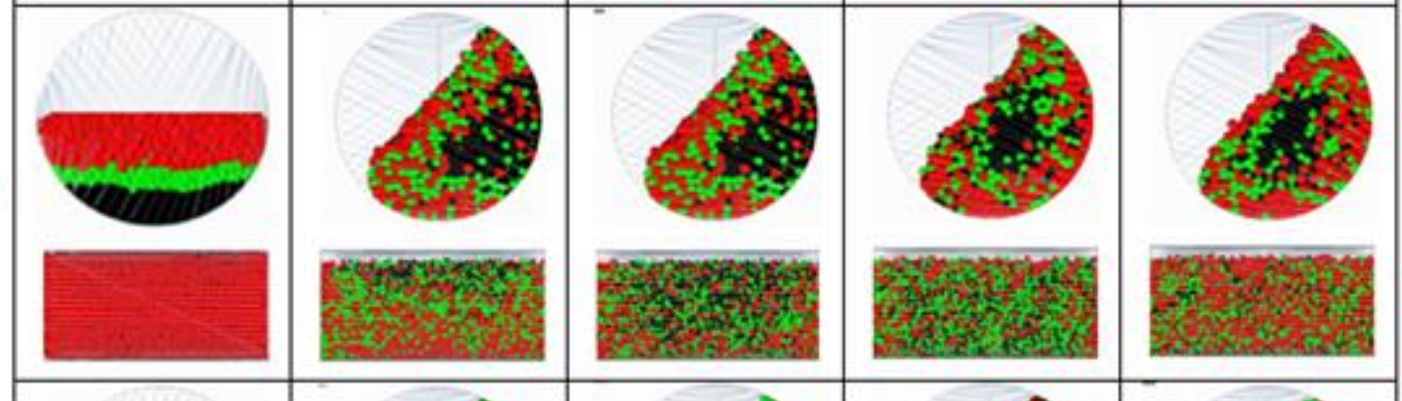

c)

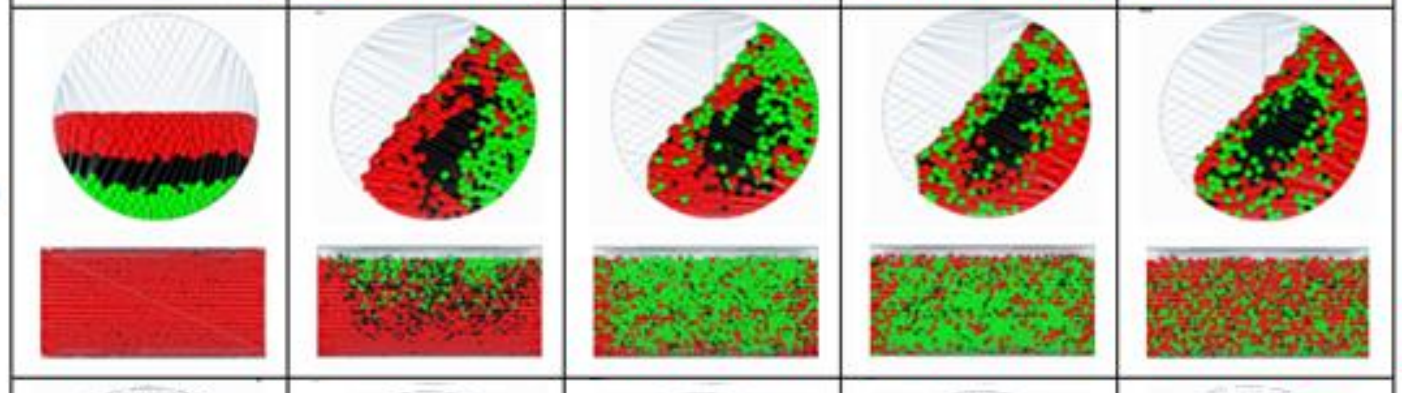

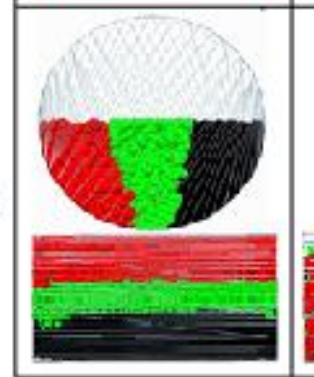

$\mathbf{T}=0 \mathrm{Sec}$

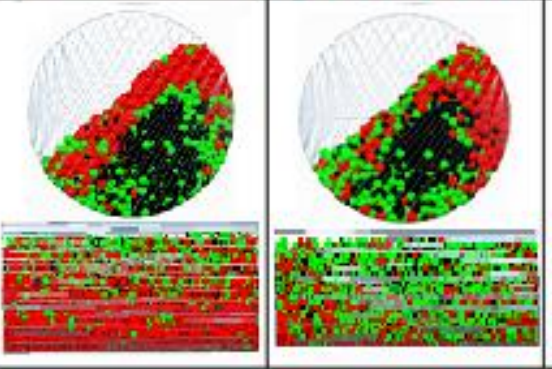

$\mathbf{T}=\mathbf{5}$ Sec

$\mathbf{T}=10 \mathrm{Sec}$

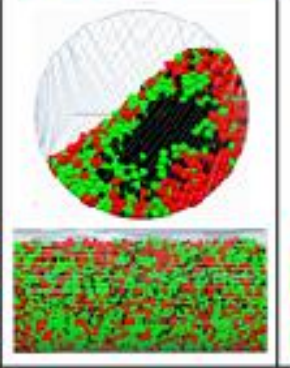

$\mathbf{T}=15 \mathrm{Sec}$

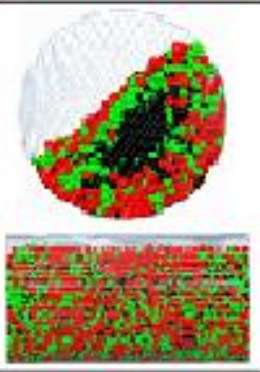

$\mathbf{T}=\mathbf{2 0}$ Sec

Figure 12: Snapshots of the mixing of the tri-disperse particles at $30 \mathrm{rpm}$ for the (a) top-bottom larger-to-smaller, (b) top-bottom smaller-to-larger, (c) top-bottom random, (d) side-side initial loading. Black particles with a diameter of $3.0 \mathrm{~mm}$, green particles with a diameter of $4.0 \mathrm{~mm}$, and red particles with a diameter of $5.0 \mathrm{~mm}$. 
Figure 13 depicts the mixing index versus time for different initial loadings of the tri-disperse particles at $30 \mathrm{rpm}$. It can be seen that the degree of mixing increased from an initial value to a maximum point and was then slightly decreased. These data show that we were not able to achieve a completely homogeneous tri-disperse particle with the mixing index of $\Psi=1$ due to the segregation of the particles with different sizes (see Figure 13). The degrees of mixing for the top-bottom smaller-to-larger and larger-to-smaller initial loadings were higher compared to those achieved for the other initial loading methods. It must be mentioned that the initial mixing index for the top-bottom larger-to-smaller, top-bottom smaller-to-larger, top-bottom random, and sideside initial loadings were $0.351,0.345,0.324$, and 0.130 , respectively. The higher initial mixing index for the top-bottom larger-to-smaller was due to the fact that the small particles, which loaded on top of the large particles, moved down through the void spaces among the large particles according to the sieving/percolation mechanism (Hogg, 2009). This resulted in a higher initial contact surface between the small and large particles for this initial loading method. 


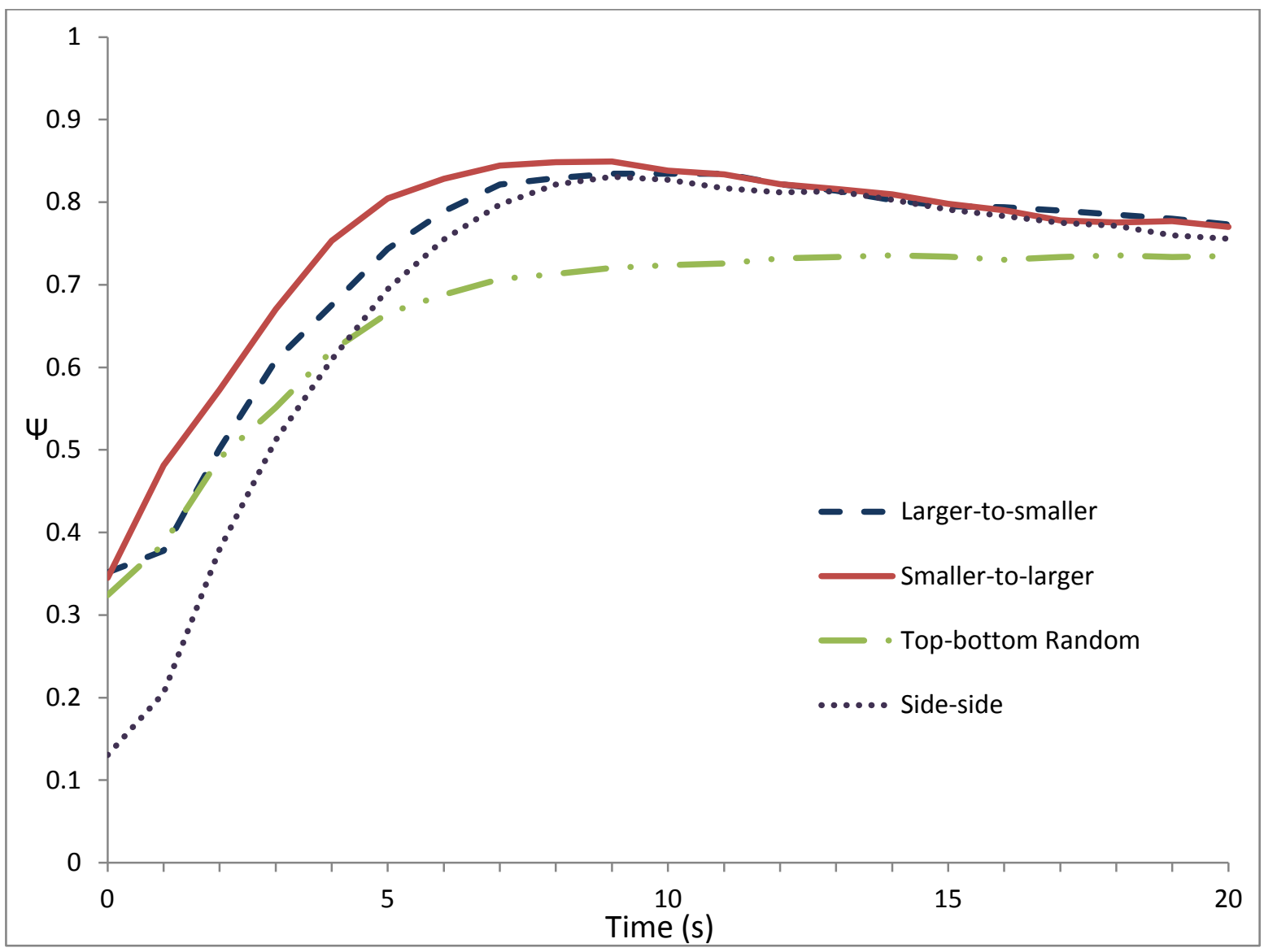

Figure 13: Mixing index versus time for the different initial loading methods of the tri-disperse particles mixed at $30 \mathrm{rpm}$. 


\subsubsection{Poly-disperse Particles}

To assess the mixing of poly-disperse particles, 31,830 glass beads with a diameter of $2.0 \mathrm{~mm}$, 9,432 glass beads with a diameter of $3.0 \mathrm{~mm}, 2,038$ glass beads with a diameter of $5.0 \mathrm{~mm}, 742$ glass beads with a diameter of $7.0 \mathrm{~mm}$, and 254 glass beads with a diameter of $10 \mathrm{~mm}$ were loaded into the rotary drum mixer. As it has been listed in Table 2, the total mass of each set of particles was the same (333 g) and the angular velocity of the drum was fixed at $30 \mathrm{rpm}$.

Figure 14 depicts the snapshots of the polydisperse particles for two side-side and four topbottom initial loading methods captured at $0,5,10,15$, and $20 \mathrm{~s}$. For the top-bottom initial loading, we employed three different loading methods.

In the top-bottom larger-to-smaller loading method, the bottom of the drum was filled with the largest glass beads $(10 \mathrm{~mm})$ and then the other particles with the sizes of 7, 5, 3, and $2 \mathrm{~mm}$ were loaded on top of the largest particles in descending order by size. In the top-bottom smaller-tolarger loading method, the bottom of the drum was filled with the smallest glass beads $(2 \mathrm{~mm})$ and then the other particles with the sizes of $3,5,7$, and $10 \mathrm{~mm}$ were loaded on top of the smallest particles in ascending order by size.

In the top-bottom random \#1 initial loading, the bottom of the drum was filled with $7 \mathrm{~mm}$ glass beads and then the $3 \mathrm{~mm}, 10 \mathrm{~mm}, 2 \mathrm{~mm}$, and $5.0 \mathrm{~mm}$ glass beads were loaded. In the top-bottom random \#2 initial loading method, the bottom of the drum was filled with $3 \mathrm{~mm}$ glass beads and then the $7 \mathrm{~mm}, 2 \mathrm{~mm}, 10 \mathrm{~mm}$, and $5.0 \mathrm{~mm}$ glass beads were loaded. 
(a)

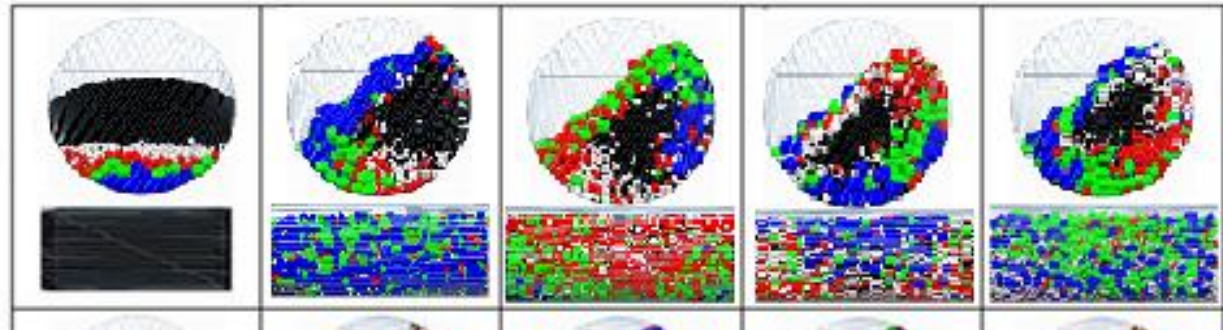

(b)

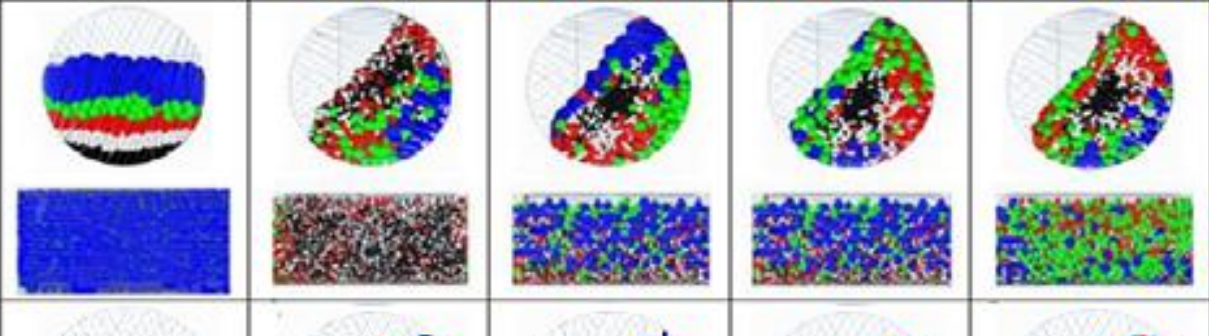

(c)

(d)

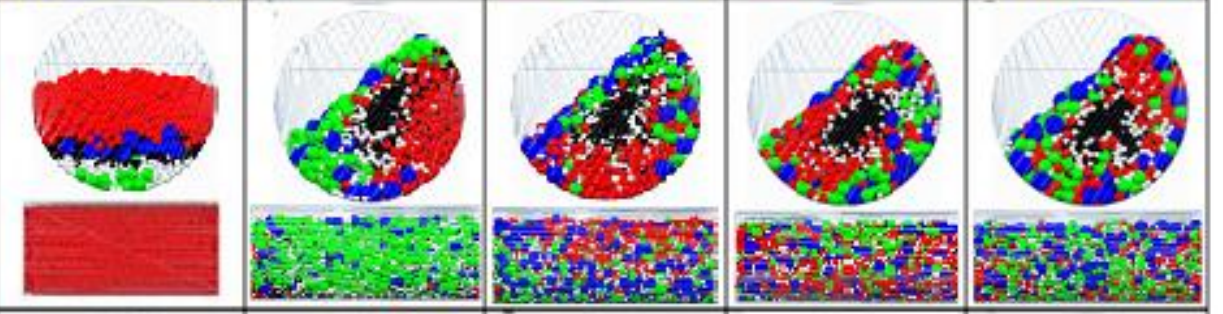

(e)

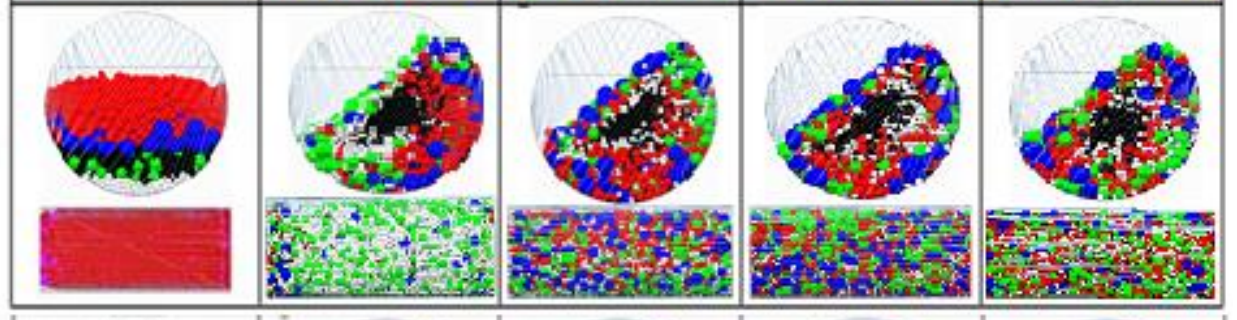

(f)

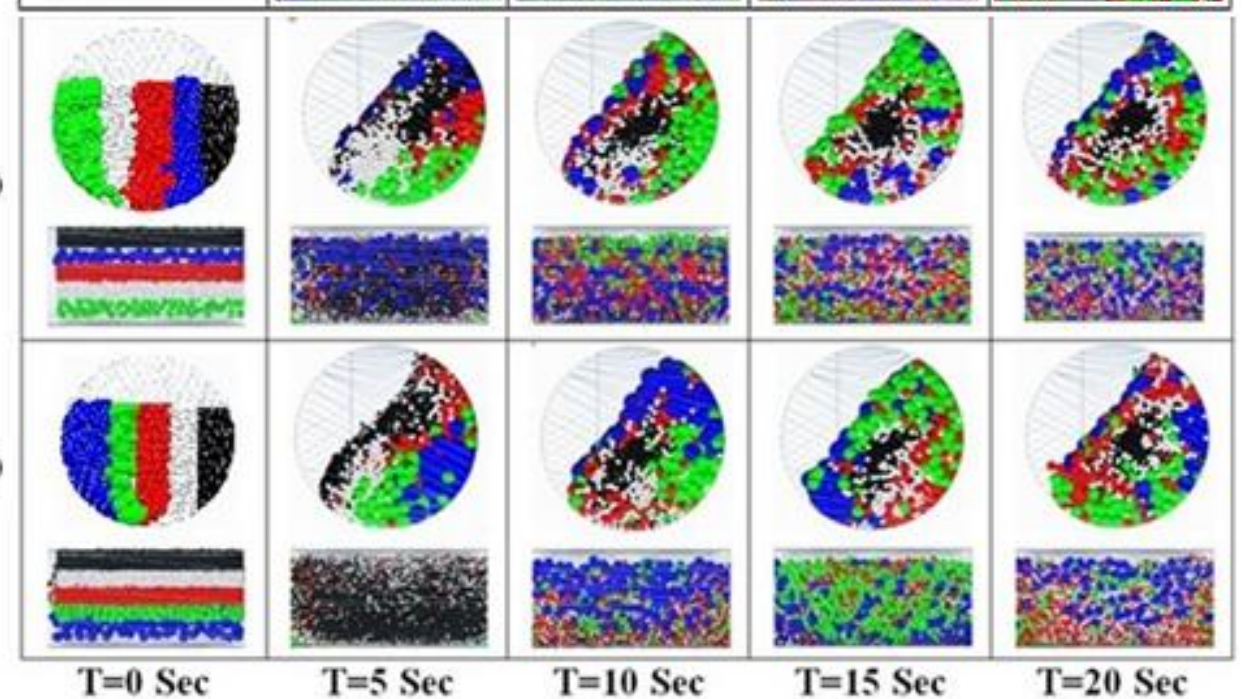

Figure 14: Snapshots of the mixing of poly-disperse particles at the drum rotational velocity of 30 rpm for: (a) top-bottom larger-to-smaller, (b) top-bottom smaller-to-larger, (c) top-bottom random \#1, (d) top-bottom random \# 2, (e) side-side random, (f) side- side- left-to-right largerto-smaller. Black particles with a diameter of $2.0 \mathrm{~mm}$, white particles with a diameter of $3.0 \mathrm{~mm}$, red particles with a diameter of $5.0 \mathrm{~mm}$, green particles with a diameter of $7.0 \mathrm{~mm}$, and blue particles with a diameter of $10 \mathrm{~mm}$. 
As can be seen in Figure 14, two types of the side-side initial loading methods were utilized in this study. In the side-side- left-to-right larger-to-smaller initial loading, the glass beads were loaded side by side into the drum in the descending order by size from the left to the right. In the second type of the initial loading, the particles were loaded randomly side by side. In this method, the sizes of the glass beads loaded from the right to the left were: $2,10,5,3$, and $7 \mathrm{~mm}$. The snapshots depicted in Figure 14 demonstrate the segregation of the poly-disperse particles during the mixing operations in the rotary drum.

Figure 15 shows the mixing index versus time for the different top-bottom and side-side initial loading methods. These results demonstrate that the mixing index increased from an initial value to a maximum point and slightly decreased before reaching a plateau. The best results were achieved with the top-bottom larger-to-smaller and the top-bottom smaller-to-larger initial loading methods.

These data also show that the final mixing indices recorded at the end of the mixing operation (i.e. $20 \mathrm{~s}$ ) for the poly-disperse particles were higher than those obtained for the tri-disperse and bi-disperse particles. This means that the impact of the segregation reduced with an increase in the degree of polydispersity. These data also provide a basic understanding for the mixing of non-cohesive poly-disperse particles inside a lab scale rotary drum mixer, that would help for future work to develop a comprehensive understanding of the mixing behavior for the polydisperse particles inside a large scale rotary mixer. 


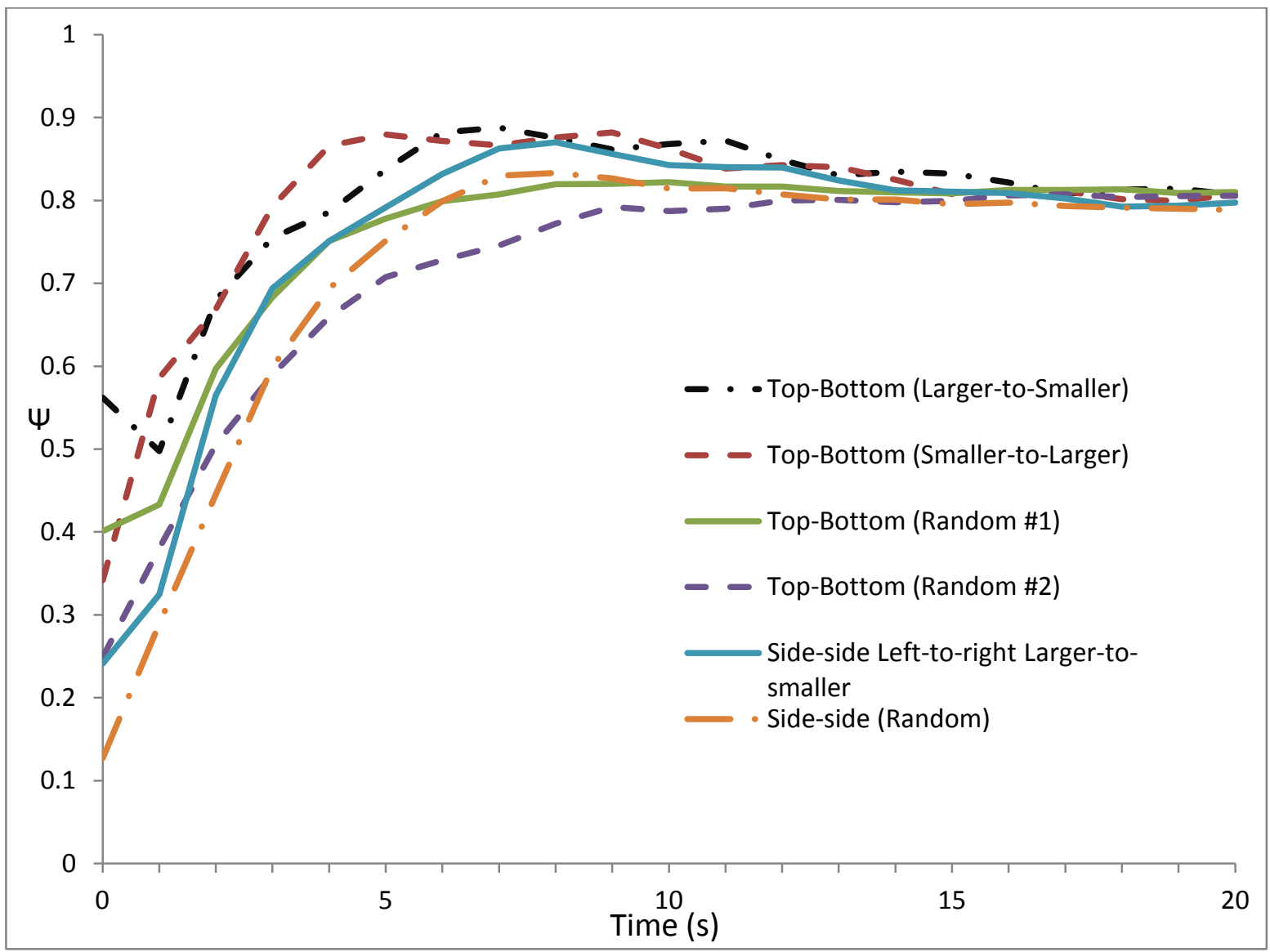

Figure 15: Mixing index versus time for the the poly-disperse particles mixed at $30 \mathrm{rpm}$ and different initial loadings. 
In fact, the presence of the additional intermediate sized particles with the sizes between the smallest and largest particles resulted in an increase in the diffusive and convective particle motion inside the mixer. This increase in the diffusive and convective motions improves the mixing mechanism, which reduces the extent of segregation caused by a mechanism called the sieving mechanism (Remy et al., 2011). Moreover, the enhancement of flow kinematics is achieved by the differences in the packing structure inside the particle bed. Remy et al. (2011) investigated the segregation of bi-disperse, tri-disperse, and poly-disperse mixtures (5 and 11 different sized particles) in a bladed mixer. They reported that the extent of the segregation for 11-size poly-disperse mixture was less compared to those obtained for the other mixtures. 


\section{Chapter 6: Evaluation of Polydisperse Solid Particles Mixing in a Slant Cone Mixer Using Discrete Element Method}

\subsection{Introduction}

Particle mixing is an essential step in a range of industrial applications such as mineral, polymers, food, ceramic, pharmaceuticals, and cosmetics processing. In chemical industries, two or more types of solid particles are often required to be mixed to some degree of homogeneity. Different types of tumbling blenders are: V-and Y-blenders, double cone, bin blenders, rotating drums, and slant cone mixer (Paul et al., 2004). It is important to mention that both symmetrical and asymmetrical designs are used in tumbling mixers. Double cone and V-shape blenders are symmetrical blenders and their axes of rotation are perpendicular to the line of symmetry. VShape blenders are commonly used for the blending of granules and powders due to their complete discharge of the final mixture, ease of cleaning, efficient blending, and short blending time (Tahvildarian et al., 2013).

The flow in a tumbling blender consists of the fast flow in the slim region near the surface, a close to non-deforming region underneath that rotates with the mixer as a rigid body, and a thin transition region in between that is distinguished by density gradients and high shear. The rapid layer is a flat and thin region of three particle diameters, which remains nearly invariable in size for the $60 \%$ fill level (Sudah et al., 2005). This analysis is best explained in the context of the rotary or quasi-two-dimensional disk mixers (Arratia et al., 2006).

Sudah et al. (2005) investigated the mixing mechanisms experimentally and computationally in a tote blender. Simulations were done for mono-disperse and bi-disperse spherical glass beads at a 1:1 scale. During the cascading region, the examination of velocity profiles from DEM 
simulations delivered information about the mechanisms of mixing. Radial mixing in a tumbling blender was shown to be orders of magnitude faster than axial mixing.

Arratia et al. (2006) explored the performance of the Bohle (bin) blender and reported that the top-bottom initial loading was more efficient than the back-front loading. They investigated the fill levels of $40 \%, 60 \%$, and $80 \%$ with both top-bottom and side-side initial loading methods at $10 \mathrm{rpm}$ and showed that the mixing efficiency obtained at the lower fill levels was higher than that at the higher fill levels. They also pointed out that the solid particles at the higher fill levels had low velocity and less space to move.

Two commercial asymmetrical blenders are the slant cone blender and the long leg V-shape design, which has one leg longer than the other. The asymmetrical blenders superimpose the axial flow of the material in the direction of rotation. Indeed, the granules inside the blender are forced across the vertical axis of the tumbler each half revolution, and this increases the quality of granules mixing in a shorter time. The slant cone mixer with an intensifier bar is an advanced type of the powder mixer (Alian et al., 2014), which is a combination of the tumbling and agitator blenders. It is used for mixtures that may agglomerate or for high intensity blending.

Our comprehensive literature review revealed that there is a lack of adequate information for the mixing of the binary, ternary, and poly-disperse particles inside the slant cone blender. Therefore, the main objective of this study is to explore the mixing quality of the binary, ternary and poly-disperse particles in a slant cone mixer as a function of the drum speed, the initial loading methods, and internal agitator speed through the discrete element method (DEM). DEM is a reliable simulation method for assessing the particulate behavior systems. 


\subsection{Results and Discussion}

To validate the DEM model developed in this study, the simulation results were compared to the experimental data qualitatively and quantitatively. For the validation tests, the mixer was filled using the top-bottom initial loading method with equal number of red and black glass beads totaling to 95,068 beads with a diameter of $3.0 \pm 0.2 \mathrm{~mm}$ to achieve $70 \%$ of the fill level approximately. The angular velocity of the drum was $15 \mathrm{rpm}$.

For accomplishing the top-bottom pattern, the bottom of the slant cone mixer was filled with the black particles and then the red particles were loaded on top of the black particles. This particular experiment lasted for $24 \mathrm{~s}$ of the real time to obtain 6.0 complete revolutions.

To validate the simulation results using the imaging method, the images of the glass beads mixture were taken at the end of each complete revolution and then compared to the snapshots of the simulation at the same real time value. As illustrated in Figure 16, there is a reasonable agreement between the simulation and experimental data.

Figure 17 shows the mixing index after each revolution. It can be seen that a good agreement was also achieved between the experimentally determined values and the simulation results. During the sampling procedure, each sample was extracted three times from every desired position. The use of sampling template disturbed the particle bed inside the mixer, and the number of particles collected by thief sampler caused the errors in the experimental data. 


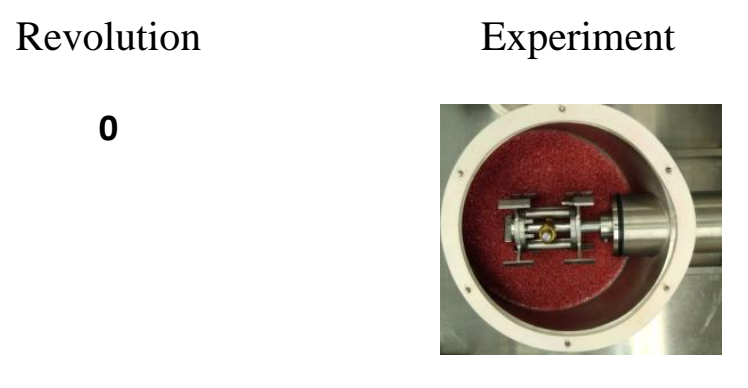

\section{Simulation}

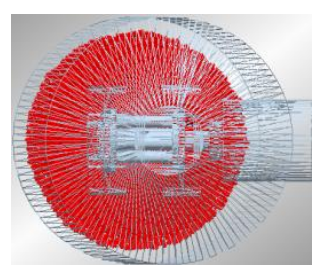

1
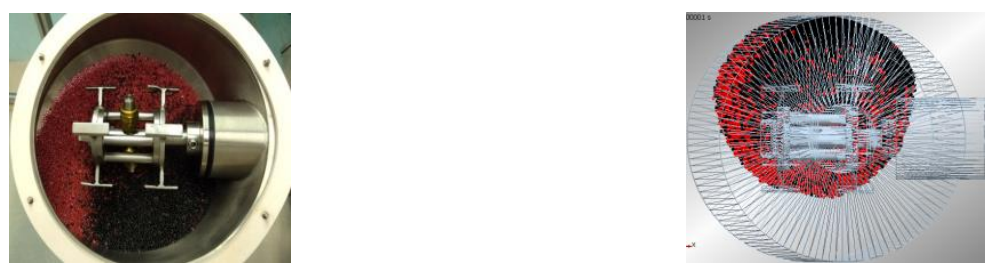

2
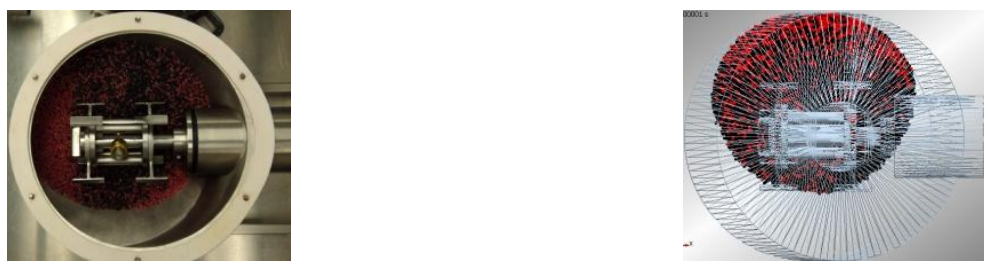

3
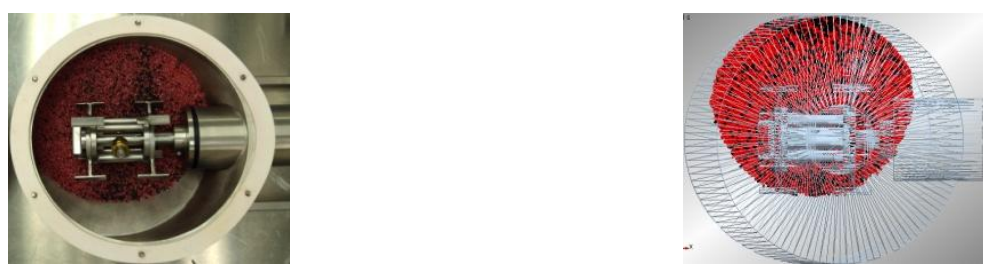

4
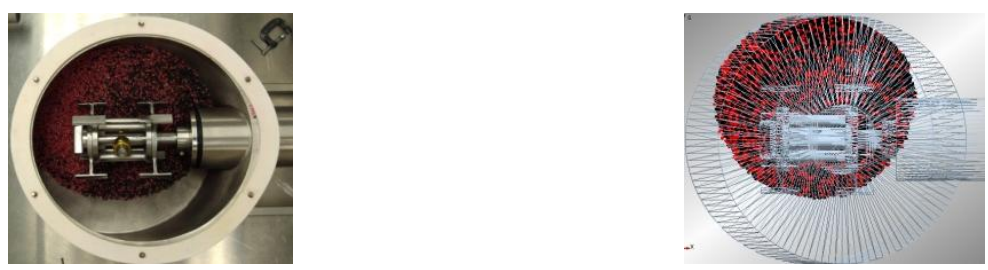

5
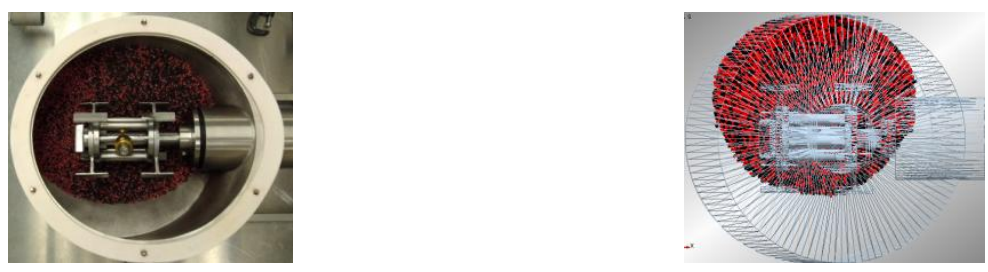

6
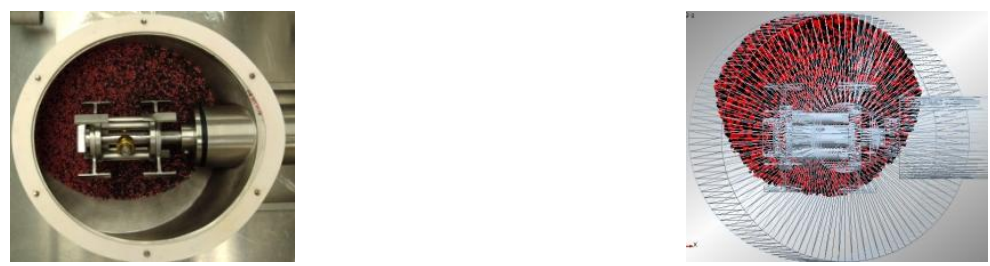

Figure 16: Comparison between the snapshots of the simulated and real solid mixtures at each revolution at the fill level of $70 \%$, drum speed of $15 \mathrm{rpm}$ and up-down initial loading while the agitator was stationary. 


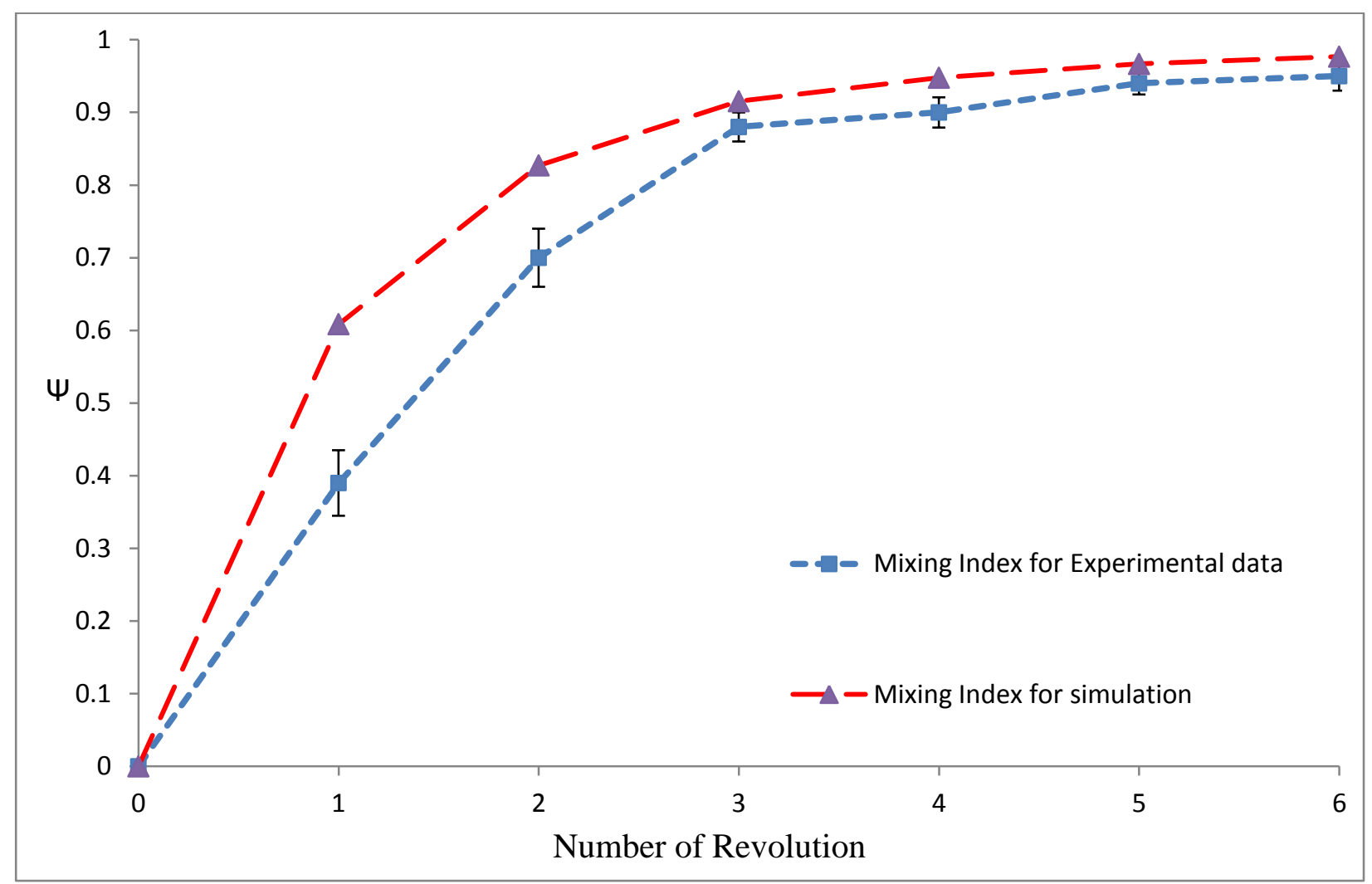

Figure 17: Comparison between the mixing index graphs achieved through the experiment and simulation at the fill level of $70 \%$, the drum speed of $15 \mathrm{rpm}$ and the top-bottom initial loading while the agitator was stationary. 


\subsubsection{Bi-disperse Particles}

At this part of the study, the effects of the initial loading methods, the drum rotational speed, and the agitator speed for mixing of bi-disperse particles were investigated.

\subsubsection{Effect of Initial Loading Methods}

To investigate the mixing of bi-disperse particles, 20,000 black colored non-cohesive glass beads with a diameter of $4.0 \mathrm{~mm}$ and 5,926 red colored non-cohesive glass beads with a diameter of 6.0 mm were loaded to reach $70 \%$ of the fill level of the mixer's geometry. As mentioned in Table 3 , the total mass of each set of particles was the same $(1,675 \mathrm{~g})$. The angular velocity of the blender was $15 \mathrm{rpm}$ to have 6.0 complete revolutions in 24 seconds of the real time. Moreover, the internal agitator was chosen to be stationary, since the tumbling effect was of the interest at this part of this study.

The effect of initial loading for bi-disperse particles (i.e. side-side, top-bottom smaller-to-larger, top-bottom larger-to-smaller, smaller back-larger front, and larger back-smaller front) on the mixing efficiency of the slant cone mixer was explored.

It must be mentioned that we employed two methods for the top-bottom initial loading of bi-disperse particles in this study as illustrated in Figure 18. In the first method, the bottom of the slant cone was filled with the larger sized particles $(6.0 \mathrm{~mm}$ diameter $)$ and then the smaller sized particles (4.0 mm diameter) were loaded on top of the larger particles. This filling method was called top-bottom larger-to-smaller initial loading. In the second method, the bottom of the slant cone was filled with the smaller sized particles $(4.0 \mathrm{~mm}$ diameter $)$ and then the larger sized particles (6.0 $\mathrm{mm}$ diameter) were loaded on top of the smaller particles. This filling method was called: top-bottom smaller-to-larger initial loading. 


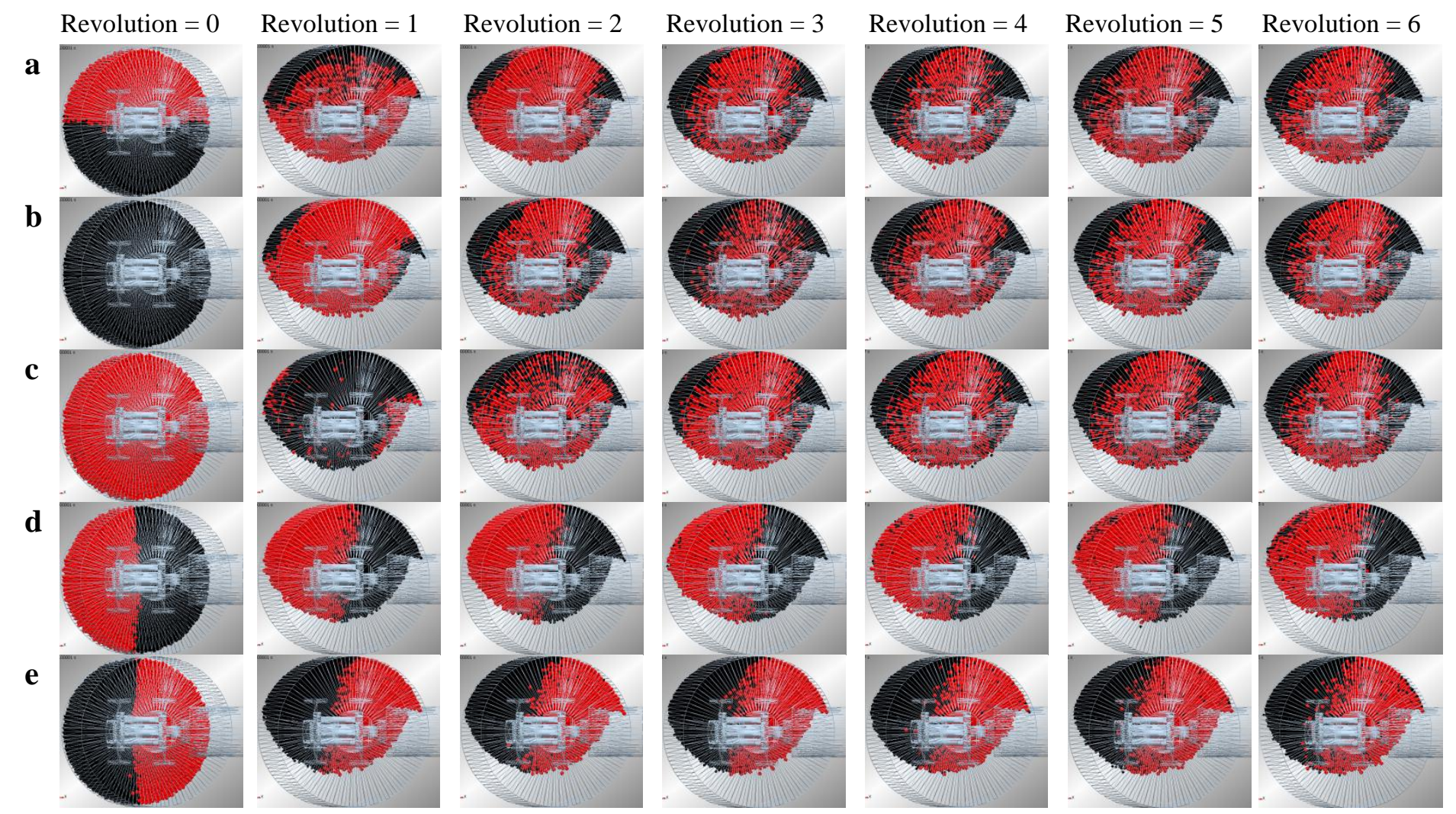

Figure 18: Snapshots of the simulated solid mixture for the bi-disperse particles at the fill level of $70 \%$ and the drum speed of $15 \mathrm{rpm}$ while the agitator was stationary (a) side-side initial loading, (b) top-bottom larger-to-smaller, (c) top-bottom smaller-to- larger, (d) smaller backlarger front, and (e) larger back-smaller front. Red particles with a diameter of $6.0 \mathrm{~mm}$, and black particles with a diameter of $4.0 \mathrm{~mm}$. 
Figure 19 depicts the mixing index versus number of revolutions computed for the five different initial loadings. It can be seen that the top-bottom smaller-to-larger initial loading method provided the highest mixing efficiency, and the side-side and top-bottom loadings were both more efficient than the back-front loading. According to these data, after 3.0 revolutions, the mixing index values for both top-bottom and side-side loadings were over 0.80 , whereas this value for the back-front loadings were near 0.45 . The reason for the low mixing efficiency in the smaller back-larger front and larger back-smaller front cases were that the movement paths of each set of particles (black or red) were perpendicular to the expected paths for mixing; as a result each set of particles was mixed mostly with the same set instead of being mixed with another set of the particles. In other words, the homogenization process was extremely dependent on the dispersive transport, which is a slow process (Arratia et al., 2006).

From Figure 19 it can be seen that the mixing index value for the top-bottom loading at zero revolution was higher than those for the side-side and back-front loading patterns. This was due to the fact that the initial contact surface between the black and red particles was larger in the top-bottom smaller-to-larger and the top-bottom larger-to-smaller patterns compared to the other two loadings. To better demonstrate these findings, Figure 18 shows the snapshots of the slant cone mixer simulations for five different loading patterns at the end of each complete revolution. 


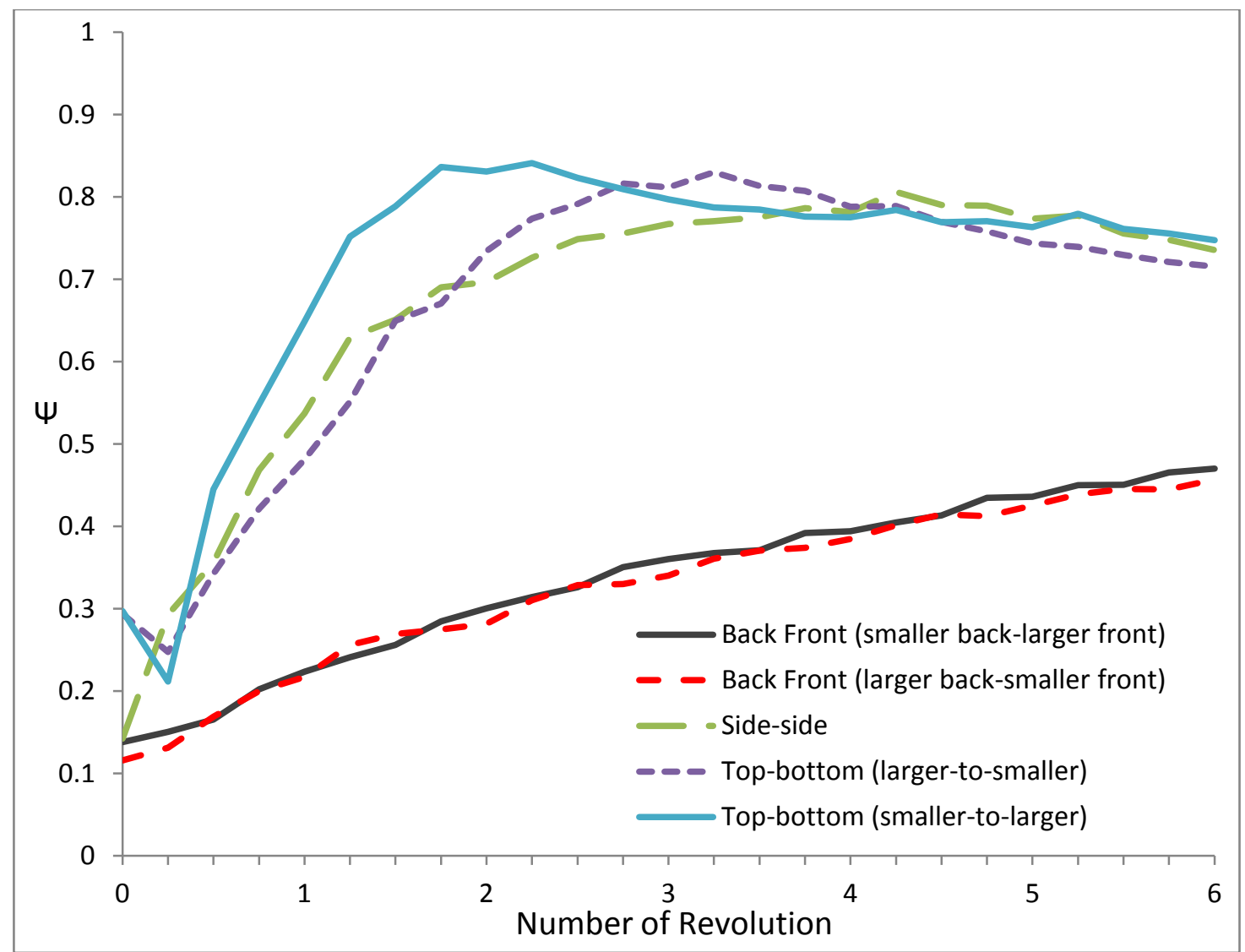

Figure 19: Mixing index versus number of revolution for the different initial loading of bidisperse particles at the fill level of $70 \%$ and the drum speed of $15 \mathrm{rpm}$ while the agitator was stationary. 
The mixing simulations for the side-side and top-bottom initial loading methods were extended from 6.0 to 10 revolutions in order to understand more about the mixing and/or segregation mechanism.

Figure 20 shows the snapshots of the slant cone mixer simulations for the three different initial loading methods at the end of each complete revolution. At the second rotation, a good mixing quality for the solid particles was achieved at the top bottom smaller-to-larger loading method. In other words, the red and black particles obtained the best mixing quality in compared to the other snapshots for the same loading method. Starting from the fourth rotation, the segregation patterns were developed, and the black and red particles formed two separate zones.

Figure 21 depicts the mixing index versus number of revolutions computed for the side-side and the top-bottom different initial loadings. It can be seen that the mixing quality achieved for the top-bottom smaller-to-larger was higher than those for the side-side and top-bottom larger-tosmaller.

These data show that the degree of mixing at the top-bottom smaller-to-larger reached a maximum of $\psi=0.861$ at 2.25 revolutions and then decreased with time till it reached a plateau $(\Psi=0.680)$. On the other hand, the graphs for the degree of mixing at the side-side and topbottom larger-to-smaller reached a maximum of $\psi=0.805$ at 4.25 revolutions and 3.25 revolutions, respectively; then, both mixing indices graphs decreased with time until it reached a plateau.

Based on these mixing results, the following simulations in this study were conducted for the top-bottom smaller-to-larger initial loading method under 6.0 complete revolutions. 


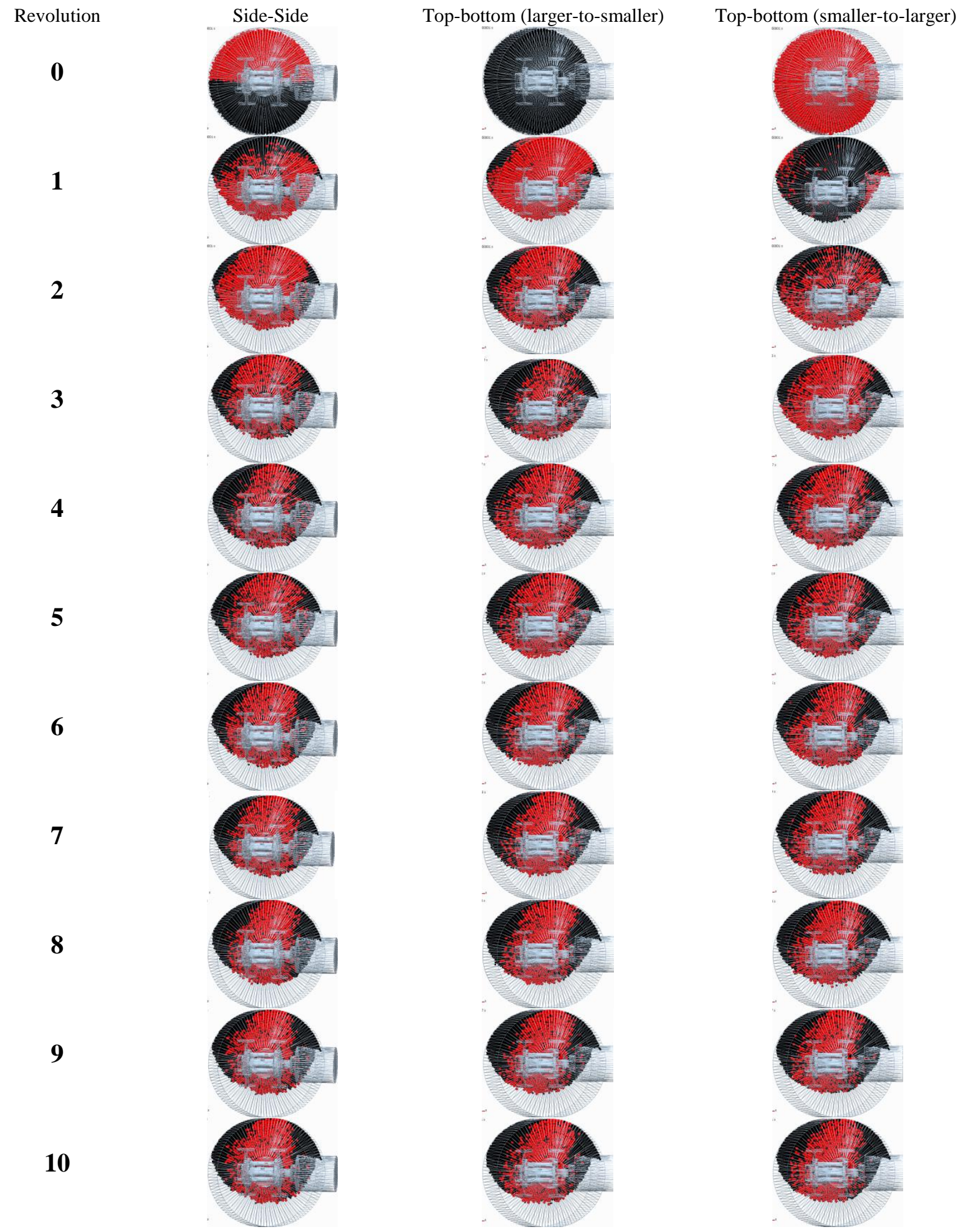

Figure 20: Snapshots of the simulated solid mixture for the bi-disperse particles at the fill level of $70 \%$ and the drum speed of $15 \mathrm{rpm}$ while the agitator was stationary (a) side-side initial loading, (b) top-bottom larger-to-smaller, and (c) top-bottom smaller- to-larger. Red particles with a diameter of $6.0 \mathrm{~mm}$, and black particles with a diameter of $4.0 \mathrm{~mm}$ 
Previous researchers explored the effect of the initial loading for mono-disperse particles inside the symmetrical tumbling mixers such as the v-blender, double cone, and pan coater. For instance, Moakher et al. (2000) studied the V-blender and double-cone mixer. They showed that the back-front initial loading method had a lower mixing efficiency than the top-bottom loading method. Sahni et al. (2011) investigated the mixing inside the Pan coater, and showed that the back-front loading method had a lower mixing efficiency than the side-side initial method.

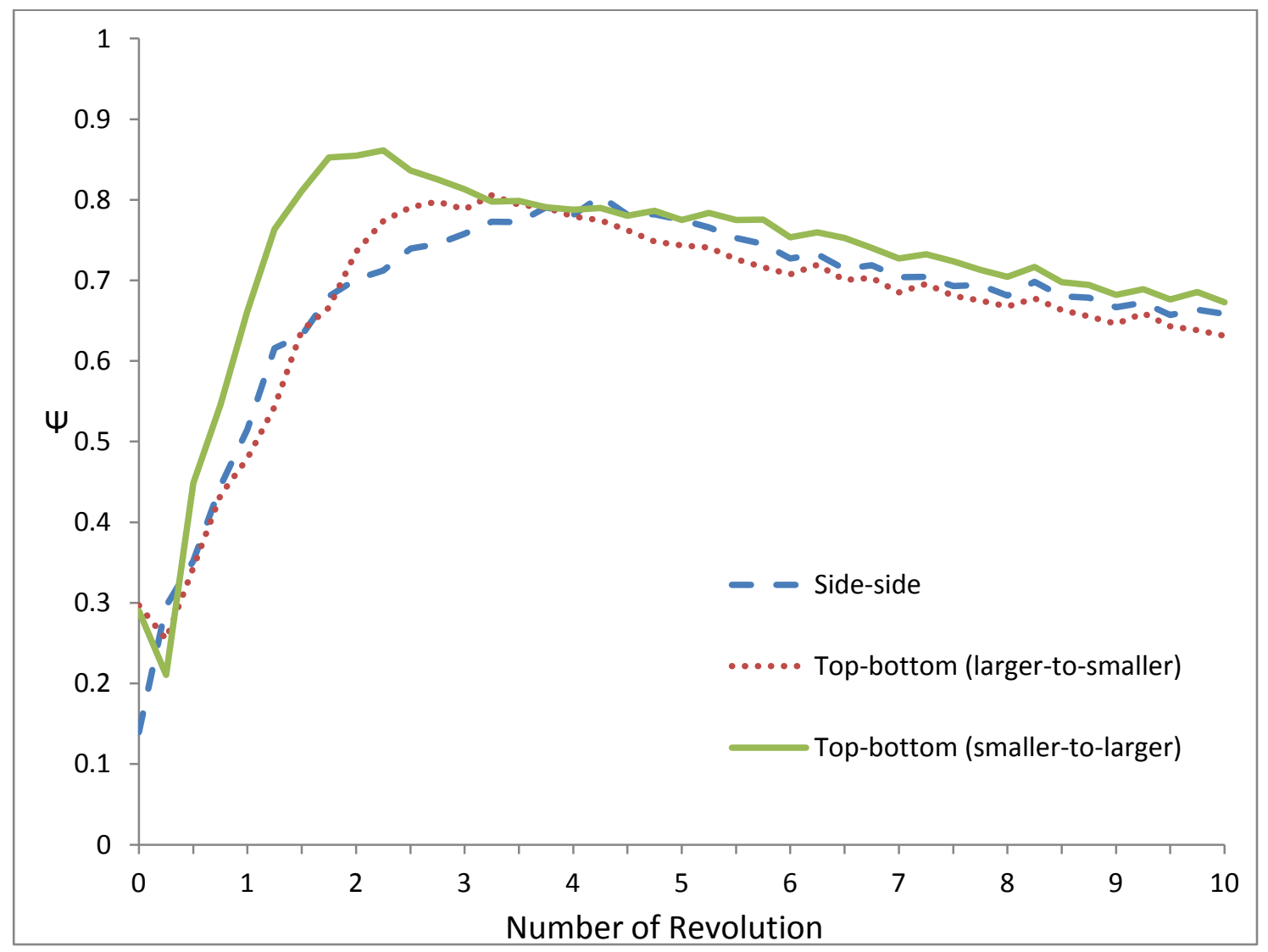

Figure 21: Mixing index versus number of revolution for the different initial loading of bidisperse particles at the fill level of $70 \%$ and the drum speed of $15 \mathrm{rpm}$ while the agitator was stationary. 


\subsubsection{Effect of the Drum Rotational Speed}

DEM was utilized to study the effect of the blender angular velocity on the mixing efficiency of bi-disperse particles in the slant cone mixer. The rotational speed was varied from $7.0 \mathrm{rpm}$ to 55 rpm. In these simulations, the top-bottom smaller-to-larger initial loading was used to charge 20,000 black glass beads with a diameter of $4.0 \mathrm{~mm}$ and 5,926 red glass beads with a diameter of $6.0 \mathrm{~mm}$ into the vessel. The fill level was $70 \%$ and the agitator inside the blender was stationary since the main objective of this investigation was to assess the effect of the rotational velocity of the drum on the mixing quality.

Figure 22 illustrates the snapshots of the mixing of the bi-disperse particles in the slant cone blender for the top-bottom smaller-to-larger initial loading at six drum speeds. These snapshots show that the larger particles (red) accumulated at the centre and the smaller particles (black) moved to the boundaries of the loaded mass. This separation between small and large particles was due to the segregation according to the trajectory side-to-side mechanism (Tang and Puri, 2004). Alexander et al. (2004) investigated the segregation mechanism for the bi-disperse noncohesive glass beads inside a V-blender. At low rotational velocities, the trajectory segregation mechanism induced by surface flow separated the small and large particles. The large particles accumulated on the convex side, whereas the small particles collected on the concave side of the bend. At high rotational velocities, the large particles moved into the center of each shell, while the small particles accumulated near the center of the V-blender.

Figure 23 demonstrates the mixing index versus number of revolutions for six different drum rotational speeds $(7.0,15,22.5,30,45$ and $55 \mathrm{rpm})$. It can be seen that an increase in the angular velocity enhanced the mixing index. It should be noted that the mixing indices at the 22.5 and 30 rpm reached to $\psi=0.840$ after 3.0 revolutions, whereas the degree of mixing at $7.0 \mathrm{rpm}$ reached 
a maximum of $\psi=0.790$ after 1.5 revolutions and then decreased with time till it reached a

plateau $(\Psi=0.650)$.

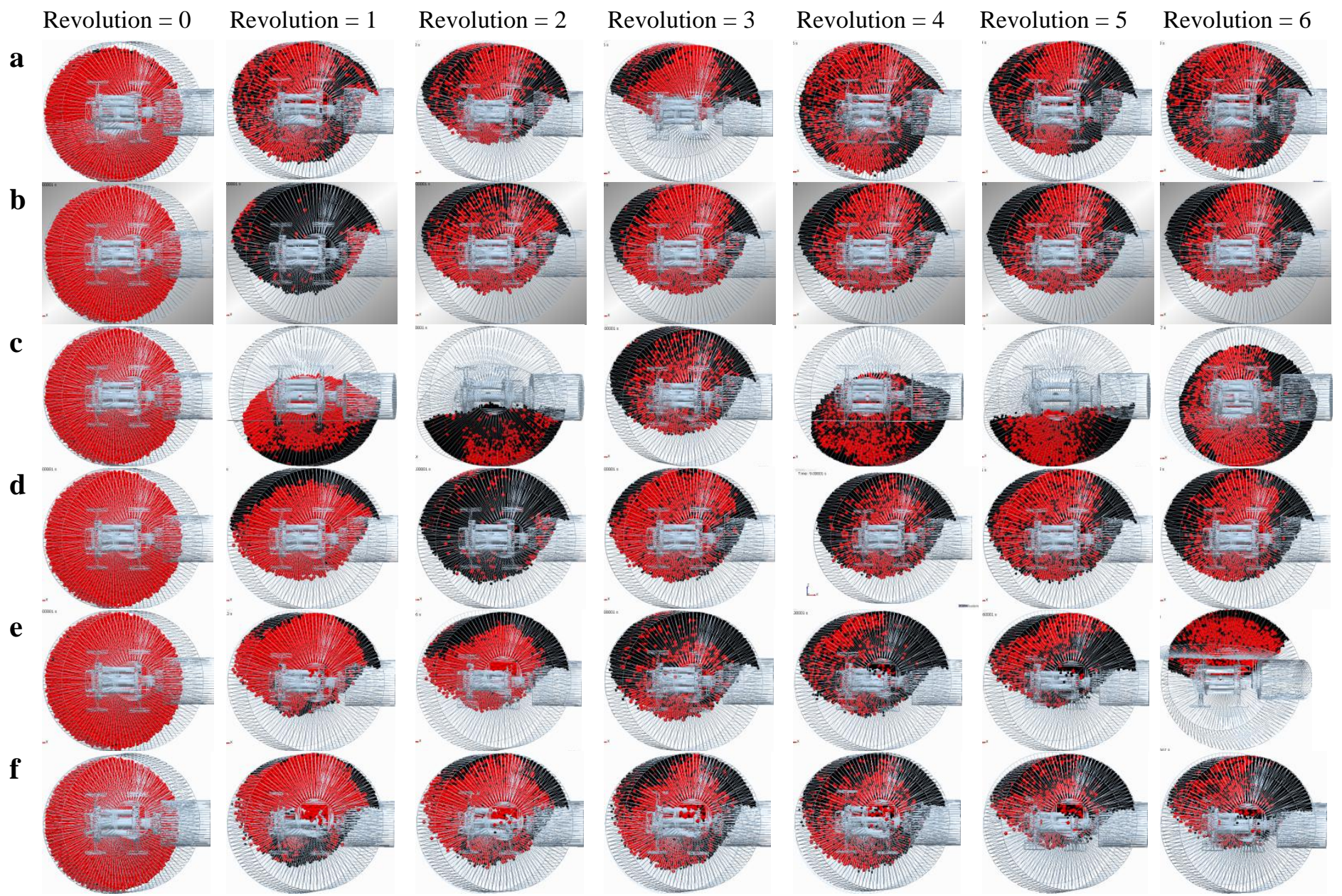

Figure 22: Snapshots of the simulated solid mixture at different drum speeds for the bi-disperse particles at the fill level of $70 \%$ and the top-bottom smaller-to-larger initial loading method while the agitator was stationary. (a) the drum speed of $7.0 \mathrm{rpm}$, (b) the drum speed of $15 \mathrm{rpm}$, (c) the drum speed of $22.5 \mathrm{rpm}$, (d) the drum speed of $30 \mathrm{rpm}$, (e) the drum speed of $45 \mathrm{rpm}$, and (f) the drum speed of $55 \mathrm{rpm}$. Red particles with a diameter of $6.0 \mathrm{~mm}$, and black particles with a diameter of $4.0 \mathrm{~mm}$. 


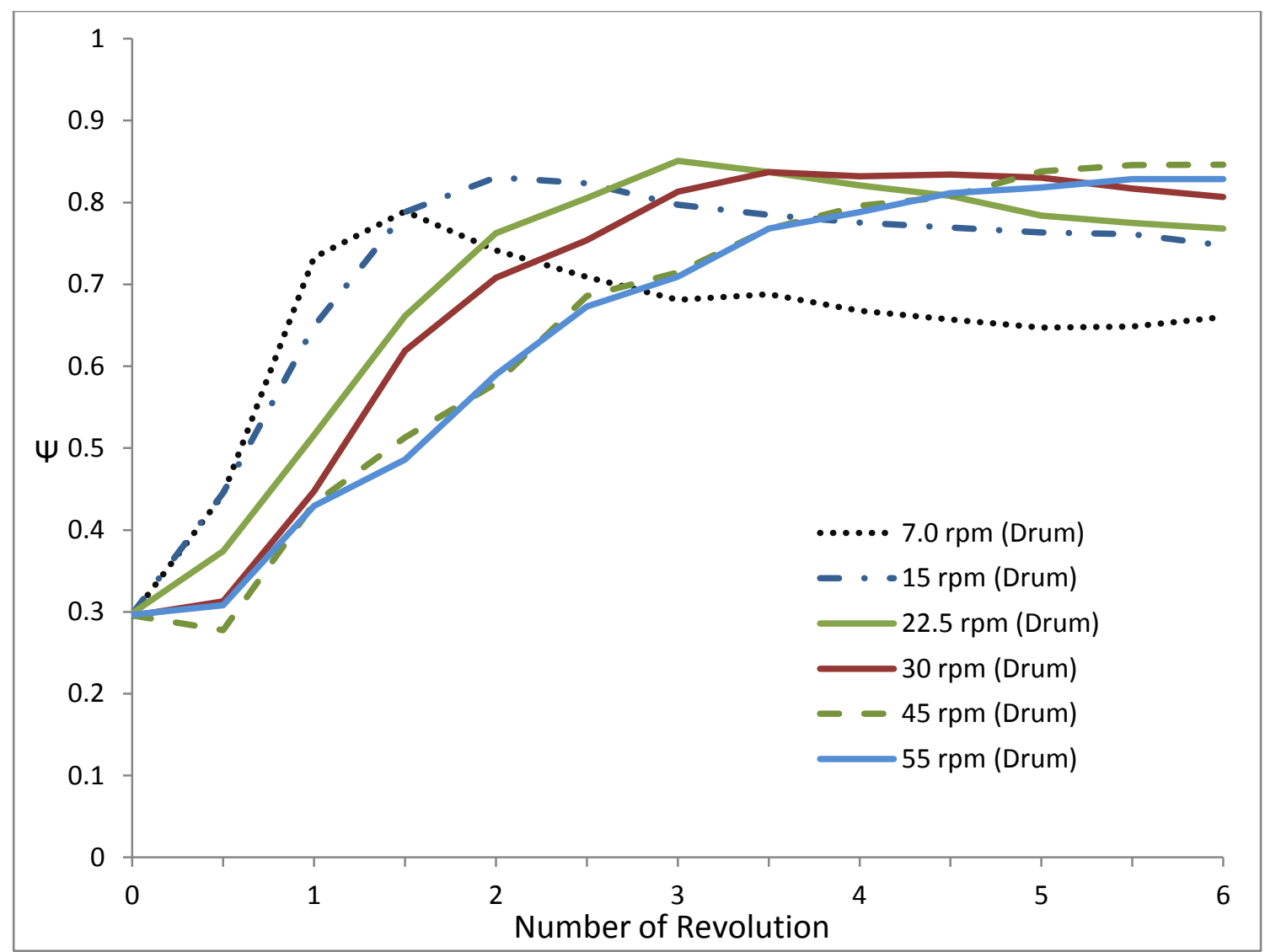

Figure 23: Mixing index versus number of revolution for the different drum speeds of bidisperse particles at the fill level of $70 \%$ and the top-bottom smaller-to-larger initial loading method while the agitator was stationary. 
The determination of the optimal angular velocity for a blender is a challenging task because at the higher angular velocities, the blender may give enough centrifugal force to hold the particles on the blender walls. Furthermore, at the higher velocities, the particles may be prevented from tumbling freely and as a result the particles are kept at the periphery of the drum. On the other side, at the lower angular velocities, the blender cannot deliver the required cascading motion and shear rates resulting in a lower efficiency of the mixing. The previous two scenarios could cause a reduction in the mixing efficiency (Lemieux et al., 2008; Sahni et al., 2011).

As shown in Figure 23, the mixing indices at $45 \mathrm{rpm}$ and $55 \mathrm{rpm}$ increased with the number of revolution till they reached a plateau with a mixing index around 0.83 . However, at the lower rotational speeds, the mixing index increased with the number of revolutions and then decreased until it reached a plateau. The difference in mixing performances between those achieved at the low rotational velocities (7.0 and $15 \mathrm{rpm})$ and the medium velocities (22.5 and $30 \mathrm{rpm})$ were larger than that between the medium and high angular velocities (45 and $55 \mathrm{rpm}$ ). Although at the higher rotational velocities a better mixing efficiency is achieved, however, more energy is consumed and higher maintenance costs might be needed.

Lemieux et al. (2008) investigated the mixing performances of the V-blender and bin-blender, and showed that with increasing the rotational speed of the mixer, mixing efficiency was increased for both blenders; however, this effect was less dominant for the bin-blender compared to that of the V-blender. Sahni et al. (2011) investigated the pan coater mixer. Their studies showed that the mixing efficiency was enhanced with an increase in the rotational velocity of the mixer. 


\subsubsection{Effect of the Agitator Speed}

The use of the agitator installed inside the slant cone mixer depends on the mixture size. In other words, the agitator should be utilized only when the mixer is slightly overloaded. Also, the use of an agitator reduces the mixing time by applying more energy to the particles. In this part of the study, the effect of the agitator on the mixing performance of the slant cone mixer is investigated for the same bi-disperse particles that were used earlier. It was observed in the previous section that the mixing index increased from an initial value to a maximum and decreased slightly before reaching a plateau for the bi-disperse particles for different initial loading methods and the drum speed of $15 \mathrm{rpm}$ as a direct result of the segregation of the particles with different sizes. For this reason, the effect of the agitator on minimizing the segregation patterns should be investigated. The agitator speed employed in this study was $+100 \mathrm{rpm}$ while the rotational speed of the vessel was maintained at $15 \mathrm{rpm}$. The positive rpm sign means that the rotation mode was co-rotating (i.e. the same direction for the drum and the agitator rotation). The top-bottom smaller-to-larger and top-bottom larger-to-smaller loading methods with $100 \%$ fill level were utilized in order to compare the mixing indices achieved with the agitator speeds of 0 and $+100 \mathrm{rpm}$.

50,000 black colored non-cohesive glass beads with a diameter of $4.0 \mathrm{~mm}$ and 14,815 red colored non-cohesive glass beads with a diameter of $6.0 \mathrm{~mm}$ were loaded to reach $100 \%$ of the fill level. As mentioned in Table 3, the total mass of each set of particles was the same $(4,190.5 \mathrm{~g})$.

In the co-rotating mode, the particles near the agitator have the highest velocity. This could be justified by Newton's second law for rotational motion (Jiang et al., 2011). The total momentum of each particle is the vector sum of the momentums applied by the drum and the agitator. 
In the co-rotating mode, since these vectors are in the same direction, the sum of the momentums results in a larger magnitude than that in the stationary agitator mode. Since the mixing quality depends on the movement of the particles, a higher mixing index was achieved by the co-rotating mode (Alian et al., 2014).

Figure 24 depicts the snapshots of the bi-disperse particles for the top-bottom smaller-to-larger and larger-to-smaller initial loading methods captured at the end of 0, 3, and 6 revolutions. These snapshots demonstrate that the use of the agitator for the bi-disperse particles enhanced the mixing quality and reduced the segregation of the particles with different sizes.

Figure 25 shows the mixing index versus time for the different loading methods and the agitator speeds of 0 and $+100 \mathrm{rpm}$. These results demonstrate that the mixing index increased from an initial value with the number of revolution before reaching a plateau. It can be seen that the mixing indices achieved for the top-bottom smaller-to-larger with a rotating agitator were significantly higher than those at the same loading method with a stationary agitator. These data also show that the final mixing indices recorded at the end of the mixing operation (i.e. 6.0 revolutions) for the bi-disperse particles with a rotating agitator was higher than those obtained for the bi-disperse particles with a stationary agitator at the fill level of $100 \%$. In fact, the use of the agitator is required to mobilize the bi-disperse particles in the radial direction, which improves the quality of mixing. Overall, the segregation (de-mixing) was reduced due to the rotation of the agitator.

Alian et al. (2014) studied the effect of the agitator on the quality of mixing for mono-disperse particles inside the slant cone mixer at the fill level of $100 \%$. They showed that the mixing quality was improved tremendously by the rotation of the agitator compared to that achieved with the stationary agitator. 


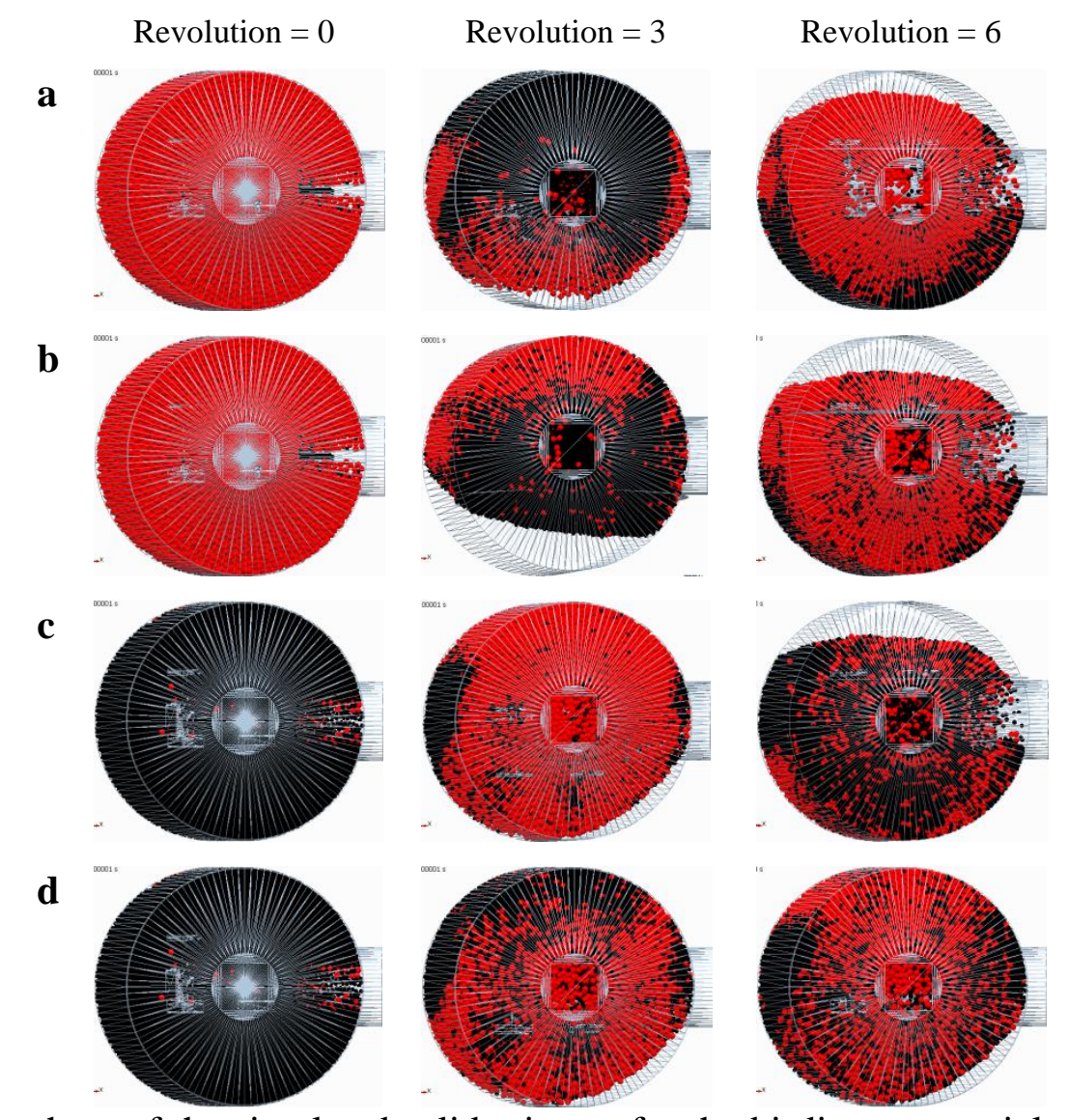

Figure 24: Snapshots of the simulated solid mixture for the bi-disperse particles at the fill level of $100 \%$ and the drum speed of $15 \mathrm{rpm}$ (a) top-bottom smaller-to-larger with a stationary agitator, (b) top-bottom smaller-to-larger with an agitator speed of $100 \mathrm{rpm}$, (c) top-bottom larger-to-smaller with a stationary agitator, and (d) top-bottom larger-to-smaller with an agitator speed of $100 \mathrm{rpm}$. Red particles with a diameter of $6.0 \mathrm{~mm}$, and black particles with a diameter of $4.0 \mathrm{~mm}$. 


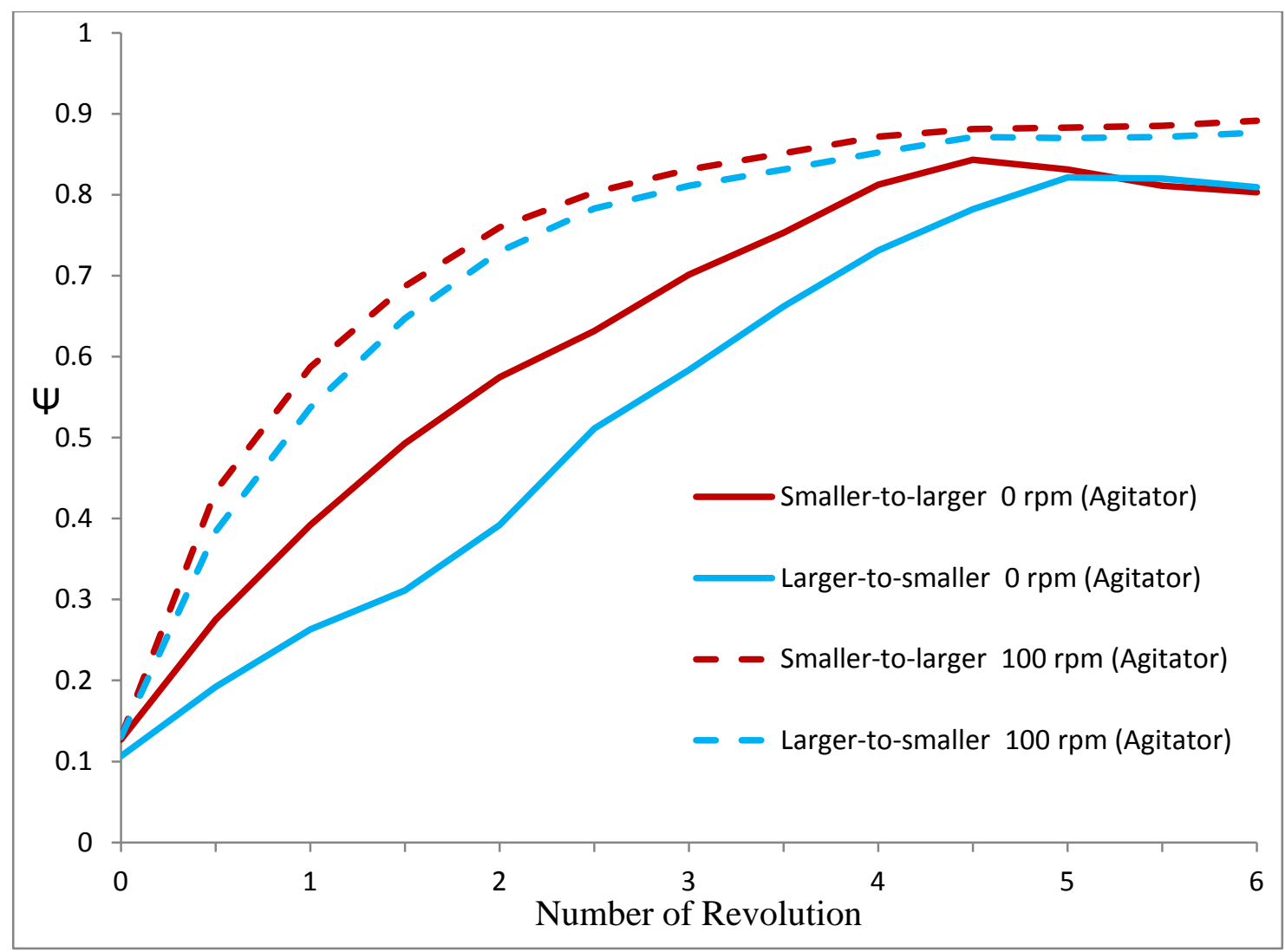

Figure 25: Mixing index versus number of revolution of the bi-disperse particles at the fill level of $100 \%$ and the top-bottom smaller-to-larger and larger-to-smaller loading methods while the agitator was rotating with the speeds of 0 , and $+100 \mathrm{rpm}$. 


\subsubsection{Tri-disperse Particles}

DEM was used to study the effect of the vessel angular velocity on the mixing efficiency of tridisperse mixtures in the slant cone mixer. Similar to the bi-disperse systems, rotational speed was varied from $7.0 \mathrm{rpm}$ to $55 \mathrm{rpm}$.

In these simulations, the top-bottom smaller-to-larger initial loading was used to charge 13,328 black glass beads with a diameter of $4.0 \mathrm{~mm}, 6,824$ red glass beads with a diameter of $5.0 \mathrm{~mm}$, and 3,949 gray glass beads with a diameter of $6.0 \mathrm{~mm}$ into the slant cone mixer. As shown in Table 3, the total mass of each set of particles was the same (1,116.6 g). The fill level was $70 \%$ and the agitator inside the vessel was stationary since the main objective of this part of the study was to assess the effect of the rotational velocity of the drum.

It must be mentioned that we employed one initial loading method to charge the tri-disperse particles into the slant cone mixer. The bottom of the slant cone was filled with the smaller sized particles (4.0 $\mathrm{mm}$ diameter) and the medium sized particles $(5.0 \mathrm{~mm}$ diameter) were loaded on top of the smaller particles. The larger particles $(6.0 \mathrm{~mm}$ diameter) were then loaded on top of the medium particles. This filling method was called top-bottom smaller-to-larger initial loading.

Figure 26 shows the snapshots of the solid mixture obtained through the simulations at the end of each complete revolution for six rotational velocities. Figure 26 shows that the larger particles accumulated at the centre and the smaller particles moved to the boundaries of the loaded mass, whereas the red particles $(5.0 \mathrm{~mm}$ diameter) accumulated mostly between the gray particles $(6.0$ $\mathrm{mm}$ diameter) and the black particles (4.0 mm diameter) in the middle of the loaded mass. This separation between different size particles was due to the segregation according to the trajectory side-to-side mechanism (Tang and Puri, 2004). 


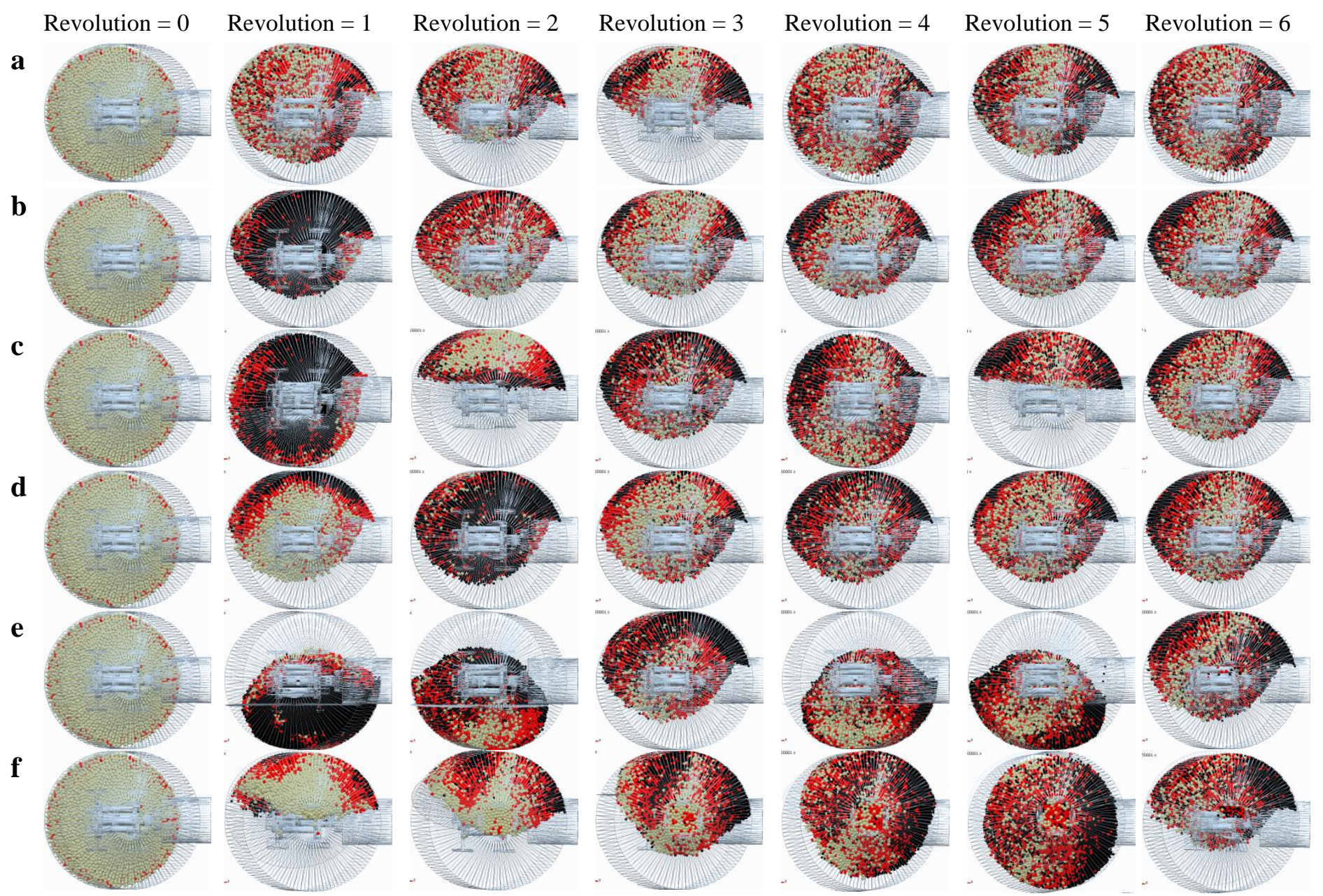

Figure 26: Snapshots of the simulated solid mixture at different drum speeds for the tri-disperse particles at the fill level of $70 \%$ and the top-bottom smaller-to-larger initial loading method while the agitator was stationary. (a) the drum speed of $7.0 \mathrm{rpm}$, (b) the drum speed of $15 \mathrm{rpm}$, (c) the drum speed of $22.5 \mathrm{rpm}$, (d) the drum speed of $30 \mathrm{rpm}$, (e) the drum speed of $45 \mathrm{rpm}$, and (f) the drum speed of $55 \mathrm{rpm}$. Gray particles with a diameter of $6.0 \mathrm{~mm}$, red particles with a diameter of $5.0 \mathrm{~mm}$, and black particles with a diameter of $4.0 \mathrm{~mm}$. 
Similar to the bi-disperse studies, Figure 27 demonstrates the mixing index versus number of revolutions for six different drum rotational speeds $(7.0,15,22.5,30,45$ and $55 \mathrm{rpm})$. It should be noted that the mixing indices at the $15 \mathrm{rpm}$ reached $\psi=0.870$ after 3.0 revolutions, whereas the degree of mixing at $45 \mathrm{rpm}$ reached a maximum of $\psi=0.830$ after 4.5 revolutions and then decreased with time until it reached a plateau $(\psi=0.834)$. These data show that we were not able to achieve a completely homogeneous tri-disperse particle with the mixing index of $\psi=1$ due to the segregation of the particles with different sizes.

It must be mentioned that the initial mixing index for the top-bottom smaller-to-larger initial loading was $\psi=0.330$.

The lower initial mixing index for the top-bottom smaller-to-larger was due to the fact that the large particles, which loaded on top of the small particles, failed to move down through the void spaces among the small particles according to the sieving/percolation mechanism (Hogg, 2009). This resulted in a lower initial contact surface between the small and large particles for this initial loading method. 


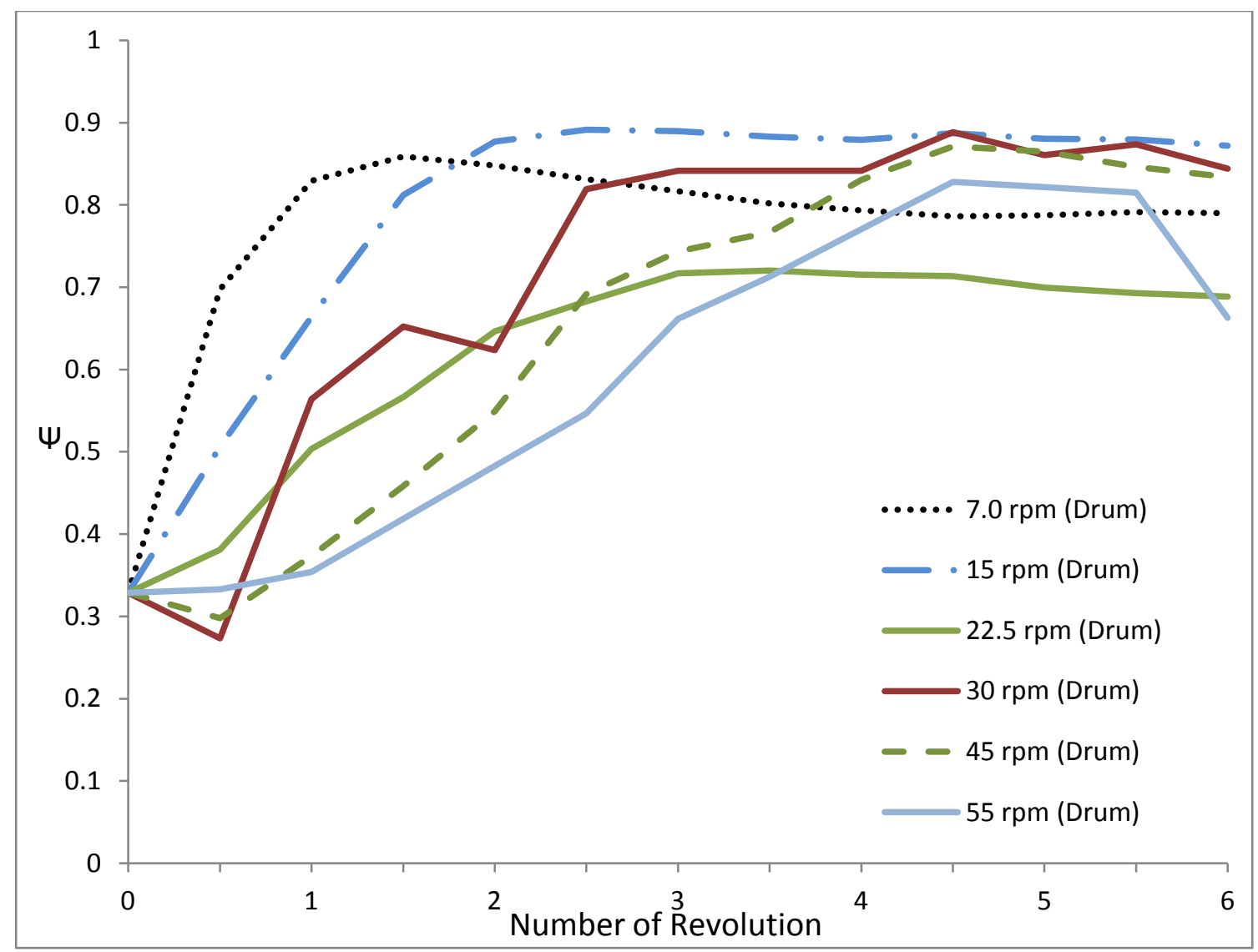

Figure 27: Mixing index versus number of revolution for the different drum speeds of tridisperse particles at the fill level of $70 \%$ and the top-bottom smaller-to-larger initial loading method while the agitator was stationary. 


\subsubsection{Poly-disperse Particles}

DEM was used to study the effect of the vessel angular velocity on the degree of mixing of polydisperse mixtures in the slant cone mixer. The rotational speed was varied from $7.0 \mathrm{rpm}$ to 55 rpm, similar to those employed for the bi-disperse and tri-disperse systems.

The top-bottom smaller-to-larger loading method was utilized for the poly-disperse particles. In this method, the bottom of the slant cone was filled with the smallest glass beads $(3.0 \mathrm{~mm})$ and then the other particles with the sizes of 4.0,5.0, and $6.0 \mathrm{~mm}$ were loaded on top of the smallest particles in ascending order by size.

In these simulations, 23,696 green glass beads with a diameter of $3.0 \mathrm{~mm}, 9,997$ black glass beads with a diameter of $4.0 \mathrm{~mm}, 5,118$ red glass beads with a diameter of $5.0 \mathrm{~mm}$, and 2,962 gray glass beads with a diameter of $6.0 \mathrm{~mm}$ were loaded into the slant cone mixer. As it has been listed in Table 3, the total mass of each set of particles was the same (837.5 g). The fill level was $70 \%$ and the agitator inside the vessel was stationary since the main objective of this part of the study was to assess the effect of the rotational velocity of the drum.

Figure 28 depicts the snapshots of the poly-disperse particles for the top-bottom smaller-to-larger initial loading method at six different drum speeds captured at the end of each complete rotation cycle. These images demonstrate the segregation of the poly-disperse particles during the mixing operations in the slant cone mixer. Figure 28 shows that the larger particles accumulated at the centre and the smaller particles moved to the boundaries of the loaded mass, whereas the medium particles were surrounded from the outer surfaces by the larger particles. Figure 28 shows that the largest number of $6.0 \mathrm{~mm}$ gray particles, $5.0 \mathrm{~mm}$ red particles, and $4.0 \mathrm{~mm}$ black particles were found at the center of the mixture after 6.0 drum rotations. 


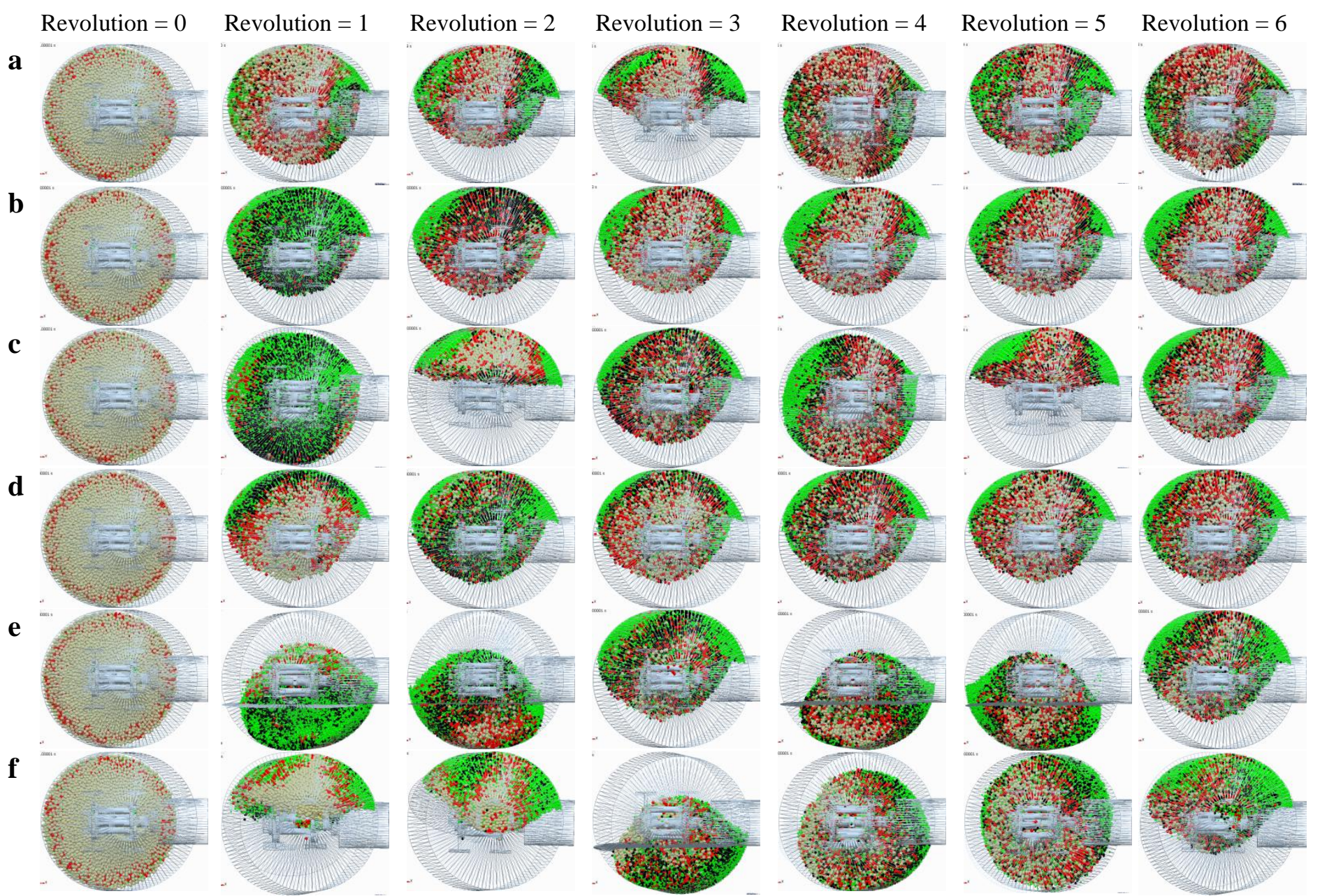

Figure 28: Snapshots of the simulated solid mixture at different drum speeds for the polydisperse particles at the fill level of $70 \%$ and the top-bottom smaller-to-larger initial loading method while the agitator was stationary. (a) the drum speed of $7.0 \mathrm{rpm}$, (b) the drum speed of $15 \mathrm{rpm}$, (c) the drum speed of $22.5 \mathrm{rpm}$, (d) the drum speed of $30 \mathrm{rpm}$, (e) the drum speed of 45 $\mathrm{rpm}$, and (f) the drum speed of $55 \mathrm{rpm}$. Gray particles with a diameter of $6.0 \mathrm{~mm}$, red particles with a diameter of $5.0 \mathrm{~mm}$, black particles with a diameter of $4.0 \mathrm{~mm}$, and green particles with a diameter of $3.0 \mathrm{~mm}$. 
Figure 29 presents the mixing index versus number of revolution for the different drum speeds. The results for $7.0,15,22.5$, and $30 \mathrm{rpm}$ show that the mixing index increased from an initial value to a maximum point and slightly decreased before reaching a plateau, whereas the results for $45 \mathrm{rpm}$ and $55 \mathrm{rpm}$ demonstrate that the mixing index increased with the number of revolution until it reached a plateau. Moreover, the highest mixing index was achieved with the drum speed of $55 \mathrm{rpm}$. In fact, the increase in the diffusive and convective motions improves the mixing mechanism, which reduces the extent of segregation caused by the sieving mechanism (Remy et al., 2011).

These data also show that the final mixing indices recorded at the end of the mixing operation (i.e. 6.0 revolutions) for the poly-disperse particles were higher than those obtained for the bidisperse and tri-disperse particles. This means that the impact of the segregation reduced with an increase in the degree of polydispersity. In fact, the presence of the additional intermediate size particles with the sizes between the smallest and largest particles resulted in an increase in the diffusive and convective particle motion inside the mixer.

These data also provide a basic understanding for the mixing of non-cohesive poly-disperse particles inside a lab scale slant cone mixer, that would help the researchers in future studies to develop more understanding of the mixing quality for poly-disperse particles inside a large scale slant cone mixer.

Remy et al. (2011) investigated the segregation of the bi-disperse, tri-disperse, and poly-disperse mixtures (5 and 11 different size particles) in a bladed mixer. They reported that the extent of the segregation for 11-size poly-disperse mixture was less than those obtained for the other mixtures. 


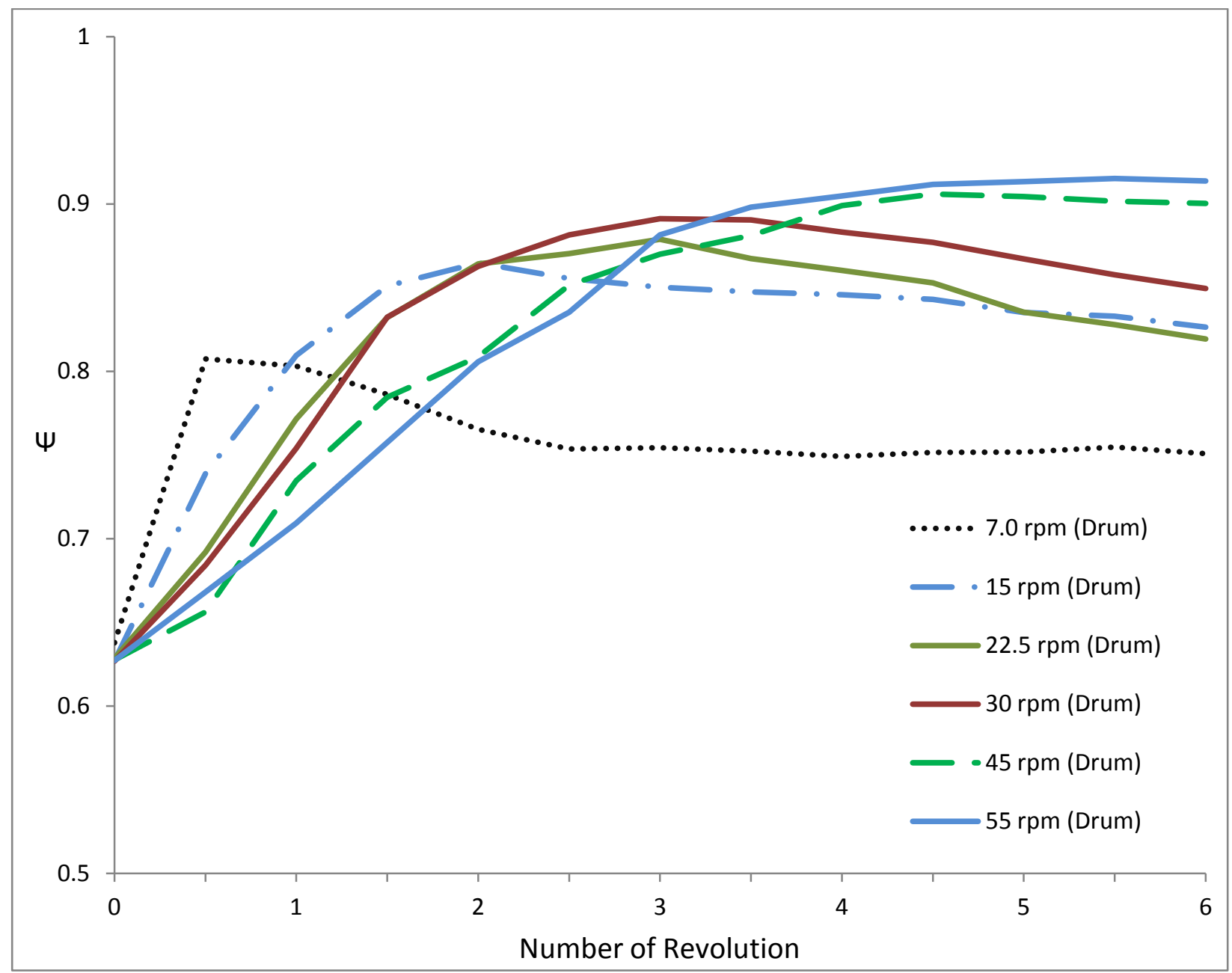

Figure 29: Mixing index versus number of revolutions for the different drum speeds of polydisperse particles at the fill level of $70 \%$ and the top-bottom smaller-to-larger initial loading method while the agitator was stationary. 


\section{Chapter 7: Conclusions and Recommendations for future work}

\subsection{Conclusions}

Discrete element method (DEM) was successfully utilized to study the mixing of mono-disperse, bi-disperse, tri-disperse, and poly-disperse solid particles in a lab-scale rotary drum and a slant cone mixer as a function of rotational drum speed, particle size, agitator speed, and initial loading method. The Hertz-Mindlin contact model was used to calculate the total contact force. 54 simulations were done in this study for the two mixers. To compute the mixing index, the simulation domain for the rotary drum and slant cone mixers were divided into 144 cells and 3,375 cells, respectively. Each cell was considered as a sample for mixing calculations. The following initial loading methods were employed with both mixers for the bi-disperse solid particles: top-bottom smaller-to-larger, top-bottom larger-to-smaller, and side-side position. In addition to these loading methods, the smaller back-larger front and larger back-smaller front positions were investigated for the slant cone mixer. The drum rotational speeds in the slant cone study were $7.0,15,22.5,30,45$, and $55 \mathrm{rpm}$, and the rotary drum speeds were $5.5,15$, and 30 rpm.

To validate the DEM model of the rotary drum, the snapshots of the mixing of the solid particles, which were obtained through the experiment and simulations, were compared and reasonable agreement was observed between these results. The model developed in the slant cone study was validated by experimental data obtained using sampling and imaging methods.

With the rotary drum, the best mixing results for the mono-disperse systems were achieved when the side-side and top-bottom loading methods were utilized with $30 \mathrm{rpm}$ angular velocity. 
The best mixing results for the bi-disperse particles were attained when the top-bottom smallerto-larger initial loading method was utilized. The highest mixing index was achieved at the drum speeds of $30 \mathrm{rpm}$ and $45 \mathrm{rpm}$ for the rotary drum and slant cone mixer, respectively. Also, with the same loading method, the best mixing quality was achieved for the tri-disperse particles with the rotary mixer at the drum speed of $30 \mathrm{rpm}$.

The effect of the agitator speed on the mixing performance for the bi-disperse particles inside the slant cone mixer was investigated. The agitator speed employed in this study was $+100 \mathrm{rpm}$ (same rotation direction as of drum) while the rotational speed of the drum was maintained at 15 rpm. The fill level of particles inside the mixer was increased to $100 \%$ (as recommended by the manufacturer for use of the agitator), and the top-bottom smaller-to-larger and larger-to-smaller loading methods were utilized at 0 and $+100 \mathrm{rpm}$ agitator speeds. The addition of the agitator for the bi-disperse particles increased the mixing quality and reduced the segregation of particles with different sizes.

For the slant cone mixer, the top-bottom smaller-to-larger initial loading method was utilized for tri-disperse and poly-disperse particles. It was found that the mixing quality of tri-disperse particles decreased at higher drum rotational velocities and the highest mixing index was obtained at the drum speed of $15 \mathrm{rpm}$. In addition, the highest mixing index for poly-disperse particles was obtained at the drum speed of $55 \mathrm{rpm}$.

For the poly-disperse solid particles inside the rotary drum mixer, the following initial loading methods were employed: top-bottom smaller-to-larger, top-bottom larger-to-smaller, top-bottom random positions, side-side left-to-right larger-to-smaller, and side-side random position. 
However, the use of the top-bottom smaller-to-larger and the top-bottom larger-to-smaller loading methods resulted in the highest mixing indices at the drum speed of $30 \mathrm{rpm}$.

It is important to mention that the perfectly mixed system was achieved for the mono-disperse particles inside the rotary drum mixer. However, due to the segregation of the particles with different sizes, a good mix was not attained for both mixers with the bi-disperse, tri-disperse, and poly-disperse particles. In fact, the simulation results of the rotary drum showed the accumulation of the smaller particles at the centre and the larger particles at the boundary of the loaded mass inside the mixer. This finding supports the segregation of the particles according to the percolation mechanism. On the contrary, the simulation results for the slant cone showed the separation of the smaller particles at the drum walls and the accumulation of the larger particles at the center of the loaded mass inside the mixer. This finding supports the segregation of the different sized particles according to the trajectory side-to-side mechanism.

Also, the simulation results for the slant cone and rotary drum mixer showed that the impact of the segregation was reduced as the degree of the polydispersity was increased. In fact, the presence of the additional intermediate sized particles with the intermediate sizes led to an increase in the convective and diffusive particle motion, which improved the mixing quality and reduced the extent of segregation caused by the sieving mechanism. 


\subsection{Recommendations for Future Work:}

The following topics are suggested for future work:

1. Mixing for cohesive poly-disperse particles in the slant cone mixer.

2. Mixing behavior of poly-disperse particles with different densities in the rotary drum and slant cone mixer.

3. Mixing of poly-disperse particles with non-spherical geometries in the rotary drum and slant cone mixer.

4. Mixing of the poly-disperse particles in the rotary drum equipped with baffles. 


\section{Nomenclature:}

$a_{k} \quad$ Acceleration for the studied particle $\left(\mathrm{m} / \mathrm{s}^{2}\right)$

$C_{n \text { rest }}$ Coefficient of restitution

$E_{e f} \quad$ Young's modulus $\left(\mathrm{N} / \mathrm{m}^{2}\right)$

$F_{n} \quad$ Normal force resulting from the contact of particle A with particle B (N)

$F_{t} \quad$ Tangential force resulting from the contact of particle A with particle B (N)

$F_{\text {total,k}}$ Total force acting on a particle $(\mathrm{N})$

$F_{t D} \quad$ Tangential damping force $(\mathrm{N})$

$G_{e q} \quad$ Equivalent Shear modulus $\left(\mathrm{N} / \mathrm{m}^{2}\right)$

g Acceleration of gravity $\left(\mathrm{m} / \mathrm{s}^{2}\right)$

$\mathrm{I}_{\mathrm{K}} \quad$ Moment of inertia of a particle $\left(\mathrm{kg} \cdot \mathrm{m}^{2}\right)$

$k_{n} \quad$ Normal spring stiffness $\left(\mathrm{N} / \mathrm{m}^{2}\right)$

$K_{r} \quad$ Rolling stiffness of the spring $\left(\mathrm{N} / \mathrm{m}^{2}\right)$

$L \quad$ Distance from the center of one particle to the contact plane with the other particle (m)

$\mathrm{M}_{\mathrm{ef}} \quad$ Effective particle mass $(\mathrm{kg})$

$m_{A} \quad$ Mass of particle $\mathrm{A}(\mathrm{kg})$

$N \quad$ Normal unit vector

$n_{M} \quad$ Total particle number fraction in cell $\mathrm{M}$

$\mathrm{R}_{\mathrm{ef}} \quad$ Effective radius of the colliding particles (m)

$\mathrm{R}_{\mathrm{A}} \quad$ Radius of particle $\mathrm{A}(\mathrm{m})$ 
$\begin{array}{ll}\mathrm{R}_{\mathrm{B}} & \text { Radius of particle } \mathrm{B}(\mathrm{m}) \\ S_{t} & \text { Tangential spring stiffness }\left(\mathrm{N} / \mathrm{m}^{2}\right) \\ T_{\text {total }, k} & \text { Total torque acting on a particle }(\mathrm{N} \cdot \mathrm{m}) \\ T_{r} & \text { Rolling resistance torque }(\mathrm{N} \cdot \mathrm{m}) \\ \mathrm{x}_{\mathrm{j}}^{\mathrm{M}} & \text { Number fraction of species } \mathrm{j} \text { in cell M }\end{array}$

Greek Letters

$\alpha \quad$ Torsional deformation between particles

$\beta \quad$ Damping coefficient

$\delta_{\mathrm{n}} \quad$ Normal overlap

$\delta_{t} \quad$ Tangential displacement

$\dot{\delta}_{t} \quad$ Relative tangential velocity $(\mathrm{m} / \mathrm{s})$

$\zeta_{r} \quad$ Rolling damping coefficient

$\mu_{R} \quad$ Rolling friction coefficient

$v_{\mathrm{A}} \quad$ Poisson coefficient

$v_{\mathrm{B}} \quad$ Poisson coefficient

$\pi \quad$ Degree of mixing of all particle species at a specific time step

$\Psi \quad$ Degree of mixing for Poly-disperse systems

$\omega \quad$ Relative angular velocity of a particle ( $\mathrm{rad} / \mathrm{s})$

$\frac{d \omega}{d t} \quad$ Angular acceleration of a particle $\left(\mathrm{rad} / \mathrm{s}^{2}\right)$ 


\section{Bibliography:}

Abouzeid, A.Z.M., Douglas, W.F., 2010. Mixing-demixing of particulate solids in rotating drums. International Journal of Mineral Processing 95, 40-46.

Ahmadian, H., Hassanpour, A., Ghadiri, M., 2011. Analysis of granule breakage in a rotary mixing drum: Experimental study and distinct element analysis. Powder Technology 210, 175180.

Alexander, A., Shinbrot, T., Muzzio, F.J., 2001. Granular segregation in the double-cone blender: Transitions and mechanisms. American Institute of Physics 13, 578-588.

Alexander, A., Shinbrot, T., Johnson, B., Muzzio, F.J., 2004. V-blender segregation patterns for free-flowing materials: effects of blender capacity and fill level. International Journal of Pharmaceutics 269, 19-28.

Alizadeh, E., Dube, O., Bertrand, F., Chaouki, J., 2013. Characterization of Mixing and Size Segregation in a Rotating Drum by a Particle Tracking Method. AlChE Journal 59, 1894-1905.

Alian, M., Ein-Mozaffari, F., Upreti, S.R., Wu, J., 2014. Using discrete element method to analyze the mixing of the solid particles in a slant cone mixer. Chemical Engineering Research and Design (Accepted).

Arntz, M.M.H.D., Den Otter,W.K., Briels, W.J., Bussmann, P.J.T., Beeftink, H.H., Boom, R.M., 2008. Granular Mixing and Segregation in a Horizontal Rotating Drum: a simulation study on the impact of rotational speed and fill level. AlChE Journal 54, 3133-3146.

Arratia, P.E., Nhat-hang Duong, Muzzio, F.J., Godbole, P., Reynolds, S., 2006. A study of the mixing and segregation mechanisms in the Bohle Tote blender via DEM simulations. Powder Technology 164, 50-57.

Bertrand, F., Leclaire, L.A., Levecque, G., 2005. DEM-Based Models for the Mixing of Granular Materials. Chemical Engineering Science 60, 2517- 2531.

Bharadwaj, R., Ketterhagen, R.W., Hancock, B.C., 2010. Discrete element simulation study of a Freeman powder Rheometer. Chemical Engineering Science 65, 5747- 5756.

Bizon, C., Shattuck, M. D., Swift, J. B., McCormick, W. D., Swinney, H.L., 1998. Patterns in $3 \mathrm{D}$ vertically oscillated granular layers: simulation and experiment. Physical Review Letters $80,57-60$. 
Bridgwater, J., 2003. The dynamics of granular materials-towards grasping the fundamentals. Granular Matter 4, 175-181.

Bridgwater, J., 2010. Mixing of particles and powders: Where next? Particuology 8, 563- 567.

Brone, D., Wightman, C., Connor, K., Alexander, A., Muzzio, F.J., Robinson, P., 1997. Using flow perturbations to enhance mixing of dry powders in V-blenders. Powder Technology 91, $165-172$.

Brone, D., Alexander, A., Muzzio, F.J., 1998. Quantitative characterization of mixing of dry powders in V-blenders. AIChE Journal 44, 271-278.

Brone, D., Muzzio, F.J., 2000. Enhanced mixing in double-cone blenders. Powder Technology 110, 179-189.

Campbell, C.S., 1982. Shear flows of granular materials. PhD Thesis California Institute of Technology.

Campbell, C.S., 2002. Granular shear flows at the elastic limit. Journal of Fluid Mechanics 465, 261-291.

Campbell, C.S., 2006. Granular material flows - An overview. Powder Technology 162, 208-29.

Carrigy, M.A., 1963. The K.A. Clark Volume: A Collection of Papers in Athabasca Oil Sands. Research Council of Alberta, Edmonton.

Cundall, P.A., Strack, O.D.L., 1979. A discrete numerical model for granular assemblies. $\underline{\text { Journal }}$ of Geotechnique 29, 47-65.

Chand, R., Khaskheli, M.A., Qadir, A., Ge, B., Shi, Q., 2012. Discrete particle simulation of radial segregation in horizontally rotating drum: Effects of drum-length and non-rotating endplates. Physica A 391, 4590- 4596.

Chandratilleke, G.R., Yu, A.B., Bridgwater, J., 2012. A DEM study of the mixing of particles induced by a flat blade. Chemical Engineering Science 79, 54-74.

Chaudhuri, B., Mehrotra, A., Muzzio, F. J., Tomassone, M. S., 2006. Cohesive effects in powder mixing in a tumbling blender. Powder Technology 165, $105-114$.

Cho, J., Zhu,Y., Lewkowicz, K., Lee, S., Bergman, T., Chaudhuri, B., 2012. Solving Granular Segregation problems using a biaxial rotary mixer. Chemical Engineering and Processing: Process Intensification 57, 42-50. 
Conway, S.L., Goldfarb, D.J., Shinbrot, T., Glasser, B.J., 2003. Free surface waves in wallbounded granular flows. Physical Review Letters 90, 1- 4.

Conway, S.L., Glasser, B.J., 2004. Density waves and coherent structures in granular Couette flows. Physics Fluids 16, 509-529.

Daumann, B., Nirschl, H., 2008. Assessment of the mixing efficiency of solid mixtures by means of image analysis. Powder Technology 182, 415-423.

De Silva, S., Dyroy, A., Enstad, G.G., 2000. Segregation mechanisms and their quantification using segregation testers, in: Rosato, A.D., Blackmore, D.L.(Eds.), IUTAM Symposium on Segregation in Granular Flows. Kluwer Academic Publishers, Boston, pp. 11-29.

Ding, Y.L., Forster, R.N., Seville, J.P.K., Parker, D.J., 2001. Scaling relationships for rotating drums. Chemical Engineering Science 56, 3737- 3750.

Di Renzo, A., Di Maio, F.P., 2004. Comparison of Contact-force Models for the Simulation of Collisions in DEM-based Granular Flow codes. Chemical Engineering Science 59, 525-541.

Fan, L.T., Chen, S.J., Watson, C.A., 1970. Annual Review Solids Mixing. Industrial and Engineering Chemistry 62, 53-69.

Faqih, A., Chaudhuri, B., Muzzio, F.J., Tomassone, M.S., Alexander, A., Hammond, S., 2006. Flow- Induced Dilation of Cohesive Granular Materials. AIChE Journal 52, 4124- 4132.

Felix, G., Falk, V., D'Ortona, U., 2007. Granular flows in a rotating drum: the scaling law between velocity and thickness of the flow. European Physical Journal E 22, 25-31.

Forterre, Y., Pouliquen, O., 2001. Longitudinal vortices in granular flows. Physical Review Letters 86, 5886-5889.

Forterre, Y., Pouliquen, O., 2002. Stability analysis of rapid granular chute flows: Formation of longitudinal vortices. Journal of Fluid Mechanics 467, 361-387.

Glasser, B.J., Goldhirsh, I., 2001. Scale dependence, correlations, and fluctuations of stresses in rapid granular flows. Physics Fluids 13, 407-420.

Geldart, D., 1990. Powder processing - the overall view, in: Rhodes, M. (Ed.), Principles of Powder Technology. John Wiley \& Sons, Chichester, pp. 1-8.

Goldhirsch, I., 2003. Rapid Granular Flows. Annual Review of Fluid Mechanics 35, 263- 297.

Gotoh, K., Masuda, H., Higashitani, K., 1997. Powder Technology Handbook, second ed. Taylor $\&$ Francis, New York. 
Gray, M.R., Mehta, B., Masliyah, J.H., 1993. Liquid-side mass transfer coefficients for liquids and slurries in a rotating drum. Chemical Engineering Science 48, 3442-3446.

Gray, M., Banerjee, D., Fedorak, P., Hashimoto, A., Masliyah, J., Pickard, M., 1994. Biological remediation of anthracene-contaminated soil in rotating bioreactors. Applied Microbiology and Biotechnology 40, $933-940$.

Hogg, R., 2009. Mixing and Segregation in Powders: Evaluation Mechanisms and Processes. KONA powder and particle journal 27, 1-17.

Hopkins, M.A., Louge, M.Y., 1991. Inelastic Microstructure in Rapid Granular Flows of Smooth Disks. Physics Fluids A 3, 47-57.

Hopkins, M.A., Jenkins, J. T., Louge, M.Y., 1992. On the structure of 3D shear flows, in: Shen, H.H., Satake, M., Mehrabadi, M., Chang, C.S., Campbell, C.S. (Eds.), Advances in Micromechanics of Granular Materials. Elsevier, Ann Arbor, pp. 271-279.

Jauhari, R., Gray, M.R., Masliya, J.H., 1998.Gas-solid mass transfer in a rotating drum. Canadian Journal of Chemical Engineering 76, 224-232.

Jenkins, J.T., Mancini, F., 1989. Kinetic theory for binary mixtures of smooth, nearly elastic spheres. Physics Fluids A 1, 2050-2057.

Jiang, M., Zhao,Y., Liu, G., Zheng, J., 2011. Enhancing mixing of particles by baffles in a rotating drum mixer. Particuology 9, 270-278.

Johnson, K.L., 1987. Contact Mechanics. Cambridge University Press, Cambridge.

Kruggel-Emden, H., Wirtz, S., Scherer, V., 2008. A study on tangential force laws applicable to the discrete element method (DEM) for materials with viscoelastic or plastic behavior. $\underline{\text { Chemical }}$ Engineering Science 63, 1523 - 1541.

Kudrolli, A., 2004. Size separation in vibrated granular matter. Reports on Progress in Physics 67, 209- 247.

Lacey, P.M.C., 1954. Developments on the theory of particle mixing. Applied Chemistry 4, 257268.

LaMarche, K., Conway, S., Glasser, B., Shinbrot, T., 2007. Cellular automata model of gravitydriven granular flows. Granular Matter 9, 219-229. 
Lemieux, M., Léonard, G., Doucet, J., Leclaire, L.A., Viens, F., Chaouki, J., Bertrand, F., 2008. Large-scale numerical investigation of solids mixing in a V-blender using the discrete element method. Powder Technology 181, 205-216.

Liu, X., Metzger, M., Glasser, B.J., 2007. Couette flow with a bidisperse particle mixture. Physics of Fluids 19, 1- 20.

Lun, C.K.K., Savage, S.B., Jeffrey, D., Chepurniy, N., 1984. Kinetic theories for granular flow: inelastic particles in Couette flow and slightly inelastic particles in a general flow field. $\underline{\text { Journal }}$ of Fluid Mechanics 140, 223- 256.

Lun, C.K.K., 1996. Granular dynamics of inelastic spheres in Couette flow. Physics Fluids 8, 2868- 2883.

Malhotra, K., Mujumdar, A.S., Imakoma, H., Okazaki, M., 1988. Fundamental particle mixing studies in an agitated bed of granular materials in a cylindrical vessel. Powder Technology 55, 107-114.

Malhotra, K., Mujumdar, A.S., Okazaki, M., 1990. Particle flow patterns in a mechanically stirred two-dimensional cylindrical vessel. Powder Technology 60, 179-189.

Masuda, H., Higashitani, K., Yoshida, H., 2006. Powder technology handbook. Taylor \& Francis, Boca Raton.

Manickam, S.S., Shah, R., Tomei, J., Bergman, T.L., Chaudhuri, B., 2010. Investigating mixing in a multi-dimensional rotary mixer: experiments and simulations. Powder Technology 201, 8392.

Manjunath, K., Dhodapkar, S., Jcob, K., 2004. Mixing of particulate solids in the process industries, in: Paul, E., Atiemo-Obeng, V., Cresta, S. (Eds.), Handbook of Industrial Mixing. John Wiley \& Sons, New Jersey, pp. 924-986.

McGlinchey, D., 1998. Assessment of segregation in industrial processes. Powder Bulk Solids Technology 22, 54-56.

McNamara, S., Young, W.R., 1992. Inelastic collapse and clumping in a one dimensional granular medium. Physics Fluids 4, 496-504.

Meier, S.W., Lueptow, R.M., Ottino, J.M., 2007. A dynamical systems approach to mixing and segregation of granular materials in tumblers. Advances in Physics 56, 757-827. 
Moakher, M., Shinbrot, T., Muzzio, F.J., 2000. Experimentally validated computations of flow, mixing and segregation of non-cohesive grains in 3D tumbling blenders. Powder Technology $109,58-71$.

Mosby, J., de Silva, S.R., Enstad, G.G., 1996. Segregation of particulate materials-Mechanisms and testers. KONA Powder 14, 31-42.

Muzzio, F.J., Robinson, P., Wightman, C., Brone, D., 1997. Sampling practices in powder blending. International Journal of Pharmaceutics 155, 153-178.

Muzzio, F.J., Alexander, A., Goodridge, C., Shen, E., Shinbrot, T., 2004. Solids Mixing Part A: Fundamentals of Solids Mixing, in: Paul, E., Atiemo-Obeng, V., Cresta, S. (Eds.), Handbook of Industrial Mixing. John Wiley \& Sons, New Jersey, pp. 887-983.

Nityanand, N., Manley, B., Henein, H., 1986. An analysis of radial segregation for different sized spherical solids in rotary cylinders. Process Metal 17B, 247- 257.

Onwulata, C., 2005. Encapsulated and Powdered Foods. CRC Press, Boca Raton.

Ottino, J.M., Khakhar, D.V., 2002. Scaling of granular flow processes: From surface flows to design rules. AIChE Journal 48, 2157-2166.

Paul, E.L., Atiemo-Obeng, V., Kresta, S.M., 2004. Handbook of Industrial Mixing: science and practice. John Wiley \& Sons, New Jersey.

Porion, P., Sommier, N., Faugere, A., Evesque, P., 2004. Dynamics of size segregation and mixing of granular materials in a 3D-blender by NMR imaging investigation. Powder Technology 141, 55-68.

Prescott, J.K., 2001. Pharmaceutical Process Scale-up, in: Levin, M. (Ed.), Powder Handling. Marcel Dekker, New York, 133-149.

Remy, B., Khinast, J.G., Glasser, B.J., 2009. Discrete Element Simulation of Free Flowing Grains in a Four-Bladed Mixer. AlChE Journal 55, 2035- 2048.

Remy, B., Khinast, J.G., Glasser, B.J., 2011. Polydisperse granular flows in a bladed mixer: Experiments and simulation of cohesionless spheres. Chemical Engineering Science 66, 18111824.

Renaud, M., Thibault, J., Trusiak, A., 2000. Solids Transportation Model of an Industrial Rotary Dryer. Drying Technology 18, 843- 865. 
Ristow, G.H., 1996. Dynamics of granular materials in a rotating drum. EuroPhysics Letters 34, 263-268.

Romanski, F.S., Dubey, A., Chester, A.W., Tomassone, M.S., 2011. Dry catalyst impregnation in a double cone blender: A computational and experimental analysis. Powder Technology 221, 57-69.

Sahni E., Yau R., Chaudhuri, B., 2011. Understanding granular mixing to enhance coating performance in a pan coater: experiments and simulations. Powder Technology 205, 231-241.

Savage, S.B., Dai, R., 1992. Some aspects of bounded and unbounded shear flows of granular material, in: Shen, H.H., Satake, M., Mehrabadi, M., Chang, C.S., Campbell, C.S. (Eds.), Advances in Micromechanics of Granular Materials. Elsevier, Ann Arbor, pp. 151-161.

Savage, S.B., Jeffrey, D. J., 1981. The stress tensor in a granular flow at high shear rates. Journal of Fluid Mechanics 110, 255-272.

Schulze, D., 2007. Powders and Bulk Solids: Behavior, Characterization, Storage and Flow. Springer, Berlin.

Sudah, O. S., Arratia, P. E., Alexander, A., Muzzio, F. J., 2005. Simulation and Experiments of Mixing and Segregation in a Tote Blender. AIChE Journal 51, 836- 844.

Tahvildarian, P., Ein-Mozaffari, F., Upreti, S.R., 2013. Study of circulation intensity and axial dispersion of non-cohesive solid particles in a V-Blender via DEM simulations. Particuology 11, 619- 626.

Tang, P., Puri, V.M., 2004. Methods for minimizing segregation: a review. Particulate Science and Technology 22, 321-337.

Tardos, G.I., Khan, M.I., Schaeffer, D.G., 1998. Forces on a slowly rotating, rough cylinder in a Couette device containing a dry, frictional powder. Physics of Fluids 10, 335-341.

Tijskens, E., Ramon, H., DeBaerdemaeker, J., 2003. Discrete element modeling for process simulation in agriculture. Journal of Sound and Vibration 266, 493- 514.

Vidales, A.M., Ippolito, I., Benegas, O.A., Aguirre, F., Nocera, O.C., Baudino, M.R., 2006. Granular components of cement: Influence of mixture composition. Powder Technology 163, 196- 201.

Walton, O.R., Braun, R.L., 1986. Viscosity, granular-temperature, and stress calculations for shearing assemblies of inelastic, frictional disks. Journal of Rheology 50, 949-980. 
Walton, O.R., 1993. Numerical simulation of inclined chute flow of monodisperse, inelastic, frictional spheres. Mechanics of Materials 16, 239-247.

Wang, Z.L., Finlay, W.H., Peppler, M.S., Sweeney, L.G., 2006. Powder formation by atmospheric spray-freeze-drying. Powder Technology 170, 45-52.

Wibowo, C., Ng, K.M., 2001. Operational issues in solids processing plants: Systems view. AIChE Journal 47, 107-125.

Woo, S.H.,Park, J.M.,1999. Evaluation of drum bioreactor performance used for decontamination of soil polluted with polycyclic aromatic hydrocarbons. $\underline{\text { Chemical Technology }}$ and Biotechnology 74, 937-944.

Zamankhan, P., Mazouchi, A.,Sorkomaa, P., 1997. Some qualitative features of the Couette flow of monodisperse, smooth, inelastic spherical particles. Applied Physics Letters 71, 3790-3792. 